\title{
ESTIMATIVA DA EVAPOTRANSPIRAÇÃO DE REFERÊNCIA A PARTIR DA EQUAÇÃO DE PENMAN-MONTEITH, DE MEDIDAS LISIMÉTRICAS E DE EQUAÇÕES EMPÍRICAS, EM PARAIPABA, CE
}

\section{ALMIRO TAVARES MEDEIROS}

Tese apresentada à Escola Superior de Agricultura "Luiz de Queiroz", Universidade de São Paulo para obtenção do título de Doutor em Agronomia, Área de Concentração: Irrigação e Drenagem.

PIRACICABA

Estado de São Paulo - Brasil

Fevereiro - 2002 


\section{ESTIMATIVA DA EVAPOTRANSPIRAÇÃO DE REFERÊNCIA A PARTIR DA EQUAÇÃO DE PENMAN-MONTEITH, DE MEDIDAS LISIMÉTRICAS E DE EQUAÇÕES EMPÍRICAS, EM PARAIPABA, CE}

\section{ALMIRO TAVARES MEDEIROS}

Engenheiro Agrônomo

Orientador: Prof. Dr. PAULO CESAR SENTELHAS

Tese apresentada à Escola Superior de Agricultura "Luiz de Queiroz", Universidade de São Paulo, para obtenção do título de Doutor em Agronomia, Área de Concentração: Irrigação e Drenagem.

PIRACICABA

Estado de São Paulo - Brasil

Fevereiro - 2002 
Dados Internacionais de Catalogação na Publicação (CIP)
DIVISÃO DE BIBLIOTECA E DOCUMENTAÇÃO - ESALO/USP

Medeiros, Almiro Tavares

Estimativa da evapotranspiração de referência a partir da equação de Penman-Monteith, de medidas lisimétricas e de equações empíricas em Paraipaba, CE / Almiro Tavares Medeiros. - - Piracicaba, 2002.

103 p. : il.

Tese (doutorado) - Escola Superior de Agricultura Luiz de Queiroz, 2002. Bibliografia.

1. Estimativa 2. Evapotranspiração 3. Irrigação 4. Lisimetro 5. Modelo Penman-Monteith 6. Relação solo-água-planta-atmosfera I. Título

CDD 551.572

"Permitida a cópia total ou parcial deste documento, desde que citada a fonte - $\mathrm{O}$ autor" 
Dedico esse trabalho a Deus pela sabedoria, a minha esposa Angelita e aos meus filhos Rodrigo, Camila e Daniel, que souberam suportar minha ausência, me dando força e incentivo sem os quais dificilmente eu suportaria.

"Como posso perder a fé na justiça da vida, se os sonhos dos homens que dormem em colchão de penas não é mais bonito do que os sonhos dos que dormem no chão".

Dostoiéwski 


\section{AGRADECIMENTOS}

Universidade Federal do Ceará por intermédio do Departamento de Engenharia Agrícola, pela oportunidade e confiança.

Aos Professores e funcionários do Departamento de Engenharia Agrícola (UFC), pelo apoio, que de alguma forma, contribuíram para o sucesso desse trabalho.

A Coordenação de Aperfeiçoamento de Pessoal de Nível Superior (CAPES), através do Programa Institucional de Capacitação de Docente e Técnica (PICDT), pela bolsa concedida para custeio dos estudos.

À Escola Superior de Agricultura "Luiz de Queiroz", da Universidade de São Paulo, através dos Departamentos de Engenharia Rural e de Ciências Exatas, pela oportunidade oferecida para a realização deste trabalho.

Ao Professor Dr. Paulo César Sentelhas pela orientação e camaradagem dispensados, ao Prof. Marcos Vinícius Folegatti e os demais professores dos departamentos, pela contribuição valiosa para o trabalho. 
Aos colegas de turma: Marcos Conceição, Wellington, Thales, Moretti, Valdemício, Aderson, Tim, Tamara, Ronaldo, Leonardo, Jarbas, Ênio e outros que porventura tenha esquecido de citar, meus agradecimentos pelo companherismo e convivência. 


\section{SUMÁRIO}

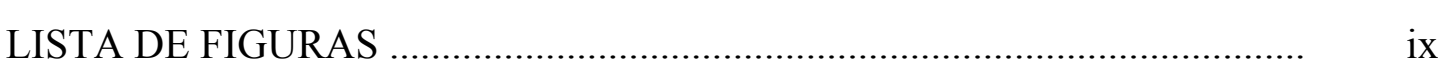

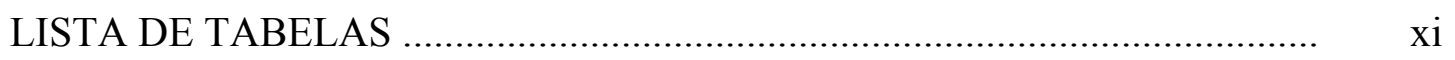

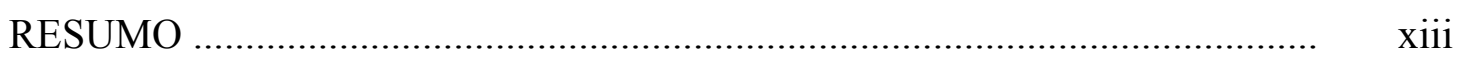

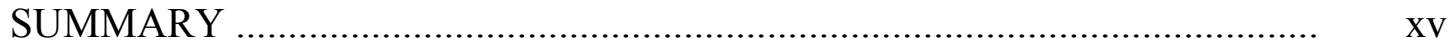

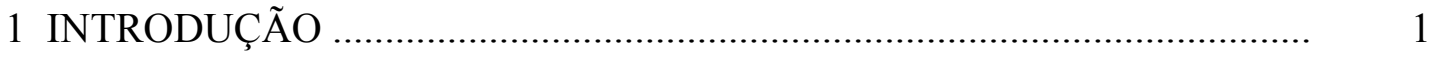

2 REVISÃO DE LITERATURA ……………………………………….....

2.1 Definição de evapotranspiração ................................................................... 3

2.2 Cultura de referência..................................................................................

2.3 Fatores que afetam a evapotranspiração .....................................................

2.4 Lisimetria .......................................................................................... 12

2.5 Equação de Penman-Monteith (PMon) para estimativa de ETo.................. 15

2.6 Comparação entre métodos de estimativa de evapotranspiração de

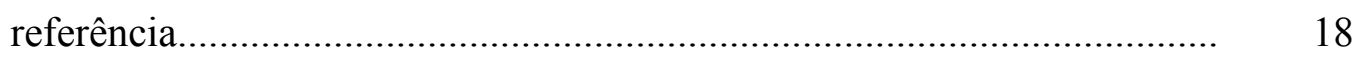

2.7 Outros métodos de estimativa da evapotranspiração de referência alternativos de acordo com os dados disponíveis..................................... 21

3 MATERIAL E MÉTODOS .................................................................. 25

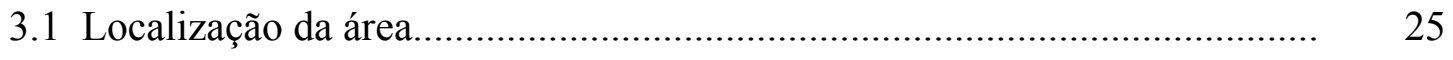

3.2 Caracterização do local......................................................................... 25

3.3 Instalação do lisímetro........................................................................... 26

3.4 Calibração e manejo do lisímetro.................................................................. 27 


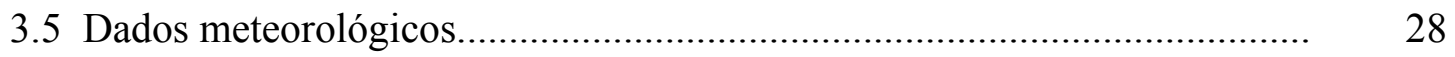

3.6 Análise dos dados........................................................................... 29

3.6.1 Avaliação do lisímetro............................................................................... 29

3.6.1.1 Equação de Penman-Monteith (PM)................................................ 30

3.6.1.2 Algoritmos para o cálculo da Evapotranspiração de Referência pelo Método de Penman-Monteith-FAO/56 ................................................... 31

3.6.1.2.1 Dados de entrada........................................................................... 31

3.6.1.2.2 Parâmetros e variáveis......................................................................... 32

3.6.2 Avaliação de equações de estimativa de ETo.............................................. 37

3.6.2.1 Equação de Thornthwaite, 1948 (EToTh).............................................. 37

3.6.2.2 Equação de Thornthwaite modificada....................................................... 38

3.6.2.3 Equação de Hargreaves \& Samani......................................................... 38

3.6.2.4 Equação do Tanque de Evaporação-FAO................................................. 39

3.6.2.5 Equação de Priestley-Taylor...................................................................... 40

3.7 Proposição de equações para estimativa da ETo........................................... 40

3.8 Análise dos resultados............................................................................... 41

4 RESULTADOS E DISCUSSÃO...............................................................

4.1 Análise das condições climáticas.................................................................. 44

4.2 Avaliação do lisímetro de pesagem na estimativa de ETo............................ 46

4.3 Avaliação de outros métodos de estimativa de ETo........................................ 53

4.3.1 Método de Thornthwaite.......................................................................... 53

4.3.2 Método de Thornthwaite modificado (Camargo et al., 1999).................... 57

4.3.3 Método de Hargreaves \& Samani(1985)................................................. 60

4.3.4 Método do Tanque de evaporação Classe A-FAO........................................ 63

4.3.5 Método de Priestley-Taylor (1972).............................................................. 67

4.4 Análise dos ajustes propostos nas equações de Camargo et al. (1999) e de Priestley-Taylor (1972)......................................................................

4.4.1 Método de Camargo et al. (1999) - Thornthwaite, com temperatura

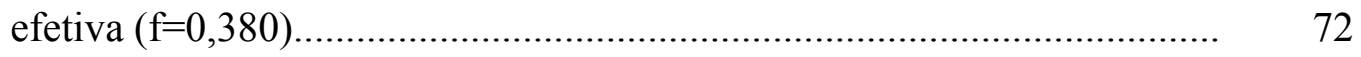


4.4.2 Método de Camargo et al. (1999) - Thornthwaite, com temperatura

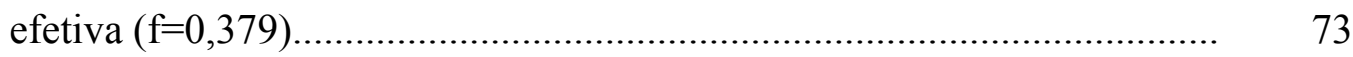

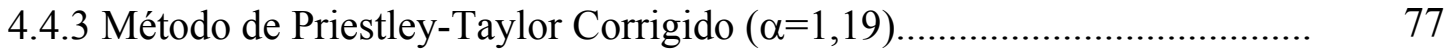

4.5 Análise geral dos métodos de estimativa de ETo nas escalas de tempo

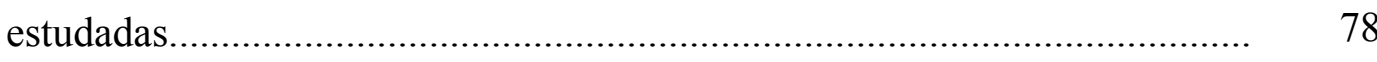

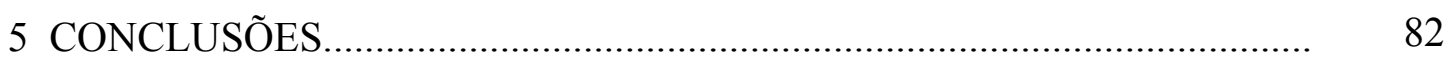

ANEXO............................................................. 83

REFERÊNCIAS BIBLIOGRÁFICAS _.................................................... 95 


\section{LISTA DE FIGURAS}

Página

1 Representação esquemática do lisímetro de pesagem instalado na Estação Experimental do Vale do Curu, no CNPAT/EMBRAPA, em Paraipaba, CE.....................................................................

2 Dados médios mensais de temperatura máxima e mínima do ar e de radiação solar global, nos anos de 1997 (a) e 1998 (b), em

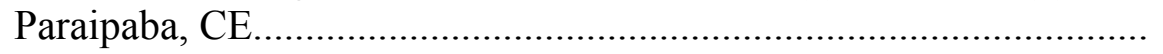

3 Extrato do balanço hídrico climatológico mensal, segundo Thornthwaite \& Mather (1955), durante os anos de 1997 e 1998 em Paraipaba, CE. As barras horizontais indicam os períodos analisados.

4 Variação mensal da umidade relativa do ar e da velocidade do vento, no ano de 1997, em Paraipaba, CE.

5 Variação mensal da umidade relativa do ar e da velocidade do vento, no ano de 1998, em Paraipaba, CE.

6 Relação entre evapotranspiração de referência estimada pelo método de Penman-Monteith (PM) e a evapotranspiração medida no lisímetro (lys) de pesagem, nas escalas diária (a), qüinqüidial (b) e decendial (c), em Paraipaba, CE, durante a estação chuvosa dos anos de 1997 e 1998.

7 Relação entre evapotranspiração de referência estimada pelo método de Penman-Monteith (PM) e pelo método de Thornthwaite (Th), nas escalas diária (a), qüinqüidial (b) e decendial (c), em Paraipaba, CE, durante a estação chuvosa dos anos de 1997 e 1998. 
8 Relação entre evapotranspiração de referência estimada pelo método de Penman-Monteith (PM) e pelo método de Thornthwaite com temperatura efetiva (Tef), nas escalas diária (a), qüinqüidial (b) e decendial (c), em Paraipaba, CE, durante a estação chuvosa dos anos de 1997 e 1998.

9 Relação entre evapotranspiração de referência estimada pelo método de Penman-Monteith (PM) e pelo método de Hargreaves \& Samani, nas escalas diária (a), qüinqüidial (b) e decendial (c), em Paraipaba, CE, durante a estação chuvosa dos anos de 1997 e 1998

10 Relação entre evapotranspiração de referência estimada pelo método de Penman-Monteith (PM) e pelo método do Tanque Classe A - FAO, nas escalas diária (a), qüinqüidial (b) e decendial (c), em Paraipaba, CE, durante a estação chuvosa dos anos de 1997 e 1998

11 Relação entre evapotranspiração de referência estimada pelo método de Penman-Monteith (PM) e pelo método de PriestleyTaylor $(\alpha=1,26)$, nas escalas diária (a), qüinqüidial (b) e decendial (c), em Paraipaba, CE, durante a estação chuvosa dos anos de 1997 e 1998

12 Relação entre evapotranspiração de referência estimada pelo método de Penman-Monteith (PM) e pelo método de Camargo et al (1999) ajustado ( $\mathrm{f}=380)$, nas escalas diária (a), qüinqüidial (b) e decendial (c), em Paraipaba, CE, durante a estação chuvosa dos anos de 1997 e 1998.

13 Relação entre evapotranspiração de referência estimada pelo método de Penman-Monteith (PM) e pelo método de Camargo et al (1999) ajustado ( $\mathrm{f}=379$ ), nas escalas diária (a), qüinqüidial (b) e decendial (c), em Paraipaba, CE, durante a estação chuvosa dos anos de 1997 e 1998

14 Relação entre evapotranspiração de referência estimada pelo método de Penman-Monteith (PM) e pelo método de PriestleyTaylor ajustado $(\alpha=1,19)$, nas escalas diária (a), qüinqüidial (b) e decendial (c), em Paraipaba, CE, durante a estação chuvosa dos anos de 1997 e 1998. 


\section{LISTA DE TABELAS}

1 Valores dos coeficientes de desempenho conforme Camargo e

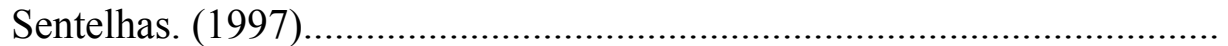

Página

2 Coeficientes de correlação (r), índice de concordância (d) e de desempenho (c) e erros médio absoluto (EMA), máximo (EM), sistemático (Es) e aleatório (Ea), entre ETo medida no lisímetro e estimada pelo método de Penman-Monteith, nas escalas diária, qüinqüidial e decendial, em Paraipaba, CE.

3 Coeficientes de correlação (r), índice de concordância (d) e de desempenho (c) e erros médio absoluto (EMA), máximo (EM), sistemático (Es) e aleatório (Ea), entre ETo estimada pelos métodos de Thornthwaite e de Penman-Monteith, nas escalas diária, qüinqüidial e decendial, em Paraipaba, CE.

4 Coeficientes de correlação (r), índice de concordância (d) e de desempenho (c) e erros médio absoluto (EMA), máximo (EM), sistemático (Es) e aleatório (Ea), entre ETo estimada pelos métodos de Thornthwaite, com temperatura efetiva e de Penman-Monteith, nas escalas diária, qüinqüidial e decendial, em Paraipaba, CE.

5 Coeficientes de correlação (r), índice de concordância (d) e de desempenho (c) e erros médio absoluto (EMA), máximo (EM), sistemático (Es) e aleatório (Ea), entre ETo estimada pelos métodos de Hargreaves \& Samamni e de Penman-Monteith, nas escalas diária, qüinqüidial e decendial, em Paraipaba, CE

6 Coeficientes de correlação (r), índice de concordância (d) e de desempenho (c) e erros médio absoluto (EMA), máximo (EM), sistemático (Es) e aleatório (Ea), entre ETo estimada pelos métodos de Tanque Classe A-FAO e de Penman-Monteith, nas escalas diária, qüinqüidial e decendial, em Paraipaba, CE. 
7 Coeficientes de correlação (r), índice de concordância (d) e de desempenho (c) e erros médio absoluto (EMA), máximo (EM), sistemático (Es) e aleatório (Ea), entre ETo estimada pelos métodos de Priestley-Taylor $(\alpha=1,26)$ e de Penman-Monteith, nas escalas diária, qüinqüidial e decendial, em Paraipaba, $\mathrm{CE}$.

8 Coeficientes de correlação (r), índice de concordância (d) e de desempenho (c) e erros médio absoluto (EMA), máximo (EM), sistemático (Es) e aleatório (Ea), entre ETo estimada pelos métodos de Camargo et al. (1999), ajustado ( $\mathrm{f}=0,380)$ e de Penman-Monteith, nas escalas diária, qüinqüidial e decendial, em Paraipaba, CE.......................

9 Coeficientes de correlação (r), índice de concordância (d) e de desempenho (c) e erros médio absoluto (EMA), máximo (EM), sistemático (Es) e aleatório $(\mathrm{Ea})$, entre ETo estimada pelos métodos de Camargo et al. (1999), ajustado $(f=0,379)$ e de Penman-Monteith, nas escalas diária, qüinqüidial e decendial, em Paraipaba, CE.

10 Coeficientes de correlação (r), índice de concordância (d) e de desempenho (c) e erros médio absoluto (EMA), máximo (EM), sistemático (Es) e aleatório $(\mathrm{Ea})$, entre ETo estimada pelos métodos de Priestley-Taylor $(\alpha=1,19)$ e de Penman-Monteith, nas escalas diária, qüinqüidial e decendial, em Paraipaba, CE.

11 Ordenação dos métodos de estimativa de evapotranspiração de referência(ETo), com base no índice de desempenho "c", na base diária, qüinqüidial e decendial, me relação ao método de Penman-Monteith....... 


\title{
ESTIMATIVA DE EVAPOTRANSPIRAÇÃO DE REFERÊNCIA A PARTIR DA EQUAÇÃO DE PENMAN-MONTEITH, DE MEDIDAS \\ LISIMÉTRICAS E DE EQUAÇÕES EMPÍRICAS, NAS \\ CONDIÇÕES DE PARAIPABA, CE
}

\author{
Autor: ALMIRO TAVARES MEDEIROS \\ Orientador: Prof. Dr. PAULO CESAR SENTELHAS
}

\section{RESUMO}

Tendo em vista a distribuição irregular de chuvas no nordeste, a irrigação se torna de grande importância, uma vez que passa a ser a principal alternativa racional de exploração das culturas agrícolas. Num projeto de irrigação, a evapotranspiração da cultura (ETc) é a variável mais importante, pois determina qual a quantidade de água a ser reposta, de forma a manter a produtividade a níveis rentáveis. Sendo a ETc função da evapotranspiração de referência (ETo), a determinação desta passa a ser fundamental em projetos, no planejamento e no manejo de irrigação. Dentro deste contexto o presente estudo teve por objetivo avaliar a estimativa da ETo, utilizando, para tanto, medidas lisimétricas e métodos de estimativa que foram comparados com valores de ETo obtidos com a equação de Penman-Monteith (Allen et al., 1998). Os métodos de estimativa de ETo empregados foram: Thornthwaite (1948), Thornthwaite modificado por Camargo et al. (1999), Tanque de Evaporação Classe A (Allen et al., 1998), Hargreaves \& Samani (1985) e Priestley \& Taylor (1972). A análise foi realizada em relação ao período de março a junho dos anos de 1997 e 1998, com dados coletados em uma estação meteorológica automática instalada na Estação Experimental do Vale do Curu, no Centro Nacional de Pesquisa em Agroindústria Tropical, pertencente à EMBRAPA, Paraipaba, $\mathrm{CE}$, onde também se encontrava instalado um lisímetro de pesagem (área = $2,205 \mathrm{~m}^{2}$ ), com células de carga. A análise foi baseada em dados diários, qüinqüidiais e 
decendiais, utilizando-se a análise de regressão, os índices de concordância de Willmott (1985) e de desempenho de Camargo e Sentelhas (1997), além dos seguintes erros: erro médio absoluto (EMA), erro máximo (EM), erro sistemático (Es) e erro aleatório (Ea). Os resultados obtidos mostraram que os dados medidos em lisímetro, se ajustaram de forma regular aos valores de ETo estimados pelo método de Penman-Monteith, nas três escalas de tempo avaliadas, o que indica a possibilidade de problemas na operação e manutenção desse dispositivo. Com relação aos métodos de estimativa de ETo, os que melhor se ajustaram aos valores obtidos por Penman-Monteith foram: Priestley \& Taylor (1972) nas escalas diária e decendial e Thornthwaite modificado por Camargo et al. (1999) na escala qüinqüidial, porém, com erros sisitemáticos. Devido a isso, foram propostos ajustes com base nesses métodos. O ajuste constou de modificações no coeficiente $(f)$ do método de Thornthwaite modificado por Camargo et al. (1999) e no parâmetro $\alpha$ da equação de Priestley-Taylor (1972), que foram modificados respectivamente para 0,379 e 1,19. Observou-se um desempenho considerado bom para o método de Priestley-Taylor $(\alpha=1,19)$ e muito bom para Thornthwaite modificado por Camargo et al. (1999) $(f=0,379)$, indicando a potencialidade de seus usos em condições climáticas semelhantes às desse estudo, quando há limitação de dados meteorológicos. 


\title{
REFERENCE EVAPOTRANSPIRATION ESTIMATED BY PENMAN-MONTEITH EQUATION, LYSIMETRIC MEASURES AND EMPIRICAL EQUATIONS IN PARAIPABA, STATE OF CEARÁ, BRAZIL
}

\author{
Author: ALMIRO TAVARES MEDEIROS \\ Adviser: Prof. Dr. PAULO CESAR SENTELHAS
}

SUMARY

The irregular distribuition of rain in the Brazil's northeast region become irrigation very important, being the main rational alternative to produce food. In an irrigation project the crop evapotranspiration (ETc) is the most important variable, which determine how much water is necessary to be applied to maintain the yield at high levels. Being ETc funcion of reference evapotranspiration (ETo), the determination of this variabel is fundamental in irrigation projects and schedule. In this context, this study aimed to evaluate ETo estimates from lysimetric measures and other methods, which were compaired with the ETo values obtained by Penman-Monteith equation (Allen et al., 1998). The methods used were: Thornthwaite (1948), Thornthwaite modified by Camargo et al. (1999), Class A pan (Allen et al., 1998), Hargreaves \& Samani (1985) and Priestley-Taylor (1972). The data were analysed during the period from march to june, in 1997 and 1998. The meteorological data were collected in an automatic weather 
station located at Vale do Curu Experimental Station, in the Tropical Agroindustry National Research Center, belonged to EMBRAPA, in Paraipaba, State of Ceará, Brazil, where a weighing lysimeter using strain gauge was installed (area $=2,205 \mathrm{~m}^{2}$ ). The data analysis were based on daily, quinquidial and decendial time scale, and were done utilizing regression analysis, agreement (Willmott, 1981) and performance (Camargo \& Sentelhas, 1997) indexes, and the following errors: absolute mean error (EMA), maximum error (EM), sistematic error (Es) and random error (Ea). The results obtained showed that ETo lysimeric measures did not fit well with ETo estimated by PenmanMonteith equation in all time scales evaluated, what problably is related to the problems in the operation and maintenance of this equipament. In relation to the other methods to estimate ETo, the best fits were obtained with Priestley-Taylor (1972), for daily and decendial data, and with Thornthwaite modified by Camargo et al. (1999), for quinquidial data. Howerer, these methods presented sistematic errors, being proposed adjusts in the parameters $f$ for the Thornthwaite modified by Camargo et al. (1999) and $\alpha$ for the Priestley-Taylor methods, which were modified, recpectively, to 0.379 and 1.19. With these modifications these methods improved the ETo estimation, increasing the accuracy and decreasing the errors, being classified by the performance index as good and very good, indicating their potenciality for be used in similar climatic conditions of this study, where complete set of weather data are not available. 


\section{INTRODUÇÃO}

A região nordeste tem potencial reconhecido de grande produtora de frutas tropicais. Entretanto, eventos de seca têm inibido a expressão desse potencial, o que faz da irrigação atividade obrigatória em empreendimentos agrícolas.

Em um projeto de irrigação, diversas variáveis são importantes quando se deseja o uso racional da água. Porém, a estimativa de consumo de água pelas culturas assume grande destaque, na medida em que se busca maximizar produção e minimizar custos.

O consumo de água pelas culturas é denominado de evapotranspiração da cultura (ETc), que é a ocorrência simultânea de dois processos importantes no cultivo das plantas, a evaporação da água do solo e a transpiração das plantas. Existem maneiras de se medir a evapotranspiração, mas devido aos altos custos dos equipamentos, tais técnicas quase sempre se restringem à pesquisa (Pereira et al., 1997a).

$\mathrm{Na}$ ausência de equipamentos de medidas de evapotranspiração da cultura, os pesquisadores, muitas vezes, lançam mão de estimativas baseadas na evapotranspiração de referência (ETo) e no coeficiente de cultura $(\mathrm{Kc})$. A ETo se refere a uma cultura hipotética (similar a um gramado), mantida sob condições ideais de crescimento, podendo ser determinada por equações, desde as mais simples, como as baseadas na temperatura, (Thornthwaite, 1948 e Hargreaves \& Samani, 1985), até as mais complexas, que envolvem o balanço de energia ao nível das plantas, como o método se Penman-Monteith (Monteith,1965).

A Comissão Internacional de Irrigação e Drenagem (ICID) e a Organização das Nações Unidas para Agricultura e Alimentação (FAO), consideram o método de 
Penman-Monteith (Allen et al., 1998), como padrão de estimativas da evapotranspiração de referência, a partir de dados meteorológicos, sendo utilizado também para avaliar outros métodos (Smith, 1991).

Diversos trabalhos vêm mostrando que o desempenho desse método é satisfatório, quando comparado com medidas em lisímetros: Allen (1986), Allen et al. (1989), Jensen et al. (1990), Allen et al. (1994a), Ribeiro (1996), Maggiotto (1996); Camargo \& Sentelhas (1997), Sentelhas (1998), Pereira (1998) e Hussein (1999). Muitas vezes, no entanto, seu emprego é restringido pela disponibilidade de dados meteorológicos, o que acaba exigindo o uso de métodos mais simples.

Atualmente, no nordeste brasileiro, especificamente no Ceará, o método de estimativa de ETo proposto por Hargreaves (1974), vem sendo empregado para determinação de ETc, apesar de não ser o mais adequado, por resultar em superestimativas nas condições de semiaridez do nordeste (Souza \& Yoder, 1994).

Com base no que foi exposto anteriormente, a proposta do presente trabalho foi a de avaliar o desempenho de um lisímetro de pesagem e de diferentes métodos na estimativa da ETo, nas escalas diária, qüinqüidial e decendial, frente ao método de Penman-Monteith, com a parametrização da FAO (Allen et al., 1998), nas condições climáticas de Paraipaba, CE.

Com base nos resultados obtidos, foram propostas alterações nas equações de Thornthwaite modificado por Camargo et al. (1999) e de Priestley-Taylor (1972), visando ajustá-las às condições de estudo. 


\section{REVISÃO DE LITERATURA}

\subsection{Definição de evapotranspiração}

A evapotranspiração é um termo bastante estudado devido a sua importância, qual seja, a estimativa do consumo de água pelas plantas. A primeira citação foi efetuada por Thornthwaite em 1948, citado por vários autores entre eles Medeiros (1996). Para Thornthwaite (1948), o fenômeno chamado de evapotranspiração potencial, é considerado como: a perda máxima de água em uma superfície de solo bem umedecido, completamente coberta com vegetação, em fase de desenvolvimento ativo e com dimensões suficientemente grandes, de modo a minimizar os efeitos de energia advectiva local. Se alguma dessas condições não forem atendidas, tem-se a evapotranspiração real. Quase que simultaneamente, Penman (1948), na Inglaterra, também definiu a evapotranspiração potencial (ETP), ressaltando que a vegetação deveria ser rasteira e com altura uniforme. De um modo geral, a grama foi tomada como padrão, em razão da sua utilização nos postos meteorológicos (Pereira et al., 1997a).

Outra definição muito citada por estudiosos do assunto é a de Penman (1948), em que o autor define evapotranspiração potencial como o processo de transferência d'água para a atmosfera, na unidade de tempo, de uma superfície totalmente coberta por vegetação verde, de porte baixo, em pleno desenvolvimento e sem restrição de água no solo.

Essa definição foi muito utilizada até que surgiu a necessidade de um conceito mais geral para o termo evapotranspiração, dada às diferenças entre as culturas utilizadas, mesmo se tratando de variedades de grama, no conceito da referida variável. 
Surgiu então a definição de evapotranspiração de referência (ETo). Desse modo ETo foi definida no Boletim 24 da FAO como: "taxa de evapotranspiração para uma extensa superfície, com cobertura gramada de altura uniforme, entre 8 e $15 \mathrm{~cm}$, em crescimento ativo, com o solo completamente sombreado e sem déficit de água (Doorenbos \& Pruitt., 1977; Jensen et al., 1990 e Al-Ghobari, 2000), para grama de referência rebaixada através de cortes.

Segundo Camargo \& Camargo (2000), Thornthwaite considerou a evapotranspiração potencial (ETP), como um elemento meteorológico normal, padrão, que representa a precipitação necessária para atender à necessidade de água de uma cobertura vegetal.

Diversos trabalhos foram publicados relacionados ao requerimento de água pelas culturas, merecendo destaque os seguintes: a) a primeira edição do Manual 70 da ASCE (American Society of Civil Engineers), b) a segunda edição do Manual 70 da ASCE, c) o Boletim 24 da FAO d) a revisão proposta por especialistas realizada pela FAO e outros órgãos ligados à área em 1991; e) último Boletim da FAO número 56, de 1998.

A primeira edição do Manual 70 da ASCE foi realizada pelo antigo Comitê do Uso Consuntivo de Água para as Culturas Irrigada e Vegetação Nativa, que iniciou seu trabalho em 1965. Um progresso limitado ocorreu em 1968. Em 1969 efetivou-se uma maior revisão, até que em 1973 o Relatório de Uso Consuntivo foi terminado e finalmente publicado em 1974.

A segunda edição do Manual 70 da ASCE foi publicada em 1989 após várias revisões, por Jensen et al. (1990).

O Manual 24 da FAO, publicado por Doorenbos \& Pruitt (1977), teve o objetivo de orientar os pesquisadores com relação à determinação do requerimento de água pelas culturas. Os autores recomendam o cálculo da evapotranspiração das culturas, em três estádios como segue: 1) determinação do efeito do clima no requerimento de água pelas culturas, dados pela evapotranspiração de referência (ETo), 2) o efeito das características da cultura no requerimento de água, dado pelo coeficiente da cultura $(\mathrm{Kc})$ e 3 ) o efeito das condições locais e práticas agrícolas no 
requerimento de água pelas culturas, advecção, dimensão do campo, disponibilidade de água, salinidade e métodos de cultivo e irrigação.

O Manual 24 da FAO apresenta sugestões da aplicação de métodos bastante conhecidos que determinam a evapotranspiração de referência, para diferentes condições climáticas. Esses métodos são: Blaney-Criddle, Radiação, Penman e Tanque de Evaporação.

O Manual № 70 da ASCE editado por Jensen et al. (1990), objetiva: definir e interpretar a terminologia de evapotranspiração ou uso consuntivo; proporcionar treinamento de engenheiros, educadores e pesquisadores com um resumo breve dos fatores que controlam a evapotranspiração; descrever métodos modernos de medida e estimativa de evapotranspiração; descrever os fatores mais importantes a serem considerados na determinação do requerimento de água na irrigação para fazendas, projetos e bacias fluviais; resumir a medida representativa de evapotranspiração de culturas irrigadas; avaliar a precisão de vários procedimentos de estimativa sob os vários tipos de climas; apresentar melhoramentos para estimativa de evapotranspiração e apresentar uma bibliografia selecionada para informações adicionais.

O Relatório de Consultores Especialistas nos Procedimentos para Revisão do Roteiro da FAO, com relação a Previsões de Requerimento de Água pelas culturas (Smith, 1991), chegou a conclusão unânime que a equação combinada de melhor performance na estimativa de ETo é a de Penman-Monteith.

Mais recentemente, Allen et al. (1994 a e b), apresentaram uma atualização na definição de evapotranspiração de referência (ETo) e no procedimento de cálculo da referida variável. Devido, principalmente, à diversidade de gramas consideradas na definição da cultura de referência, os autores recomendam uma grama hipotética, com valores fixos de albedo $(0,23)$, altura de $0,12 \mathrm{~m}$ e resistência do dossel de $70 \mathrm{sm}^{-1}$.

A última publicação da FAO, o Boletim 56 (Allen et al., 1998), novamente atualiza os procedimentos de cálculo de evapotranspiração de referência (ETo), analisa aspectos relacionados à determinação do coeficiente das culturas $(\mathrm{Kc})$ e recomenda procedimentos de avaliação dos dados empregados nas estimativas de ETo. 


\subsection{Cultura de Referência}

Geralmente, na literatura oriunda de outros países, aceita-se que seja usada na definição de ETo, uma grama cultivada em clima frio, "cool-season", tipo $\mathrm{C}_{3}$ com rugosidade, densidade, área foliar e resistência total do dossel com características semelhantes a perenial ryegrass (Lolium perene L.) ou alta fescue (Festuca arundinacea Schreb. "Alta”) (Allen et al., 1994 a).

Hargreaves (1989) recomenda a grama "cool season", como referência na estimativa de ETo.

Pesquisadores americanos usaram a alfafa (lucerne) como cultura viva de referência para definir a ETo, devido suas características de rugosidade se aproximarem da maioria das culturas agrícolas (Allen et al., 1994a; Jensen et al., 1990 e Wright, 1991). Entretanto, devido ao fato da grama ter maior facilidade de conservação de suas características e de adaptabilidade a diversos locais, os estudiosos trabalham mais com essa cultura.

Quando comparada as estimativas de ETo obtidas com grama e com alfafa utiliza-se uma relação entre elas. Allen et al. (1989) apresenta uma tabela, relacionando ETo da alfafa e da grama para várias condições de latitude e altitude, que variam de $0^{\circ}$ em Yangambi, Zaire; a $-38^{\circ}$ em Aspendale, Austrália e de $-30 \mathrm{~m}$ de altitude em Brawley, Califórnia; a 2774m em South Park, Colorado, compreendendo locais áridos e úmidos. Os autores obtiveram, em média, ETalfafa / ETgrama $=1,32$. Essa relação foi mais baixa para climas úmidos.

Allen (1990), no seu programa de estimativa de ETo conhecido como REF-ET, recomenda que na ausência dessa relação, deve-se utilizar o valor entre evapotranspiração da grama e da alfafa igual a 2.

Medeiros \& Folegatti (2000) numa análise de dados de Pentecoste, Ceará, encontraram uma relação entre evapotranspiração calculada a partir do modelo de Penman-Monteith, entre grama e alfafa de 0,9395 e alfafa e grama de 1,064. Esses resultados estão próximos dos encontrados por Allen et al. (1989), cujos valores variam de 1,15 a 1,25 . 
As relações apresentadas, por Allen et al. (1989), demonstram que a alfafa tem maior rugosidade e menor resistência total da superfície, em relação a grama cortada, resultando em ETo mais elevada.

A diversidade de valores apresentados por Allen et al. (1989), em vários locais para relação entre ETalfafa/ETgrama, revela que o coeficiente da cultura, quando calculado em relação a ETc/ETgrama, deverá variar de acordo com o clima para as culturas mais rugosas do que a grama, ou com resistência total da superfície menor que a grama (Allen et al., 1994a).

Algumas variedades de alfafa apresentam diferenças com relação ao caule e folhas e controle dos estômatos. Essa variação pode gerar diferenças no cálculo de ETo com a alfafa que de acordo com (Wright, 1988, citado por Allen et al., 1994a) chegam a $10 \%$. Além do mais, por ser difícil o crescimento da alfafa em determinadas regiões tropicais, ou em regiões muito frias, o que dificulta sua adoção, como cultura de referência e o uso dessa cultura para validar métodos de estimativa de ETo. A alfafa deve ser colhida periodicamente, interrompendo os registros de medidas de ETo, sendo necessário o uso da equação de Penman-Monteith, para preencher os períodos de ausência de dados contínuos de ETo (Allen et al.,1994a).

Pelas limitações da alfafa, cientistas e engenheiros concordam, que a grama mantêm melhor suas característica e representatividade no decorrer do ano. Acrescentase, ainda, a adaptabilidade e disponibilidade, para validações da mesma em diversos locais (Allen et al., 1994a).

\subsection{Fatores que afetam Evapotranspiração}

A evapotranspiração depende de fatores climáticos como: temperatura do ar, umidade relativa do ar, radiação solar, velocidade do vento, chuva e pressão de vapor, como principais variáveis. Com relação à cultura depende de fatores como: área foliar, estádio de desenvolvimento, arquitetura foliar, resistência do dossel e outros que geralmente estão associados o um valor do coeficiente de cultura (Kc). 
Um outro fator que interfere na evapotranspiração é a irrigação. Segundo Allen \& Pruitt (1986), a irrigação modifica as condições climáticas locais resfriando o ar, tornando-o mais úmido, além de reduzir a turbulência nas massas de ar que avançam de áreas não irrigadas para as áreas irrigadas. Isso reduz o potencial evaporativo das massas de ar e, conseqüentemente, a evapotranspiração. Esses autores relatam que estudos anteriores têm demonstrado uma redução na temperatura média do ar de $2^{\circ} \mathrm{C}$ a $5^{\circ} \mathrm{C}$ em áreas irrigadas, quando comparadas com áreas sem irrigação, com aumento correspondente de umidade relativa e decréscimo no déficit de pressão de vapor.

Com relação aos fatores climáticos segundo Hargreaves (1994), o vento influencia a advecção, sendo as interações do vento com a temperatura, umidade relativa, déficit de pressão de vapor, e outros, difíceis de serem estimadas por equações.

Segundo Mukammal \& Bruce ${ }^{1}$, citados por Chang (1968), a radiação solar é sem dúvida o elemento climático mais importante na estimativa da taxa de evapotranspiração. Entretanto, em regiões onde ocorrem advecções fortes, seja local ou regional, observada comumente quando uma área úmida é circundada por área seca, a importância relativa da radiação líquida $(\mathrm{Rn})$ decresce e a advecção, ou transferência de calor sensível das áreas secas circunvizinhas, passa a contribuir significativamente no processo de evapotranspiração, com energia até maior que aquela disponível para área úmida, aumentando, desta forma, a importância da velocidade do vento e da umidade no processo evapotranspirativo.

Amatya et al. (1992) relatam em estudo realizado na Carolina do Norte (EUA), que a radiação foi o elemento meteorológico mais importante no processo de evapotranspiração.

Segundo Pereira et al. (1997a), a evapotranspiração é controlada pela disponibilidade de energia, pela demanda atmosférica e pelo suprimento de água para as plantas no solo. A radiação depende do local (latitude), topografia da região

\footnotetext{
${ }^{1}$ MUKAMMAL, E.; I. BRUCE, J. P. Evaporation measurements by pan and atmometer. International Union of Geodesy and Geoghysics. Association of Scientific Hydrology. n.53, p.408-420, 1960.
} 
e época do ano. A disponibilidade de energia, conforme os autores, é controlada pelo poder refletor da superfície (coeficiente de reflexão-albedo) onde superfícies mais claras refletem mais, portanto, têm menos energia disponível. A demanda atmosférica é controlada pelo poder evaporante do ar (Ea) relacionado à velocidade do vento e ao déficit de pressão de vapor. Quanto maior o valor de Ea, maior será a evaporação. Os autores lembram, que existe uma interação entre a demanda de umidade pelo ar, e a água disponível no solo.

Pereira et al. (1997a), citam que a elevação da evapotranspiração em áreas vegetadas circundadas por áreas secas (advecção), é maior na interface e decresce com a distância, à medida que o vento penetra na área úmida. Na área úmida a evapotranspiração diminui à medida que caminha na direção dos ventos predominantes, até um valor limite inferior que é resultante somente do balanço vertical local de energia. Os autores denominam de área tampão (área fetch, buffer ou bordadura) a distância entre a região de transição e o ponto onde a evapotranspiração é mínima.

As principais variáveis climáticas a qual proporcionam energia para vaporização e remoção de vapor de água, a partir de superfícies evaporantes são: radiação solar, temperatura do ar, umidade relativa, velocidade do vento, déficit de pressão de vapor e nebulosidade.

Radiação Solar - A quantidade potencial de energia que alcança a superfície é determinada pelo local e época do ano, devido às diferentes posições do sol.

Ao se avaliar o efeito da radiação solar, é preciso se ter em mente que nem toda energia disponível é usada na vaporização da água. Parte dessa energia é usada, para aquecer a atmosfera e o solo.

No caso de não se dispor de dados de radiação solar incidente (Rs) medidos em determinado local, pode-se lançar mão de estimativas a partir de dados de insolação (n), considerando-se ainda, valores de $\mathrm{N}$ (fotoperíodo) e dados de radiação no topo da atmosfera (Ra), tendo conhecimento dos coeficientes de Angström (a e b) (Smith, 1991). 
Segundo Pereira et al. (1997a), na ausência de dados de Rs, Glover \& McCulloch (1958) propõem: $a=0,29 \cos \phi$, para $\phi<60$ graus e $b=0,52$ ( $\phi$ é a latitude local em graus).

Segundo Allen et al. (1998), na ausência de dados de radiação solar, esse elemento pode ser obtido a partir da diferença de temperatura. A diferença entre temperatura máxima do ar (Tmáx) e mínima do ar (Tmín), está relacionada ao grau de cobertura de nuvens no local. Condições de céu claro proporcionam uma Tmáx elevada e baixa Tmín, pois muita radiação de ondas curtas penetra e pouca radiação de ondas longas, é absorvida pela atmosfera. Caso contrário, sob condições de nebulosidade, Tmáx é relativamente menor, porque parte da radiação não alcança a superfície da terra, sendo absorvida e refletida pelas nuvens. Portanto, a diferença entre temperatura máxima e mínima é um bom indicador da fração de radiação no topo da atmosfera (Ra), que alcança a superfície da terra. Esse princípio tem sido usado por Hargreaves \& Samani para desenvolver estimativas de ETo usando somente dados de temperatura.

Aguiar et al. $(2000)^{2}$ com base em dados obtidos em uma estação convencional em Fortaleza, CE, localizada na Universidade Federal do Ceará, utilizando dados de radiação solar e insolação nos anos de 1996 a 1998, encontraram valores (coeficientes de Angström) $a$ variando de 0,2351 a 0,3280 e valores de $b$ entre 0,2653 a 0,3482. Para o ano como um todo, os autores recomendam $a=0,2608$ e $b=0,3092$.

Temperatura do ar - Essa variável tem sua importância pelo fato de ser um dos elementos climáticos mais disponíveis em estações meteorológicas. Na ausência de dados de radiação, esse elemento meteorológico pode ser usado como indicativo de energia no sistema estudado. A radiação absorvida pela atmosfera aumentam a temperatura do ar, contribuindo para o aumento do processo de evapotranspiração. Dessa forma a temperatura do ar interfere nas condições ambientais, interagindo com outras variáveis de importância para o processo de evapotranspiração.

Umidade do ar - A oferta de energia do sol e do ar é a principal fonte de energia para evaporar a água, sendo a diferença entre pressão de vapor na superfície e no ar ao

\footnotetext{
${ }^{2}$ AGUIAR, J. V.; NOGUEIRA, S. M.; ARAÚJO, E. C. B. et al. Estimativa da radiação solar a partir da insolação, na região metropolitana de Fortaleza. Comunicação Pessoal, 2000.
} 
redor, fator determinante na transferência de vapor para atmosfera. Campos bem úmidos em regiões áridas, secas e quentes, consomem mais água devido a maior disponibilidade de energia, e poder evaporante da atmosfera. Em climas úmidos de regiões tropicais, apesar da elevada quantidade de energia, a alta umidade relativa reduz a evapotranspiração, pois o ar está sempre próximo da saturação. A umidade relativa local, e a temperatura determinam o déficit de pressão de vapor.

Quando se usa uma equação combinada como a de Penman-Monteith, vários métodos de cálculo de déficit de pressão de vapor podem ser usados. De acordo com Jensen et al. (1990), o método usado pode afetar significativamente a magnitude do termo aerodinâmico.

Tétens $^{3}$ e Murray ${ }^{4}$, citado por Oliveira et al. (1998), apresentaram uma equação conveniente de cálculo da pressão de vapor saturado, com temperatura média em graus centígrados, que é usada até recentemente.

Oliveira et al. (1998), compararam doze equações de estimativa de evapotranspiração, sendo dez variações da equação de Penman-Monteith, usando diferentes métodos de cálculo do déficit de pressão de vapor e as equações de Hargreaves 1974 e 1985, no período de janeiro a setembro de 1997, divididos em período seco e chuvoso. Os autores observaram melhores estimativas de evapotranspiração, durante o período chuvoso do que o período seco. De acordo com os autores, o método de cálculo de déficit de pressão de vapor, que proporcionou melhores resultados combinados aos modelos de Penman-Monteith, para as condições de estudo, foi calculado com base na média de pressão de vapor.

A pressão de vapor saturado para determinados períodos, deve ser calculada como a média entre a pressão de vapor à temperatura máxima (Tmáx) e a temperatura mínima (Tmín) diária, no referido período, (Allen et al., 1998).

\footnotetext{
${ }^{3}$ TÉTENS, O. Uber einige meteorologicsche begriffe. Z. Geoghys. n.6, p.297-309. 1930.

${ }^{4}$ MURRAY, F. W. On the computation of saturation vapor pressure. Journal Appliced Meteorology. v.6, p.203-204. 1967.
} 
A diferença entre a pressão de vapor saturado e a atual, definem o déficit de pressão de vapor, isto é, o quanto de vapor é necessário para saturar determinado volume de ar. É um indicador da capacidade evaporativa do ar.

Velocidade do vento - $\mathrm{O}$ processo de transferência de vapor depende do aumento da velocidade do vento e da turbulência do ar, a qual transfere grandes quantidades de ar sobre a superfície evaporante. $\mathrm{O}$ vento remove a camada logo acima da superfície evaporante, criando uma condição favorável ao aparecimento de um gradiente de pressão de vapor, aumentando dessa forma o poder evaporante no local.

Em condições áridas, pequena variação na velocidade do vento, proporciona grande variação na taxa de evapotranspiração.

Todas as variáveis descritas anteriormente, participam do processo de evapotranspiração direta ou indiretamente.

Silveira (2000) analisou a importância relativa de diferentes variáveis envolvidas no cálculo de evapotranspiração, com base em séries mensais de dados. Os dados foram coletados nas bacias de Fortaleza (bacia metropolitana), Sobral (bacia do Acaraú), Pentecoste (bacia do Curu), Iguatú e Tauá (bacia do Alto Jaguaribe) e Quixeramobim (bacia do Banabuiú). As variáveis testadas foram: precipitação, temperatura máxima e mínima do ar, velocidade do vento, umidade relativa e razão de insolação. A componente de maior influência para todas as bacias estudadas, foi o gradiente de pressão de vapor do ar. O estudo mostrou que os modelos de estimativas de ETo, baseados em temperatura, não são recomendados para o Estado do Ceará.

\subsection{Lisimetria}

Segundo Aboukhaled et al. (1982), os lisímetros são grandes "containers" preenchidos com solo (ou incluso um bloco de solo) localizado no campo, para representar o ambiente local, com superfície vegetada ou em solo nu, para determinação da evapotranspiração de uma cultura em crescimento, ou de uma cobertura vegetal de referência ou, ainda, da evaporação a partir de um solo não vegetado. 
Conhecidos e utilizados há 300 anos, nestas últimas décadas foram desenvolvidos basicamente dois tipos principais, os de pesagem e os de não pesagem.

Os lisímetros de pesagem envolvem vários princípios e dispositivos de medida. Esses dispositivos podem ser: de pesagem mecânica, com balanças, de pesagem eletrônica, com células de carga indicadoras de esforço, ou, ainda, os sistemas de pesagem hidráulica.

Uma outra definição encontrada é de a Tanner (1967), citado por Aboukhaled et al. (1982), que se refere a um lisímetro como "um aparelho com volume de solo, o qual pode ser cultivado com uma determinada cultura, localizado em um "container" para isolamento, onde se pode estudar os vários termos da equação de balanço hídrico”.

Segundo Silva et al. (1999), os lisímetros podem ser classificados em categorias como: (1) não-pesáveis, com lençol freático de nível constante; (2) não-pesáveis, com drenagem livre; e (3) pesáveis, onde a variação de massa do sistema é determinada por um mecanismo de pesagem. Além disso, são classificados quanto ao tipo de perfil (reconstituído ou monolítico) e ao sistema de drenagem (a vácuo e por gravidade).

A Organização Mundial de Meteorologia (WMO, 1968) usa o termo "evapotranspiração" ou "evapotranspirômetros de solo" ou ainda "containers de solo e vegetação do qual a água perdida é medida por pesagem ou contagem, para toda entrada e saída de água da superfície e no fundo do container”, quando se referem aos lisímetros. Melhores detalhes podem ser encontrados em Aboukhaled et al. (1982).

Segundo Allen et al. (1991), quando as medidas de lisímetros diferem das estimativas feitas por modelos com forte base física, como o de Penman-Monteith-FAO, é possível que o dispositivo lisimétrico não esteja representando as condições ambientais de estudo.

Grebet \& Cuenca (1991) advertem que diversos fatores podem causar distúrbios nas medidas de lisímetro, citando a remoção de um volume considerado de solo, próximo ao lisímetro e a posterior compressão do mesmo. Isso acarreta em alteração na macroporosidade do solo, diferenciado-o das condições adjacentes.

Howell et al. (1991), observaram que as paredes dos lisímetros de pesagem podem afetar a transferência de calor para os mesmos, assim como o fluxo de água nas 
paredes. Black et al. (1968), citado pelo autor, encontraram cerca de $30 \mathrm{~W} . \mathrm{m}^{-2}$ de energia consumida, para aquecimento das paredes de dois lisímetros em Wiscosin em condições de solo nú. $\mathrm{O}$ erro foi equivalente à precisão do mesmo, cerca de $0,04 \mathrm{~mm} \cdot \mathrm{h}^{-1}$ de taxa de evapotranspiração, que deve ser menor para áreas vegetadas. A precisão de um lisímetro de pesagem, pode ser também afetada por fatores externos como: tráfego de pessoas próximas, tratos culturais, altura da cultura, etc. Operações culturais como as capinas e os cortes de grama, realizadas no lisímetro e nas proximidades, afetam as medidas de ET. Um outro problema, são as visitas de pessoas cujo tráfego, faz caminhos que mudam a hidrologia do local e o desenvolvimento da cultura ao redor do lisímetro. Muitos investigadores usam para se aproximar do lisímetro, tábuas ou tijolos, para caminharem, quando a superfície do solo está úmida. A descontinuidade da cultura determinada por diferenças entre as culturas dentro e próxima do lisímetro, também afetam a taxa de evapotranspiração (Howell et al., 1991).

Howell et al. (1985) relatam que uma proteção deve ser colocada entre as caixas interna e externa do lisímetro, com a finalidade de proteger o conjunto contra a entrada de chuva ou sujeira. A entrada de chuva ou material estranho, interferem nas medidas pesagem.

Kirkiham et al. (1991) alertam que essa distância entre paredes interna e externa, deve ser de $5 \mathrm{~cm}$ a $10 \mathrm{~cm}$. Essa distância se não for conveniente, pode se constituir numa fonte de erros, ou muito próxima, ou muito distantes entre si. A proximidade pode comprometer as leituras, as caixas podem ficar unidas se qualquer sujeira penetrar na fenda. A distância maior pode permitir a entrada de objetos estranhos e até animais de pequeno porte.

Wright (1991) relata que o fato da proteção entre paredes interna e externa ser flexível, pode causar problemas de excesso de umidade no interior do lisímetro, durante evento de chuvas ou irrigações pesadas. A água advinda de precipitações ou irrigações pesadas, se acumula no material flexível que cobre a fenda entre as paredes externa e interna do lisímetro, resultando em aumento de umidade no local, vindo depois a condensar e retornar ao lisímetro, criando um mini-ciclo hidrológico. 
Silva et al. (1999) relataram que o sistema de pesagem de um lisímetro, pode ser afetado pela temperatura de operação da célula de carga. Outra fonte de erro é o efeito de pressão do vento sobre a superfície do lisímetro, o que foi relatado por Bergamaschi et al. (1997). Segundo esses autores, as oscilações provocadas pela pressão exercida pelos ventos, podem diminuir, com o aumento do intervalo de registro.

\subsection{Equação de Penman-Monteith (PM) para estimativa de ETo}

A Comissão Internacional de Irrigação e Drenagem (ICID) e a Organização das Nações Unidas para Agricultura e Alimentação (FAO), consideram o método de Penman-Monteith (PM) como padrão de cálculo da evapotranspiração de referência, a partir de dados meteorológicos ( Smith, 1991, Allen et al., 1998).

Conforme Allen et al. (1994a), a evapotranspiração (ET) é um processo governado por trocas de energia de uma superfície vegetada e é limitado pela quantidade de energia disponível. Por isso, é possível prever a taxa de ET através do balanço de fluxos de energia, conforme a equação: $\lambda E T=R n-H-G$, em que: $\lambda E T$ é a densidade de fluxo de calor latente; $\mathrm{H}$ é o calor sensível da camada limite de equilíbrio; $\mathrm{G}$ é o calor sensível do solo; Rn é a densidade de fluxo de radiação líquida; $\lambda$ é o calor latente requerido para evaporar uma unidade de água, expresso como umidade de energia por unidade de massa.

A partir da equação de balanço de energia, pode-se calcular a razão de Bowen, partindo da premissa de que num período diário de $24 \mathrm{~h}$, o fluxo de calor do solo é muito pequeno em relação ao saldo de radiação, portanto, podendo ser desprezado $(G=0)$. Para $G=0$, a equação de balanço de energia fica reduzida a: $\lambda \mathrm{ET}=\mathrm{Rn}-\mathrm{H}$. Como a razão de Bowen $(\beta)$ é igual à relação entre o calor sensível (H) e o fluxo de calor latente $\lambda E T$, essa relação pode ser apresentada como:

$$
\beta=\frac{R n-\lambda E T}{\lambda E T} \text { ou } \beta=\frac{R n}{\lambda E T}-1
$$

Geralmente existem camadas turbulentas e complexas, dentro e acima das coberturas vegetais. Os efeitos da divisão de energia dentro da cobertura vegetal, pode 
ser explicado por meio de simples resistência. Esse fato é geralmente explicado, na teoria da "big leaf" de Monteith (1965, 1985), onde as resistências (da cobertura e aerodinâmica), operam em série entre o interior das folhas e alguma altura de referência, situada acima da vegetação (Allen et al., 1994a).

Segundo Peres (1994), Penman desenvolveu sua equação incorporando a velocidade do vento, relacionando-a a superfície de água livre, a partir de duas premissas: primeiro, que as fontes e sumidouros de calor sensível ocorrem em um mesmo plano, por exemplo, a lâmina de uma folha; segundo, que a pressão de vapor da superfície evaporante, seja igual à pressão de vapor de saturação da água a temperatura da superfície (relacionada ao calor latente). Thom (1975), citado pelo autor, relata que o fluxo de calor sensível é originado a partir da superfície das folhas, enquanto que o fluxo de calor latente tem sua origem nos espaços intercelulares da folha. Oke citado por Peres (1994), relata que, a segunda condição (anteriormente citada), dificilmente ocorre em superfícies evaporantes. Com base no exposto, ele afirma que o método de estimativa de ETo de Penman não é um caso geral, mas uma condição particular aplicada a superfícies de água livre, como um lago ou tanque de evaporação, ou ainda superfícies molhadas, como uma vegetação após a chuva ou irrigação por aspersão.

Penman (1948) não incluiu a função de resistência à transferência de vapor d'água em sua equação original. A equação, combinada com o termo aerodinâmico e resistência da superfície de uma cobertura vegetal, é chamada de equação de Penman-Monteith (Monteith, 1985).

Jensen et al. (1990) relatam que essa equação de PM, é mais precisa, quando usada na base horária e somando os valores para obter estimativa diária de ETo. Segundo os autores, exemplos de cálculos mostram claramente que quando usados elementos climáticos diários, a equação de Penman-Monteith, pode proporcionar estimativas precisas de ETo. Entretanto, deve-se ter prudência no manuseio, como advertem Doorenbos \& Pruitt (1977), o uso de dados climáticos médios em equações combinadas pode conduzir a erros significativos. Esses erros 
resultam de várias combinações entre elementos climáticos, como velocidade do vento, umidade e saldo de radiação.

Entre os erros comumente observados em medições ou estimativas de evapotranspiração de referencia, pode-se destacar os erros: erro médio absoluto (EMA) relacionados à diferença entre dados médios medidos e estimados, erro máximo (EM) diferença entre medidas e estimativas máximas, erros sistemáticos (Es) e erros aleatórios ou estatísticos (Ea). Entre os erros sistemáticos pode-se destacar os teóricos e ambientais como mais comuns nesse tipo de avaliação (Vuolo, 1992).

Conforme Peres (1994), o modelo de Penman-Monteith (PM) torna-se semelhante ao de Penman (1963), quando a resistência à troca de calor sensível e latente a partir do interior da folha $\left(r_{c}\right)$, é igual a zero $\left(r_{c}=0 \mathrm{sm}^{-1}\right)$, e substitui-se a função de velocidade do vento pelo inverso da resistência aerodinâmica $\left(r_{a}\right)$. Com o modelo assim proposto, torna-se possível estimar a evaporação de uma superfície de água livre, o que é diferente de evapotranspiração das culturas, a qual apresenta um valor mínimo de $r_{c}$ diferente de zero.

Equações de resistência aerodinâmica $\left(r_{a}\right)$ e resistência total da superfície $\left(\mathrm{r}_{\mathrm{s}}\right)$, são combinadas com o método de PM, para formar uma equação mais simples, descrevendo a grama hipotética de referência. Pela combinação de expressões generalizadas de densidade do ar $(\rho)$, com expressões simplificadas de $\mathrm{r}_{\mathrm{s}}$ e $r_{a}$ para a grama, Allen et al. (1989), Smith (1991), Allen et al. (1994a) e Allen et al. (1998), parametrizaram a chamada equação de Penman-Monteith FAO (PM-FAO).

A FAO através de seus consultores (Smith, 1991), recomendam que os métodos empíricos de estimativa de ETo, sejam calibrados e validados para outras regiões, sendo a equação PM-FAO a referência padrão para esses ajustes. Essa aplicação deve ser feita para locais próximos que tenham medidas climáticas suficientes.

Al-Ghobari (2000) relatou que a maioria das equações desenvolvidas não são universalmente aplicadas, sem as modificações ou calibração locais, para toda situação de cultura ou condição climática, especialmente em clima seco e quente. 
Allen et al. (1998) relatam que estudos realizados nos EUA e na Europa, confirmam a precisão e consistência do método de PM, para climas úmidos e áridos.

Vários autores encontraram boa correlação entre dados medidos em lisímetros e estimados pela equação de Penman-Monteith como: Allen (1986), Maggiotto (1996); Sentelhas (1998), Pereira (1998), Camargo e Sentelhas (1997), Jensen et al. (1990), Ribeiro (1996), Hussein (1999), Allen et al. (1994a) e Azevedo (1999).

Para Baselga \& Allen (1996) a equação de PM tem provado ser altamente sensível às variações no nível de umidade no solo e altura da cultura de referência, quando usando essas duas variáveis para estimativa da resistência da cobertura vegetal e aerodinâmica.

2.6 Comparação entre métodos de estimativa de evapotranspiração de referência

Na tentativa de escolher o melhor método de estimativa da evapotranspiração para um determinado local, vários pesquisadores lançam mão de artifícios diversos para comparar as diversas equações existentes entre si, buscando sempre a que melhor corresponda à realidade local.

A exemplo temos Medeiros (1996), que fez uso do programa REF-ET, comparando oito métodos, com base em dados climáticos de Pentecoste, CE e Mossoró, RN. Neste estudo o método de Penman-Monteith, de acordo com Jensen et al. (1990), foi usado como padrão de comparação. No estudo foram comparados 8 equações de estimativa de evapotranspiração. As equações que melhor se ajustaram a PM na base diária para Pentecoste, foram os métodos de Penman Kimberly (1982) e Penman-FAO. A pior performance foi observada para o método do Tanque Classe A.

Amatya et al. (1992), compararam 8 métodos de estimativa de evapotranspiração de referência (ETo): Penman-Monteith, Penman 1963, PenmanFAO, 4 métodos baseados na radiação (Makkink, Priestlay-Taylor, Turc e JensenHaise) e 1 método baseado na temperatura, Thornthwaite. Observaram boa correlação entre os valores de ETo estimados pelos 4 métodos de radiação, o método baseado na temperatura e Penman-Monteith, apresentaram alguma 
diferença. Encontraram, ainda, maior correlação para as estimativas de ETo na base mensal e menor para estimativas diárias. Segundo os autores, nenhum método específico de estimativa da ETo, tem sido adequado para todas as condições climáticas e locais.

Souza \& Yoder (1994) compararam métodos de estimativa da ETo, tendo a grama como referência, a partir de dados diários totalizados em meses no período de 1974 a 1978, para os métodos de Penman-Monteith, Hargreaves \& Samani (1985), e Hargreaves (1974). Foram usados dados de Fortaleza e do município de Pentecoste, localizado no interior do estado do Ceará, em zona semi-árida. Segundo os autores, as equações de Hargreaves (1974 e 1985) superestimaram a evapotranspiração potencial para vários meses do período, em valores que variam de uma faixa mínima de $4 \%$ a $8 \%$ e máxima entre $32 \%$ e $35 \%$. A ausência de dados completos, não permitiram uma melhor comparação.

Hargreaves (1994) relata que a qualidade dos dados é tão importante, quanto à equação utilizada.

A análise realizada por Souza \& Yoder (1994), mostrou que a equação de Hargreaves \& Samani (1985), não proporcionou boas estimativas da evapotranspiração de referência para o nordeste do Brasil, apesar da mesma se correlacionar bem com equações combinadas de Penman.

Medeiros (1998) comparou o desempenho de 12 equações de estimativa de evapotranspiração de referência (ETo), com dados obtidos em evapotranspirômetros tipo Thornthwaite-Mather, visando encontrar um método que estimasse melhor a ETo, para as condições de Santa Maria, RS. Os dados foram tomados na base qüinqüidial, durante 6 anos. O desempenho foi medido pelo coeficiente $c$ proposto por Camargo e Sentelhas (1997). Os métodos que tiveram melhor desempenho foram: Penman, Camargo e Tanner \& Pelton, com desempenhos considerados "muito bom". Os métodos de BenevidesLopez, Turc, Hargreaves \& Samani, Jensen e Haise, Makkink, Tanque Classe A e Priestley-Taylor, tiveram desempenho bom. Os métodos de Linacre e David, obtiveram mau e péssimo desempenho, respectivamente. 
Lunardi et al. (1999), trabalhando com estimativa de evapotranspiração de referência em Botucatu, SP, encontraram melhor desempenho, entre os vários métodos testados, para os de Penman-Montetith (PM), Penman-FAO, Tanque de EvaporaçãoFAO (FPan) e Radiação-FAO, com destaque para o método de Penman-Monteith.

Almeida et al. (1999) analisaram as estimativas da ETo obtidas pelas equações de Penman-Monteith (PM), Penman-FAO e o Tanque de evaporação (FPan), admitindo PM como padrão de comparação, com base em dados coletados em Botucatu-SP. Os resultados encontrados mostraram que a ETo estimada por Penman-Monteith foi menor que a calculada por Penman-FAO. Os dados diferem dos encontrados por Weiss (1982), Batchelor (1984), Allen (1986); citados pelos autores, e Jensen et al. (1990) e Hargreaves (1994).

Silva (1989) avaliou a eficiência de métodos de estimativa de ETo, a partir de dados mensais no período de 1978 a 1987, utilizando o método de Penman-FAO, como padrão na análise, contra os métodos da Radiação FAO, Blaney-Criddle corrigido pela FAO, Thornthwaite, Hargreaves (1974) e Hargreaves \& Samani (1985). A análise revelou que, ao nível de 1\% de probabilidade, os métodos de Thornthwaite e Hargreaves \& Samani (1985) não diferiram entre si, entretanto, variaram com relação aos métodos de Penman e o método baseado na radiação solar (FRad).

Stanhill (1962) analisando dados climáticos de Israel, encontrou alta correlação entre evaporação medida no evaporímetro de Piche e o termo aerodinâmico da equação de Penman (Ea). Os erros observados são ditos menores do que os causados pelo uso de pressão de vapor atual diária, no termo Ea. Em relação ao método de Thornthwaite, ele encontrou subestimativas consideráveis de ETo, dada a condição de aridez do local de estudo. O fato decorre, da equação não considerar o efeito da advecção.

Doorenbos \& Pruittt (1977), comparando a ETo estimada por equações, em Davis, CA/EUA; com dados medidos em lisímetro de $30 \mathrm{~m}^{2}$ de área, encontraram subestimativas do método de Thornthwaite, e boas estimativas com os métodos de Penman, Makkink e Jensen \& Haise. 
Al-Ghobari (2000) observou bons ajustes entre dados medidos em lisímetros em Riyadh e as equações baseadas em Penman-FAO calibradas para o local, BC-FAO (Blaney-Criddle-FAO) e FPan (Tanque de Evaporação-FAO).

Camargo e Sentelhas (1997) avaliaram o desempenho de vinte métodos de estimativa de ETo, com dados de três localidades do estado de São Paulo, com relação a dados de lisímetro, no período de 1954 a 1960. A avaliação dos dados foi baseada no coeficiente de correlação (r), de concordância (d) de Willmott e de um índice proposto de confiança ou desempenho (c). Os resultados obtidos demonstram um desempenho considerado muito bom ( $c$ entre 0,78 e 0,81 ) para os métodos de Thornthwaite, Camargo et al. (1999) e Priestley-Taylor.

Hussein (1999) comparando dados de ETo medidos em lisímetro em relação aos obtidos pelas equações de estimativa de Penman-Monteith, Penman-FAO, Penman 1963 e outros, encontrou melhor desempenho para o modelo de Penman-Monteith.

2.7 Outros métodos de estimativa de evapotranspiração de referência alternativos de acordo com os dados disponíveis

As equações abordadas neste trabalho, além de Penman-Monteith, são: Thornthwaite (1948), Thornthwaite modificada por Camargo (1999), Hargreaves \& Samani (1985), Tanque de Evaporação Classe A e Priestley-Taylor (1972).

A equação de Thornthwaite (1948) leva em consideração a evapotranspiração de grandes áreas, como bacias hidrográficas, trabalhando-se com evapotranspiração potencial, que segundo o próprio autor, é muito semelhante à condição de contorno apresentada por Penman (1948).

Camargo et al. (1999) propuseram uma equação de Thornthwaite modificada, onde substituíram a temperatura média pela temperatura efetiva (Tef), baseados na suposição de que a amplitude térmica, expressa o efeito do alto e baixo déficit de pressão de saturação de vapor no ar, partindo da premissa de que quanto mais seca a atmosfera, maior sua temperatura máxima e menor sua mínima, ou seja, a amplitude térmica aumenta. 
O método do Tanque de Evaporação é baseado na evaporação de água livre e num coeficiente do tanque $(\mathrm{Kp})$, relacionado às condições do meio onde se determinam ETo.

Doorenbos \& Pruitt (1977) apresentam no manual 24 da FAO, uma tabela com valores de Kp que depende do local onde o tanque está instalado, se é rodeado por terreno gramado ou por solo sem vegetação, além de outros fatores como: velocidade do vento, umidade relativa e tamanho da bordadura, relacionados a grama irrigada. Os autores lembram da necessidade de ajustes locais no valor de $\mathrm{Kp}$, dependendo da altura da cultura de referência e das condições climáticas existentes.

Pereira et al. (1995), propuseram uma equação para o Kp, baseado no modelo de Penman-Monteith, para um tanque em terreno gramado. Os autores concluíram que equação descrita por Smith (1991), não é uma boa parametrização para $r_{c} / r_{a}$ sob condições de clima tropical.

Allen et al. (1998), lembra que a evaporação representa o efeito integrado de variáveis climáticas como vento e umidade, além de outros aspectos como o tipo de tanque, sua localização na estação meteorológica, ou seja, se está rodeado por solo nú ou por grama rasteira. Os autores lembram que existe diferença entre evaporação que ocorre no tanque e evapotranspiração na planta, o caminho percorrido pelo vapor, apresenta-se diferente com relação às resistências de perdas de vapor d'água. Além do aspecto da transmissão de calor para o corpo do tanque. Os autores apresentam várias equações dependendo da situação de operacionalidade do tanque, se a bordadura é composta de área seca ou gramada e do tipo de tanque.

Como outra opção de equações de estimativa de evapotranspiração de referência, utilizou-se a equação de Priestley-Taylor (PT).

A equação de (PT) é uma simplificação da equação de Penman original, onde somente é contemplado o termo energético, corrigido por um coeficiente de ajuste $(\alpha)$, cujo valor no modelo original é de (1,26), (Pereira et al., 1997b). 
Segundo Peres et al. (1997), Priestley-Taylor estabeleceram empiricamente que a relação evaporação/evapotranspiração potencial de uma superfície saturada, com mínima advecção, pode ser estimada pela equação (34) (Material e métodos). PriestleyTaylor encontraram valores de $\alpha$ variando de 1,08 (evaporação em solo nú), 1,32 (evapotranspiração em solo vegetado) com valor médio de 1,26.

Allen (1986), verificou que o método de Priestley-Taylor (PT) proporcionou bons resultados em climas onde a adevecção é baixa. Entretanto, em climas áridos, onde a advecção é mais elevada, PT subestimou ETo. O autor lembra que Priestley-Taylor (1972), sugere o valor de $\alpha=1,34$, como adequado para região árida da Austrália.

Pereira e Villa Nova (1992), mostraram que as variações do parâmetro de Priestley-Taylor, são descritas pelas flutuações de calor sensível (H). Os resultados mostram que a relação é linear e positiva, na base horária e diária. As relações encontradas indicam que o valor proposto por Priestley-Taylor $(1972)(\alpha=1,26)$, para condições potenciais não representa situação de advecção. Os autores encontraram valores de $(\alpha)$ que variam de 1,01 a 1,66 .

Alguns autores determinaram esse parâmetro $(\alpha)$ para condições locais, por exemplo, Cunha $\&$ Bergamaschi (1994) encontraram valor de $\alpha=1,40 \pm 0,06$ para escala mensal, em Santa Maria, RS. Pereira et al. (1997b), determinaram valores de $\alpha$ para três localidades de São Paulo, observando variações entre elas: Campinas $(\alpha=0,99 \pm 0,17)$, Ribeirão Preto $(\alpha=1,12 \pm 0,11)$ e Pindamonhagaba $(\alpha=1,17 \pm 0,12)$.

Pereira et al. (1997a), encontraram para a grama em lisímetro de drenagem na escala mensal, valores médios anuais de $(\alpha)$ inferiores a 1,26, ou sejam, Campinas

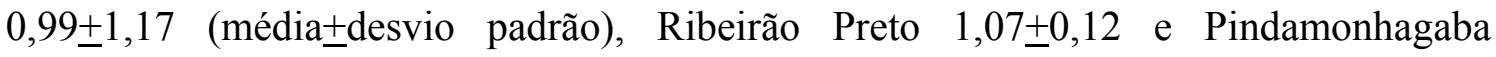
$1,17 \pm 0,11, \mathrm{SP}$.

Segundo Cunha \& Bergamaschi (1994), as características inerentes aos parâmetros de Makkink $\left(\alpha_{\mathrm{m}}\right)$ e Priestley-Taylor $(\alpha)$ impedem a universalidade dos mesmos para as culturas e locais diversos. Os autores trabalhando com alfafa em Santa Maria, RS, obtiveram valores de $\alpha_{\mathrm{m}}$ e $\alpha$ iguais a 0,88 e 1,38, para as escalas diária, 
qüinqüidial, decendial e mensal. Os autores relatam que não é prudente considerar o valor $(\alpha=1,26)$ de aplicação universal, haja visto que, o valor do parâmetro de Makkini e Priestley-Taylor, dependem da representatividade temporal, aumentando a medida em que passa de nível diário, para qüinqüidial, decendial e mensal, sucessivamente.

Medeiros (1998) encontrou um bom desempenho em estimativa de evapotranspiração de referência (ETo), na base qüinqüidial, para os métodos de Hargreaves \& Samani, Tanque Classe A e Priestley-Taylor.

Sentelhas et al. (2000), determinaram o parâmetro de Priestley-Taylor para as condições de Piracicaba, SP, encontrando valores de (média_desvio padrão) de 0,97士0,1 para o período úmido e 1,32 $\pm 0,15$ para o período seco. No período seco houve maior contribuição do termo aerodinâmico, $32 \%$ do termo energético. Os autores afirmam que houve grande dispersão de dados, quando plotados dados obtidos com o método de Priestley-Taylor $(\alpha=1,26)$ contra dados medidos em lisímetro, indicando que o valor original não se aplica ao longo do ano. Os autores observaram uma contribuição de calor sensível (por advecção) no período seco, portanto a ETo foi influenciada pelo tamanho da área tampão, no caso de $35 \mathrm{~m}$ x 90m e concluíram que o parâmetro de PriestleyTaylor, varia de acordo com as condições de umidade regional, relacionadas ao tamanho da área de bordadura e a advecção de calor sensível.

Com relação ao tamanho da bordadura, muitos estudiosos recomendam valores maiores do que $50 \mathrm{~m}$ e área de 1 ha, direção de ventos predominantes (Howell et al., 1991). Doorenbos \& Pruitt (1977), sugerem uma bordadura variando de 1:50 a 1:100, baseado no equilíbrio da camada limite acima da superfície de evaporante. Jensen et al. (1990), recomenda uma área de 1:200.

Allen et al. (1991), sugerem que se a velocidade do vento, umidade e temperatura do ar são medidos a $2 \mathrm{~m}$ de altura, a bordadura deverá ser de 100 a $400 \mathrm{~m}$. Essas recomendações deverão ser estipuladas para uma área de no mínimo 4 a 64ha, com lisímetro localizado no centro. 


\section{MATERIAL E MÉTODOS}

\subsection{Localização da Área}

O experimento foi implantado e conduzido em Paraipaba, região litorânea do Estado do Ceará, cuja latitude é de $3^{\circ} 17^{\prime} \mathrm{S}$, a longitude de $39^{\circ} 15^{\prime} \mathrm{W}$ e altitude de $30 \mathrm{~m}$, localizado na Estação Experimental do Vale do Curu, no Centro Nacional de Pesquisa em Agroindústria Tropical, pertencente a EMBRAPA (Empresa Brasileira de Pesquisa Agropecuária).

\subsection{Caracterização do Local}

Conforme a classificação de Köppen, o clima na microregião de Paraipaba, Vale do Curu, é do tipo Bshi, com maior concentração de chuvas ocorrendo de fevereiro a maio, sendo o restante do período seco. A média anual de precipitação é de $764 \mathrm{~mm}$, com evaporação (tanque classe A) de $1450 \mathrm{~mm}$ e temperatura média anual de $27^{\circ} \mathrm{C}$. O solo do local é constituído de Areia Quartzosa.

A área experimental está localizada no centro de uma área de 1ha cultivada com grama, circundada por outras áreas irrigadas com fruteiras (16ha).

$\mathrm{Na}$ área experimental foram instalados equipamentos (lisímetro e estação automática) adquiridos pela Fundação Cearense de Amparo a Pesquisa - FUNCAP, em convênio com a Universidade Federal do Ceará (UFC) e da Universidade do Tennessee, e cedidos à EMBRAPA. 


\subsection{Instalação do Lisímetro}

No local foi instalado um lisímetro com grama gengibre (Paspalum maritimum L.), opção feita por se tratar de uma variedade mais adaptada à região, cuja manutenção a uma altura em torno de $10 \mathrm{~cm}$ a $15 \mathrm{~cm}$, foi feita através de cortes periódicos. A umidade na área externa e no interior do lisímetro foi mantida próxima da capacidade de campo, por meio de irrigações com sistema de aspersão, sempre que necessário.

O lisímetro foi constituído de caixa em chapa de aço de $6 \mathrm{~mm}$ de espessura, medindo $1,5 \mathrm{~m}$ de comprimento por 1,5m de largura e 1,0m de profundidade (dimensões externas). A Figura 1 apresenta um esquema do lisímetro utilizado.

A caixa interna estava apoiada em uma balança eletrônica de precisão, a qual por sua vez estava assentada em uma laje de concreto, de $15 \mathrm{~cm}$ de espessura. Todo o conjunto era protegido por outra caixa externa, do mesmo material da caixa interna.

A caixa interna foi preenchida com solo em sua ordem de camadas, contendo ainda um sistema de drenagem.

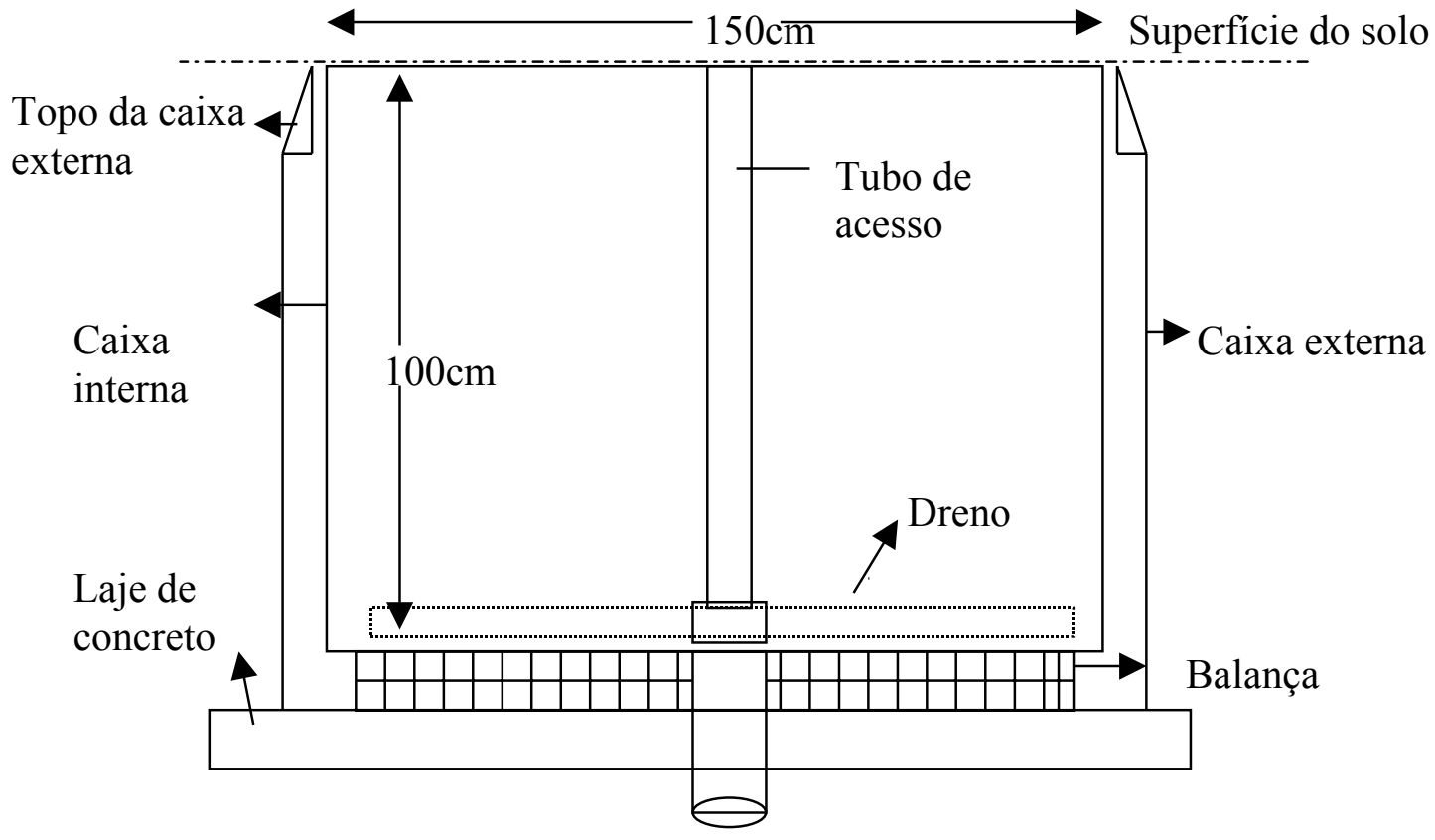

Figura 1 - Representação esquemática do lisímetro de pesagem instalado na Estação Experimental do Vale do Curu, no CNPAT/EMBRAPA, em Paraipaba, CE. 
A balança eletrônica utilizada era da marca WEIGH-TRONIX modelo DS606010, com capacidade de $4500 \mathrm{~kg}$ e precisão de $0,45 \mathrm{~kg}$ ou $0,2 \mathrm{~mm}$. A balança possuía quatro barras de pesagem, com elemento sensível e estava ligada a um sistema de aquisição de dados da marca Campbell Scientific (modelo 21X).

Os dados de pesagem do lisímetro, para efeito de cálculo, foram tomados a partir da diferença entre o peso registrado no início do dia, zero hora, e o peso no final do dia (24h). Essa diferença foi dividida pelo valor correspondente à área interna do lisímetro $\left(1,485 \mathrm{~m} \times 1,485 \mathrm{~m}=2,205 \mathrm{~m}^{2}\right)$.

\subsection{Calibração e Manejo do Lisímetro}

Todos os cuidados relacionados ao manejo da cultura (grama), ficaram a cargo de técnicos da Estação Experimental do Vale do Curu (EMBRAPA), que através de cortes periódicos (a cada 15 dias), irrigações freqüentes (3 vezes por semana) e fertirrigações (uma vez por mês), manejaram a cultura de forma a estabelecer condições adequadas para a mesma se desenvolver. Tomaram-se os cuidados necessários para mantê-la dentro das condições padrões da cultura de referência.

A calibração do lisímetro foi feita, cobrindo-se a superfície do solo da caixa interna com uma lona plástica, para evitar evaporação. Utilizaram-se 176 sacos com areia seca ao ar pesando $1000 \mathrm{~g}$, calibrados através de balança de precisão, e vedados para se evitar variação de peso. Como a área interna do lisímetro era de $2,205 \mathrm{~m}^{2}$, cada quilo colocado correspondeu a $0,453 \mathrm{~mm}$ de água. Os 176 sacos totalizaram o correspondente a $79,8 \mathrm{~mm}$, ou seja, ao dobro da faixa de trabalho prevista.

$\mathrm{Na}$ calibração, o sistema de aquisição de dados foi programado para leituras a cada 15 segundos. Foram colocados pesos, e efetuadas as medições com leituras correspondentes no sistema de aquisição de dados, de forma a coletar valores para aferição posterior. Os dados obtidos foram submetidos à análise de regressão obtendo-se a relação $\mathrm{y}=3154,558 \mathrm{x}-5455,511$, em que $y$ é a massa $(\mathrm{kg})$ e $x$ é a leitura $(\mathrm{mV})$. $\mathrm{O}$ coeficiente de determinação foi igual a 0,9994 , sendo $n=45$. O erro padrão de estimativa da regressão linear foi de $1,32 \mathrm{~kg}$ o que equivale a uma lâmina de água de $0,6 \mathrm{~mm}$. 
Maiores detalhes do processo de calibração do lisímetro podem ser encontrados em Miranda et al. (1997).

\subsection{Dados Meteorológicos}

Próximo à área experimental, haviam duas estações agrometeorológicas instaladas, sendo uma convencional, a qual forneceu os dados de evaporação do tanque classe A, e outra automática (Campbell Scientific), composta dos seguintes sensores de:

- Temperatura - marca Vaisala modelo HMP35C, com capacidade de medição na faixa de $-35^{\circ} \mathrm{C}$ a $50^{\circ} \mathrm{C}$, com precisão em torno de $0,4^{\circ} \mathrm{C}$ na faixa de $24^{\circ} \mathrm{C}$ a $48^{\circ} \mathrm{C}$ e elemento sensor do tipo termissor instalado no interior de um abrigo tipo multiplaca;

- Umidade Relativa do ar (UR) - marca Vaisala modelo HMP35C, medindo de 0 a $100 \%$, com precisão de $2 \%$ da UR, de $0 \%$ a $90 \%$ e em torno de $3 \%$ na faixa de $90 \%$ a $100 \%$. A $20^{\circ} \mathrm{C}$, incluindo a não linearidade e histerese, o aparelho apresenta uma dependência das condições de temperatura em torno de $0,04 \% \mathrm{UR} /{ }^{\circ} \mathrm{C}$. Também instalado no interior de um abrigo tipo multiplaca;

- Radiação Solar - Piranômetro marca Li-Cor modelo LI-200SZ, calibrado com saída de 97,1 microamperes por 1000watts $\mathrm{m}^{-2}$. Existe uma incerteza de calibração de $\pm 5 \%$ e uma sensibilidade de $20 \mu \mathrm{A}$ por $100 \mathrm{klux}$. Dependência de temperatura de $\pm 0,15 \%$ por ${ }^{\circ} \mathrm{C}$ (máximo).

- Velocidade e Direção do Vento - marca RM Young modelo 03001, com faixa de medida de $0 \mathrm{~ms}^{-1}$ a $50 \mathrm{~ms}^{-1}$, sendo este instalado a 2,0m de altura;

- Precipitação Pluviométrica - marca Texas Eletronics modelo TE525MM, com incrementos de $0,1 \mathrm{~mm}$ e precisão de $1 \%$ para precipitação de até $50 \mathrm{mmh}^{-1}$.

A aquisição de dados meteorológicos foi feita com um sistema de aquisição de dados da marca Campbell Scientifc (datalogger), modelo 21X, programado para realizar 
leituras dos sensores a cada 60 segundos e armazenar a média e/ou total, dependendo do elemento, a cada 60 minutos.

Os dados climáticos coletados para determinação de ETo (evapotranspiração de referência), foram relativos aos seguintes períodos: março a junho de 1997 e 1998.

\subsection{Análise dos dados}

\subsubsection{Avaliação do Lisímetro}

Efetuou-se análise do desempenho do lisímetro na medida de evapotranspiração de referência, tendo como padrão de comparação à equação de Penman-Monteith, conforme preconizada e parametrizada no Boletim da FAO nํ56 (Allen et al., 1998).

Os dados meteorológicos usados na análise foram avaliados conforme sugestão de Allen (1996) e Allen et al. (1998), em que os registros meteorológicos podem ser comparados periodicamente para verificar se os instrumentos estão funcionando como esperado.

A análise constou de dados referentes ao período de $24 \mathrm{~h}$, dados médios de 5 dias e dados médios de 10 dias, para os meses de março a junho, dos anos de 1997 e 1998. Os dados meteorológicos usados foram coletados na estação automática, para aplicação na equação de Penman-Monteith.

A partir do período escolhido, foram selecionados os dados referentes aos dias

em que não houve corte de grama, fertirrigação, drenagem, precipitação ou irrigação, garantindo dessa forma as condições de contorno, totalizando 108 dias, nos quais as análises foram aplicadas.

No Anexo 1, são apresentados os dados meteorológicos referentes aos dias analisados (108 dias) coletados na estação automatizada, que foram utilizados nos cálculos de evapotranspiração de referência com base na equação de Penman-Monteith. 


\subsubsection{Equação de Penman-Monteith (PM)}

Assumindo que fatores de transferência de difusão turbulenta para calor latente e sensível são os mesmos e que as diferenças entre fatores de transferência para o momentum e para o calor podem ser quantificadas através de relações simples, então a equação combinada de Penman-Monteith (Monteith, 1965) citado por Allen et al. (1994 a), resulta em:

$$
\lambda E T=\frac{\Delta\left(R_{n}-G\right)+\frac{\rho \cdot c_{p} \cdot\left(e_{s}-e_{a}\right) M}{r_{a}}}{\Delta+\gamma\left(1+\frac{r_{c}}{r_{a}}\right)}
$$

em que: $\left(\mathrm{e}_{\mathrm{s}}-\mathrm{e}_{\mathrm{a}}\right)$ é o déficit de pressão de vapor do ar para altura de referência medida $(\mathrm{kPa}) ; \rho$ a densidade do ar $\left(\mathrm{kg} \cdot \mathrm{m}^{-3}\right)$; cp o calor específico do ar a pressão constante $\left(\mathrm{MJ}_{\mathrm{kg}}{ }^{-1} \cdot{ }^{\circ} \mathrm{C}^{-1}\right) ; \Delta$ a declividade da curva de pressão de vapor contra temperatura $\left(\mathrm{kPa} . \mathrm{C}^{-1}\right) ; \gamma$ a constante psicrométrica $\left(\mathrm{kPa}^{\circ} \mathrm{C}^{-1}\right) ; r_{c}$ e $r_{a}$ as resistências total da cobertura e aerodinâmica $\left(\mathrm{sm}^{-1}\right)$, respectivamente; $\mathrm{M}$ o valor que depende da escala de tempo usada; Rn o saldo de radiação $\left(\mathrm{MJ} \mathrm{m}^{-2} \cdot \mathrm{d}^{-1}\right)$ e $\mathrm{G}$ a densidade de fluxo de calor do solo $\left(\mathrm{MJ} \cdot \mathrm{m}^{-2} \cdot \mathrm{d}^{-1}\right)$.

As equações de resistência aerodinâmica $\left(r_{a}\right)$ e resistência total da superfície $\left(r_{c}\right)$, tem sido combinadas com o método de Penman-Monteith, visando descrever uma vegetação hipotética de referência. Pela combinação de expressões generalizadas de densidade do ar $(\rho)$, com expressões simplificadas de $r_{c}$ e $r_{a}$ para a grama, Allen (1986), Allen et al. (1989), Smith et al. (1991) e Allen et al. (1994a), reduziram a chamada equação de Penman-Monteith FAO a: 


$$
E T o_{P M}=\frac{0,408 \Delta(R n-G)+\gamma \frac{900}{(T+273)} U_{2}\left(e_{s}-e_{a}\right)}{\Delta+\gamma\left(1+0,34 U_{2}\right)}
$$

em que: Rn e G têm as mesmas unidades $\left(\mathrm{MJ}_{\mathrm{m}} \mathrm{m}^{-2} \cdot \mathrm{dia}^{-1}\right)$; T é a temperatura média diária $\left({ }^{\circ} \mathrm{C}\right) ; \mathrm{U}_{2}$ é a velocidade média do vento medida a $2 \mathrm{~m}\left(\mathrm{~ms}^{-1}\right) ; 0,408$ corresponde a $1 / \lambda$ sendo $\lambda$ o calor latente de evaporação da água, igual a $2,45 \mathrm{MJ} \mathrm{Kg}^{-1}$ a $20^{\circ} \mathrm{C} ; 900$ é um coeficiente para a cultura de referência $\left(\mathrm{kJ}^{-1} \cdot \mathrm{kg} \cdot \mathrm{K}^{\mathrm{o}} \cdot \mathrm{d}^{-1}\right)$, que envolve os valores constantes da equação.

3.6.1.2 Algoritmos para o cálculo da Evapotranspiração de Referência pelo Método de Penman-Monteith - FAO/56

Com o propósito de padronizar o cálculo dos diferentes elementos climáticos, utilizou-se os algoritmos apresentados por Allen et al. (1998), tomando por base o fato da mesma ter sido testada, com resultados satisfatórios, sob várias condições climáticas, assumindo para alguns elementos valores fixos, a partir de sua validade global.

Para o cálculo da evapotranspiração de referência pela equação de PenmanMonteith-FAO/56, de acordo com a equação (3), segue o seguinte roteiro:

\subsection{Dados de entrada:}

Temperatura máxima (Tmáx, $\left.{ }^{\circ} \mathrm{C}\right)$;

Temperatura mínima $\left(\mathrm{Tmín}^{\circ}{ }^{\circ} \mathrm{C}\right)$;

Radiação solar global (Rs, MJ.m $\left.{ }^{-2} \cdot \mathrm{d}^{-1}\right)$;

Velocidade média do vento $\left(\mathrm{U}_{2}, \mathrm{~m} . \mathrm{s}^{-1}\right)$;

Umidade relativa máxima do ar (URmáx, \%).

Umidade relativa mínima do ar (URmín, \%).

Outros: altitude, latitude, dia Juliano, pressão atmosférica 


\subsection{Parâmetros e Variáveis}

a) 0,408 é o inverso do calor latente de evaporação a $20^{\circ} \mathrm{C}\left(\mathrm{kg} \cdot \mathrm{MJ}^{-1}\right)$;

b) $\Delta$ é a declividade da curva de pressão de saturação de vapor $\left(\mathrm{kPa}^{\circ} \mathrm{C}^{-1}\right)$ obtido a partir da equação:

$$
\Delta=\frac{4098 \cdot e_{s}}{(T+237,3)^{2}}
$$

em que: T é temperatura média do ar $\left({ }^{\circ} \mathrm{C}\right)$, dada pela média aritmética entre Tmáx e Tmín; e é a pressão de saturação vapor $(\mathrm{kPa})$;

A pressão de saturação vapor é calculada de acordo com o Boletim da FAO 56 (Allen et al., 1998), pela equação que segue:

$$
e_{s}=\left[\frac{e^{0}(\text { Tmáx })+e^{0}(\text { Tmín })}{2}\right]
$$

em que: $e^{\mathrm{o}}($ Tmáx) é a pressão de saturação de vapor à temperatura máxima $(\mathrm{kPa})$ e $\mathrm{e}^{\mathrm{o}}($ Tmín) é a pressão de saturação de vapor à temperatura mínima $(\mathrm{kPa})$ e são expressas pela equações:

$$
\begin{aligned}
& e^{0}(\text { Tmáx })=0,6108 \cdot \exp \left[\frac{17,27 \cdot T \text { Tmáx }}{\text { Tmáx }+237,3}\right] \\
& e^{0}(\text { Tmín })=0,6108 \cdot \exp \left[\frac{17,27 \cdot \text { Tmín }}{\text { Tmín }+237,3}\right]
\end{aligned}
$$


c) Saldo de radiação $(\mathrm{Rn})$

$$
\mathrm{Rn}=\mathrm{Rns}-\mathrm{Rnl}
$$

em que: Rns é o saldo de radiação de ondas curta e Rnl o saldo de radiação de ondas longas.

O saldo de radiação de ondas curtas é dado por:

$$
\operatorname{Rns}=(1-\alpha) \cdot \operatorname{Rs}
$$

em que $\alpha$ é o albedo ou coeficiente de reflexão, cujo valor recomendado para a cultura padrão é de 0,23 , e Rs é a radiação solar global $\left(\mathrm{MJ} \cdot \mathrm{m}^{-2} \cdot \mathrm{d}^{-1}\right)$.

O saldo de radiação de ondas longas é dado por:

$$
R n l=\sigma\left[\frac{\text { Tmáx }, k^{4}+\operatorname{Tmin}, k^{4}}{2}\right] \cdot\left(0,34-0,14 \sqrt{e_{a}}\right) \cdot\left(1,35 \frac{R s}{R s o}-0,35\right)
$$

em que $\sigma$ é a constante de Stefan-Boltzman $=4,903 \times 10^{-9}\left(\mathrm{MJ} \mathrm{K}^{-4} \cdot \mathrm{m}^{-2} \cdot \mathrm{d}^{-1}\right) ; \mathrm{e}_{\mathrm{a}}$ é a pressão parcial de vapor $(\mathrm{kPa})$; Rso é a radiação solar em dias de céu claro $\left(\mathrm{MJ} \cdot \mathrm{m}^{-2} \cdot \mathrm{d}^{-1}\right)$.

d) Radiação solar em dias de céu claro (Rso)

$$
\text { Rso }=\left(a_{\mathrm{s}}+b_{\mathrm{s}}\right) \operatorname{Ra}
$$

sendo $a_{s}$ e $b_{s}$ a fração da radiação extraterrestre em dias claros $(n=N)$.

Quando não se dispõe dos coeficientes acima, toma-se o valor de $a_{\mathrm{s}}+\mathrm{b}_{\mathrm{s}}=0,75$ $+2 \times 10^{-5} . z$, sendo $z$ é a altitude local. 
A equação (11), em dias com nuvens, toma o formato de:

$$
\mathrm{Rs}=\left(\mathrm{a}_{\mathrm{s}}+\mathrm{b}_{\mathrm{s}} \cdot \mathrm{n} / \mathrm{N}\right) \mathrm{Ra}
$$

em que: Ra é a radiação solar no topo da atmosfera $\left(M J \cdot m^{-2} \cdot d^{-1}\right)$, dada por:

$$
R a=\frac{24 .(60)}{\pi} G_{s c} d_{r}\left[W_{s} \operatorname{sen}(\varphi) \operatorname{sen}(\delta)+\cos (\varphi) \cos (\delta) \operatorname{sen}\left(W_{s}\right)\right]
$$

em que: Gsc é constante solar $=0,0820 \mathrm{MJ} \cdot \mathrm{m}^{-2} \cdot \mathrm{d}^{-1} ; d r$ é o quadrado da distância relativa (sol-terra) em radianos, cuja equação é:

$$
d_{r}=1+0,033 \cdot \cos \left(\frac{2 \pi}{365} J\right)
$$

sendo: J o dia juliano; $\varphi$ a latitude local em radiano; $\delta$ a declinação solar, em radiano, e Ws o ângulo horário ao pôr do sol, em radianos.

A seguir são apresentadas as equações para os cálculos de declinação solar $(\delta)$ e ângulo horário ao por do sol (Ws):

$$
\begin{aligned}
& \delta=0,409 \cdot \operatorname{sen}\left(\frac{2 \pi}{365} J-1,39\right)(\text { radianos }) \\
& W_{s}=\arccos [-\operatorname{tg}(\varphi) \cdot \operatorname{tg}(\delta)](\text { radianos })
\end{aligned}
$$

e) Fluxo de Calor do Solo

$$
G=c_{s}\left(\frac{T_{i}+T_{i-1}}{\Delta t}\right) \cdot \Delta z
$$


em que: G é o fluxo de calor do solo $\left(\mathrm{MJ}_{\mathrm{m}} \mathrm{m}^{-2} \cdot \mathrm{d}^{-1}\right) ; \mathrm{c}_{\mathrm{s}}$ a capacidade calorífica do solo $\left(\mathrm{MJ} . \mathrm{m}^{-2} \cdot \mathrm{d}^{-1}\right)$; Ti a temperatura do ar no dia i $\left({ }^{\circ} \mathrm{C}\right)$; $\mathrm{T}_{\mathrm{i}-1}$ a temperatura do ar no dia $\mathrm{i}-1\left({ }^{\circ} \mathrm{C}\right)$; $\Delta$ t o intervalo de tempo (dia) e $\Delta z$ a profundidade efetiva do solo (m).

O boletim da FAO 56 (Allen et al., 1998) recomenda que para períodos diários, G pode ser desprezível, o que foi adotado neste trabalho.

f) Constante Psicrométrica $\left(\mathrm{kPa}^{\circ} \mathrm{C}^{-1}\right)$

$$
\gamma=\frac{c_{p} \cdot P}{\varepsilon \cdot \lambda}
$$

em que: $\gamma$ é a constante psicrométrica, de acordo com Brunt (1952) citado por Smith

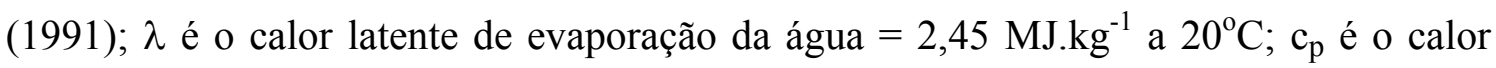
específico a pressão constante $=1,013 \cdot 10^{-3}\left(\mathrm{MJ} \mathrm{kg}^{-1} \cdot{ }^{\circ} \mathrm{C}^{-1}\right)$; e P é a pressão atmosférica (kPa), conforme Burman (1987) citado por Smith (1991) cuja equação é dada por:

$$
P=101,3\left(\frac{293-0,0065 . z}{293}\right)^{5,26}
$$

sendo: $\mathrm{z}$ a altitude local $(\mathrm{m}) ; \varepsilon=0,622$ a relação entre peso molecular do vapor da água e do ar seco.

g) Temperatura média do ar medida a $2 \mathrm{~m}$ de altura (Tméd)

$$
\text { Tméd }=\frac{(\text { Tmáx }+ \text { Tmín })}{2}
$$

h) $\mathrm{U}_{2}$ - velocidade média do vento a $2 \mathrm{~m}\left(\mathrm{~m} \cdot \mathrm{s}^{-1}\right)$ 
i) Déficit de pressão de vapor DPV em $\mathrm{kPa}$, é expresso pela equação:

$$
\mathrm{DPV}=\mathrm{e}_{\mathrm{s}}-\mathrm{e}_{\mathrm{a}}
$$

A pressão parcial de vapor $\left(\mathrm{e}_{\mathrm{a}}\right)$, de acordo com o Boletim da FAO 56 (Allen et al., 1998), deve ser calculado a partir da URmáx e URmín, caso os dados estejam disponíveis, conforme a equação que segue:

$$
e_{a}=\frac{\left[e^{o}(\text { Tmín }) \cdot \frac{U R m a ́ x}{100}\right]+\left[e^{o}(\text { Tmáx }) \cdot \frac{U R m i ́ n}{100}\right]}{2}
$$

em que: $e^{o}($ Tmín) é a pressão de saturação de vapor para temperatura mínima $(\mathrm{kPa})$ eq (7); $\mathrm{e}^{\mathrm{o}}($ Tmáx) é a pressão de saturação vapor para temperatura máxima ( $\mathrm{kPa})$ eq (6); URmáx é a umidade relativa máxima do ar (\%); URmín é a umidade relativa mínima do $\operatorname{ar}(\%)$.

A relação $\left(1+0,34 U_{2}\right)$ na equação (2) envolve as resistências da cobertura $\left(r_{c}\right)$ e aerodinâmica $\left(\mathrm{r}_{\mathrm{a}}\right)$, sendo $r_{c}=70 \mathrm{sm}^{-1}$ e $r_{a}$ calculada pela equação:

$$
r_{a}=\frac{\ln \left[\frac{\left(z_{w}-d\right)}{z_{o m}}\right] \ln \left[\frac{\left(z_{p}-d\right)}{z_{o v}}\right]}{(0,41)^{2} U_{z}}
$$

em que: $r_{a}$ é a resistência aerodinâmica à transferência turbulenta de vapor e calor sensível a partir de superfície da planta; $\mathrm{z}_{\mathrm{w}}$ a altura de medição da velocidade do vento (anemômetro); $z_{p}$ a altura de medição de temperatura e umidade (psicrômetro); $z_{o m} a$ altura da rugosidade da vegetação (cultura de referência, em m); $\mathrm{z}_{\mathrm{ov}}$ a altura da rugosidade para transferência de vapor; $d$ o deslocamento do plano zero na altura 
da vegetação $(\mathrm{m}) ; \mathrm{k}_{1}$ a constante de von Karman $=8,64 \times 10^{4}$ (quando $\mathrm{U}_{\mathrm{z}}$ estiver em $\mathrm{ms}^{-1}$ ) e $\mathrm{U}_{\mathrm{z}}$ é a velocidade do vento medida a $2 \mathrm{~m}$.

3.6.2 Avaliação de equações de estimativas da ETo

Uma outra análise foi realizada, visando identificar uma equação que se ajustasse melhor a de Penman-Monteith-FAO, na ausência de dados climáticos completos e que fosse mais simples de se aplicar. Para essa análise selecionou-se os métodos de Thornthwaite (1948), Thornthwaite modificado por Camargo et al. (1999), Tanque de Evaporação Classe A, Hargreaves \& Samani (1985) e Priestley e Taylor (1972).

\subsubsection{Equação de Thornthwaite, 1948 (EToTh)}

A equação de Thornthwaite (1948), estima a evapotranspiração de referência (ETo), de acordo com a equação:

$$
E T o T h=\frac{E T p}{30} \cdot \frac{N}{12}
$$

em que: EToTh é a evapotranspiração de referência $\left(m m \cdot d^{-1}\right)$; ETp é a evapotranspiração padronizada para um mês de 30 dias; Tm é a temperatura média diária, em ${ }^{\circ} \mathrm{C}$; I e $a$ são índices de calor obtidos a partir de dados normais da região; e $\mathrm{N}$ é o fotoperíodo (horas). O índice $a$ é calculado pela equação:

$$
\mathrm{a}=6,75 \cdot 10^{-7} \cdot \mathrm{I}^{3}-7,71 \cdot 10^{-5} \cdot \mathrm{I}^{2}+1,79 \cdot 10^{-2} \cdot \mathrm{I}+0,49239
$$

em que o índice de calor da região I é dado pela equação:

$$
I=\sum_{1}^{12}(0,2 T i)^{1,514}
$$


Para o cálculo de ETp, utiliza-se as seguintes expressões:

$$
\begin{gathered}
E T p=16 .\left(10 . \frac{T m}{I}\right)^{a} \quad\left(0<\mathrm{Tm}<26,5^{\circ} \mathrm{C}\right) \\
E T p=-415,85+32,24 . T m-0,43 . T m^{2} \quad\left(\mathrm{Tm} \geq 26,5^{\circ} \mathrm{C}\right)
\end{gathered}
$$

\section{6.2.2 Equação de Thornthwaite modificada}

Camargo et al. (1999) substituiu a temperatura média do método original de Thornthwaite (1948), pela temperatura efetiva (Tef), baseada na amplitude térmica, resultando na seguinte equação:

$$
\text { EToThc }=16\left(10 \frac{\text { Tef }}{I}\right)^{a} \cdot \frac{N}{12} \cdot \frac{1}{30}
$$

sendo Tef calculada pela seguinte equação (Camargo et al., 1999):

$$
\text { Tef = 0,36.(3Tmáx - Tmín) }
$$

\subsubsection{Equação de Hargreaves \& Samani (1985)}

Segundo Jensen et al. (1990), melhoramentos na equação de Hargreaves (1975) foram propostos por Hargreaves \& Samani (1985) resultando na expressão:

$$
\text { EToHg }=0,0023 R a .(T m a ́ x-\text { Tmín })^{1 / 2}(\text { Tm }+17,8)
$$

em que: Ra é a radiação solar no topo da atmosfera $\left(\mathrm{mm}^{-1}\right)$, calculada pela equação (13) e expressa em mm de evaporação equivalente, podendo também ser 
obtida por uso de tabelas; Tm é a temperatura média do ar $\left({ }^{\circ} \mathrm{C}\right)$; Tmáx é a temperatura máxima do $\operatorname{ar}\left({ }^{\circ} \mathrm{C}\right)$ e Tmín é a temperatura mínima do ar $\left({ }^{\circ} \mathrm{C}\right)$.

O referido método também é recomendado pela FAO (Allen et al., 1998) quando há somente disponibilidade de dados de temperatura do ar no local de estudo.

\subsubsection{Equação do Tanque de Evaporação-FAO}

A evaporação medida em tanque de evaporação implica no efeito integrado de radiação solar, vento, temperatura e umidade na superfície de água. O evaporação está relaciona à ETo, segundo Doorenbos \& Pruitt (1977), Jensen et al. (1990) e Allen et al. (1998), entre outros, da seguinte forma:

$$
\text { EToFPan }=\text { Kp.Epan }
$$

em que: EToFPan é a evapotranspiração de referência $\left(\mathrm{mmd}^{-1}\right)$; Kp é o coeficiente do tanque; Epan é a evaporação do tanque classe $\mathrm{A}\left(\mathrm{mmd}^{-1}\right)$.

O coeficiente do tanque (Kp) apresentado por Allen et al. (1998) com bordadura seca, já que os dados foram obtidos na estação convencional, é o seguinte:

$\mathrm{Kp}=$ 0,61 + 0,00341.URméd - 0,000162.U 2. URméd - 0,00000959. U $2 . \mathrm{FET}+$ 0,00327. $U_{2} \cdot \ln \left(\right.$ FET). $-0.00289 \cdot U_{2} \cdot \ln \left(86,4 \cdot U_{2}\right)-0.0106 \cdot \ln \left(86,4 \cdot U_{2}\right) \cdot \ln (F E T)+0,00063$. $[\ln (\mathrm{FET})]^{2} \cdot \ln \left(86,4 \cdot \mathrm{U}_{2}\right)$

em que: $U_{2}$ é a velocidade do vento medida a $2 \mathrm{~m}$ de altura $\left(\mathrm{ms}^{-1}\right)$; URméd é a umidade relativa média (\%); FET é a bordadura, em m, que compreende o espaço entre o tanque e o final da área de contorno, a favor dos ventos predominantes. 


\subsubsection{Equação de Priestley-Taylor}

A equação de Priestley-Taylor (1972) é uma simplificação da equação de Penman (1948), onde é abordado somente o termo adiabático. Esse termo é multiplicado por um coeficiente $(\alpha)$, que representa em termos percentuais a contribuição média do termo aerodinâmico da equação de Penman. A equação é expressa por:

$$
E T o P T=\frac{\alpha \cdot W \cdot(R n-G)}{\lambda}
$$

em que: EToPT é a evapotranspiração de referência $\left(m m . d^{-1}\right)$; Rn é o saldo de radiação $\left(M J \cdot m^{-2} \cdot d^{-1}\right) ; G$ é fluxo de calor no solo $\left(M J \cdot m^{-2} \cdot d^{-1}\right) ; \lambda$ é o calor latente de evaporação $\left(2,45 \mathrm{MJ} \cdot \mathrm{kg}^{-1}\right) ; \mathrm{W}$ é um fator de ponderação $=\Delta / \Delta+\gamma$, sendo $\Delta$ a declividade da curva de pressão de vapor, dada pela equação (4) e $\gamma$ é o coeficiente psicrométrico, dado pela equação (18).

\subsection{Proposição de equações para estimativa da ETo}

As equações de Thornthwaite modificada por Camargo et al. (1999) e Priestley e Taylor (1972), foram ajustadas de modo a melhorar a precisão e a exatidão das estimativas de ETo em relação ao método de Penman-Monteith-FAO.

Na equação de Thornthwaite modificada por Camargo et al. (1999), foi proposta a alteração do coeficiente $f$ no cálculo da Tef, como segue:

$$
\text { Tef = 0,380.(3Tmáx }- \text { Tmín) }
$$

Nessa equação, a temperatura efetiva (Tef) foi empregada no lugar da Tm das equações (27) e (28).

O valor de $f$ foi obtido por meio de simulações sucessivas, de forma a se obter o melhor ajuste. 
Um outro ajuste foi efetuado na equação de Thornthwaite modificada por Camargo et al. (1999), que resultou num valor de Tef como segue:

$$
\text { Tef }=0,370 .(3 \text { Tmáx }- \text { Tmín })
$$

A equação acima diferencia-se da anterior, pois utilizou-se somente a equação (27) na determinação de ETp, independente do valor da temperatura.

No caso da modificação efetuada no método de Priestley e Taylor, ajustou-se apenas o valor do parâmetro $\alpha$ a partir da relação:

$$
\alpha=\frac{\lambda \cdot E T o_{P M}}{W(R n-G)}
$$

\subsection{Análise dos resultados}

A análise dos resultados foi baseada em análise de regressão, no índice de Willmott (Willmott et al., 1981) e no coeficiente de confiança ou desempenho "c" introduzido por Camargo \& Sentelhas (1997) apresentados na Tabela 1.

Tabela 1. Valores dos coeficientes de desempenho conforme Camargo \& Sentelhas (1997).

\begin{tabular}{cc}
\hline Valor de "c" & Desempenho \\
\hline$>0,90$ & Ótimo \\
0,81 a 0,90 & Muito Bom \\
0,71 a 0,80 & Bom \\
0,51 a 0,70 & Mediano \\
0,41 a 0,50 & Sofrível \\
0,31 a 0,40 & Mau \\
$\leq 0,30$ & Péssimo \\
\hline
\end{tabular}


A correlação entre valores medidos e estimados é feita com base em indicadores estatísticos, de precisão, dado pelo coeficiente de correlação (r), indicando o grau de dispersão dos dados obtidos em relação à média, de exatidão (d), que está associada ao desvio entre valores estimados e medidos, dado pelo índice de Willmott e o coeficiente de desempenho (c) que é o produto de $r$ e $d\left(\mathrm{c}=\mathrm{r}^{*} \mathrm{~d}\right)$ (Camargo e Sentelhas., 1997).

A seguir é apresentada a equação do índice de concordância de Willmott:

$$
d=1-\frac{\sum_{i}^{n}(P i-O i)^{2}}{\sum_{i}^{n}(|P i-O|+|O i-O|)^{2}}
$$

$\mathrm{O}$ índice de concordância $\mathrm{d}$, varia de 0 a 1 , em que o valor 1 significa uma concordância perfeita entre dados observados e estimados, enquanto que o valor 0 , significa não haver concordância entre os valores analisados.

Também se utilizou para quantificação dos erros proporcionados pelas estimativas, o erro médio absoluto (EMA), o erro máximo (EM), o erro aleatório (Ea) e o erro sistemático (Es), que são apresentados a seguir:

$$
\begin{aligned}
& E M A=\frac{1}{N} \sum_{i}^{n}(O i-P i) \\
& E M=\max (|O i-P i|)_{i}^{n} \\
& E a=\frac{1}{N} \sum_{i}^{n}\left(P i-P^{*}\right)^{2} \\
& E S=\frac{1}{N} \sum_{i}^{n}\left(P^{*}-O i\right)^{2}
\end{aligned}
$$


em que: Oi representa os valores de ETo estimados pelo método de PMon; Pi são os valores de ETo estimados pelo lisímetro e pelos métodos de Thornthwaite, Thornthwaite modificado, Hargreaves \& Samani, Tanque de evaporação Classe A, Priestley-Taylor e os métodos de Thornthwaite e Priestley-Taylor corrigidos, N é o número de estimativas. $\mathrm{O}$ valor médio de ETo-PMon $(\mathrm{O})$ é dado pela equação:

$$
O=\frac{1}{N} \sum_{i}^{n} O i
$$

No caso de Ea e Es, o valor de P* é dado por:

$$
P^{*}=a+b . O i
$$

em que: a e b são estimados pelo método dos mínimos quadrados. 


\section{RESULTADOS E DISCUSSÃO}

A análise da evapotranspiração de referência (ETo), foi realizada com o propósito de se avaliar os dados do lisímetro de pesagem em relação aos valores obtidos com a equação de Penman-Monteith-FAO. Além desse aspecto, procurou-se identificar uma equação que se ajustasse melhor ao modelo de Penman-Monteith-FAO e que fosse de utilização mais simples, com é o caso das equações que dependem somente de temperatura do ar, evaporação ou insolação, considerando-se que existem diversas áreas litorâneas no Estado do Ceará, cujas condições climáticas se assemelham às do município de Paraipaba, CE, em que são exploradas várias culturas irrigadas, sem o conhecimento preciso da evapotranspiração da cultura (ETc).

Finalmente, com base nos resultados obtidos pelas equações de Thornthwaite simplificada por Camargo et al. (1999) e Priestley \& Taylor (1972), propôs-se um ajuste, visando a melhoria da precisão e, principalmente, da exatidão desses métodos em relação à equação de Penman-Monteith-FAO, para a condição deste estudo.

Para tanto, foram utilizadas: a análise de regressão, os índices de correlação (r), de concordância (d) e de confiança (c), além dos erros das estimativas: erro máximo (EM), erro médio absoluto (EMA), erro sistemático (Es) e erro aleatório (Ea).

\subsection{Análise das Condições Climáticas}

Os processos que governam a passagem de água do estado líquido para o de vapor, semelhante à perda de água numa planta, são diretamente influenciados por fatores inerentes à planta e aos elementos climáticos. 
Dentre os elementos climáticos que estão mais relacionados à evapotranspiração, pode-se enumerar a radiação solar, responsável pelo aporte de energia necessária para que o processo físico ocorra, a temperatura e a umidade do ar, que juntas definem o déficit de pressão de vapor próximo à superfície evaporante, e a velocidade do vento, responsável pela renovação do ar junto à superfície em questão. Esses elementos são essenciais à aplicação da equação de Penman-Momnteith-FAO e serão aqui discutidos, de modo a caracterizar o local de estudo.

Com relação à região de Paraipaba, $\mathrm{CE}$, situada próxima à linha do equador (Latitude: $3^{\circ} 17^{\prime} S$ ) e ao litoral, observa-se uma variação pouco expressiva da temperatura do ar no decorrer do ano. Desse modo, a determinação das estações climáticas se deve apenas à distribuição das chuvas, sendo uma úmida e outra seca. A radiação solar global também oscila muito pouco no decorrer do ano, devido à proximidade do equador terrestre. As chuvas podem ocorrer antes do mês de março, porém, é a partir desse mês que a estação chuvosa se estabelece. A estação chuvosa pode perdurar até o mês de junho, sendo, no entanto, o período mais úmido o que vai de março a maio. A partir de julho até fevereiro do ano posterior ocorrem precipitações pouco significativas, caracterizando a estação seca.

Observando-se os dados meteorológicos no Anexo 1, referente aos meses de março a junho dos anos de 1997 e 1998, período de coleta e análise dos dados, verificase que a umidade relativa máxima do ar, normalmente, supera os $90 \%$, sendo freqüentes valores iguais a 100\%. Já a umidade relativa mínima varia bastante, entre $40 \%$ e $77 \%$, no período mais quente do dia, no qual ocorrem as taxas mais elevadas de evapotranspiração de referência.

A temperatura média predominante durante o período analisado foi da ordem de $27^{\circ} \mathrm{C}$, caracterizando, portanto, um ambiente de calor excessivo, com contribuição significativa para o processo de evapotranspiração.

Com relação à radiação solar global, ocorreram variações entre 11,80 e 26,38 $\mathrm{MJm}^{-2} \mathrm{~d}^{-1}$, sendo os valores mais baixos correspondentes aos meses de abril e maio, durante a estação das chuvas. 
A Figura 2 apresenta a variação dos valores médios mensais de temperatura máxima e mínima e radiação solar global, durante os anos de 1997 e 1998. Pode-se observar que no período analisado, entre março e junho, as temperaturas máxima e mínima, variam muito pouco enquanto que para a radiação solar, observa-se uma redução nos valores médios durante a época chuvosa que vai de março a junho.

Paraipaba está localizada em uma região litorânea de clima semi-árido, com precipitações observadas no período em estudo, de 830,7mm no ano de 1997 e $784 \mathrm{~mm}$ no ano de 1998. A distribuição dessas chuvas no ano de 1997 foi de 534mm entre março e junho e de 184,3mm nos demais meses e no ano de 1998 foi de $503 \mathrm{~mm}$ entre março e junho e no restante do ano $281 \mathrm{~mm}$. Apesar dessa concentração das chuvas nesses quatro meses, observa-se pelo balanço hídrico climatológico (Figura 3), que praticamente não ocorre excedente hídrico ao longo do ano, enquanto que as deficiências hídricas predominam, atingindo valores entre 900 e mais de $1000 \mathrm{~mm}$ por ano.

Na Figura 4 são apresentadas as variações de umidade relativa média do ar e da velocidade média do vento, no ano de 1997. Observa-se uma variação inversa em relação os elementos meteorológicos, o que, no entanto, não denota a influência de um sobre o outro. Nota-se que o período de maior umidade relativa média do ar é justamente durante a estação chuvosa, período em que ocorrem as menores velocidades médias do vento. A mesma variação sazonal desses elementos foi observada em 1998 (Figura 5).

\subsection{Avaliação do lisímetro de pesagem na estimativa de ETo}

Com os dados de evapotranspiração de referência (ETolys) obtidos pelo lisímetro, efetuou-se a comparação com a EToPM determinada pelo método de PenmanMonteith preconizado pela FAO (Allen et al., 1998), a partir dos dados medidos em estação meteorológica automatizada. Na Figura 6 observam-se os resultados da análise de regressão, para os dados nas escalas diária, qüinqüidial e decendial.

A Tabela 2 apresenta os valores dos índices estatísticos e dos erros associados às medidas efetuadas pelo lisímetro, em relação às estimativas obtidas pelo método de Penman-Monteith, com base em dados diários, qüinqüidial e decendial. 

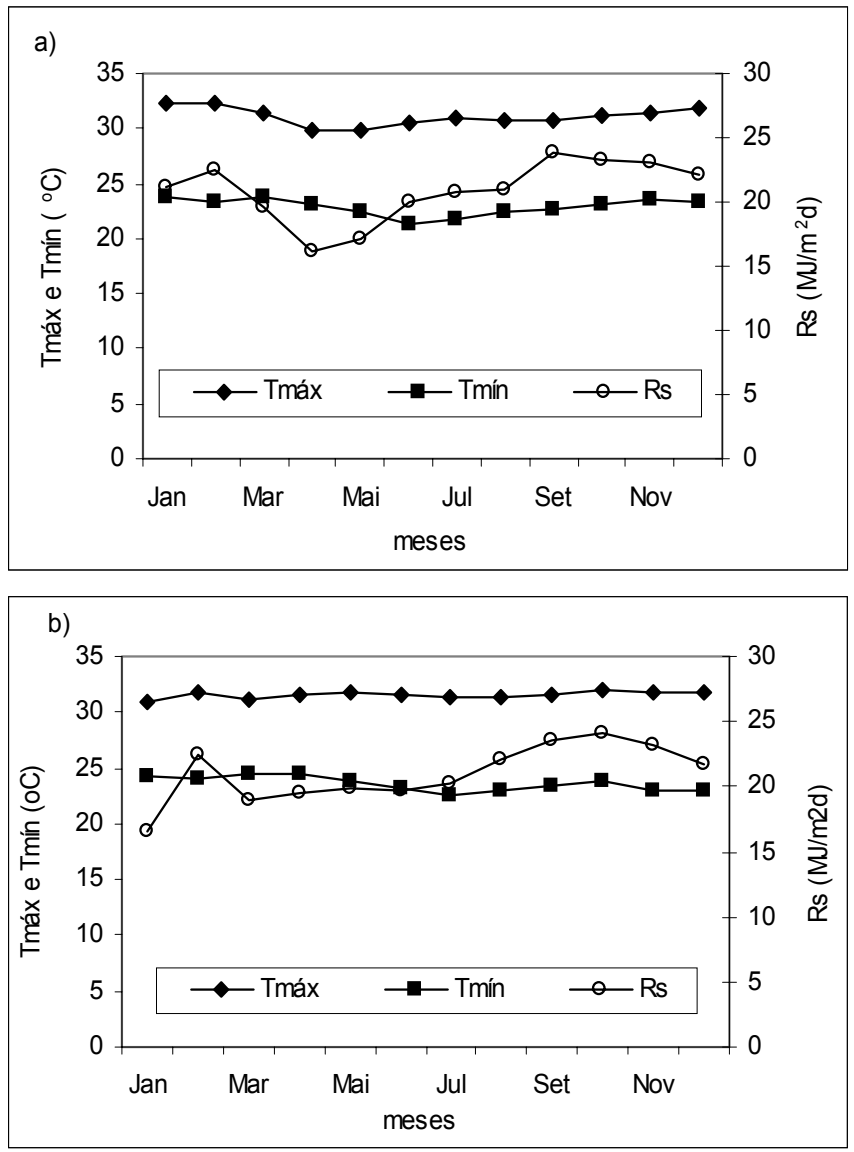

Figura 2 - Dados médios mensais de temperatura máxima e mínima do ar e de radiação solar global, nos anos de 1997 (a) e de 1998 (b), em Paraipaba, CE.

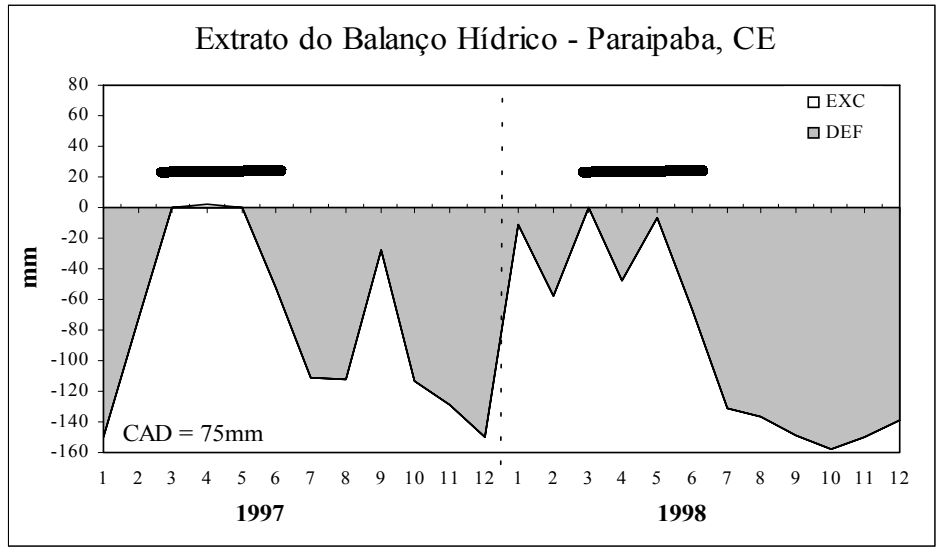

Figura 3 - Extrato do balanço hídrico climatológico mensal, segundo Thornthwaite \& Mather (1955), durante os anos de 1997 e 1998 em Paraipaba, CE. As barras horizontais indicam os períodos analisados. 


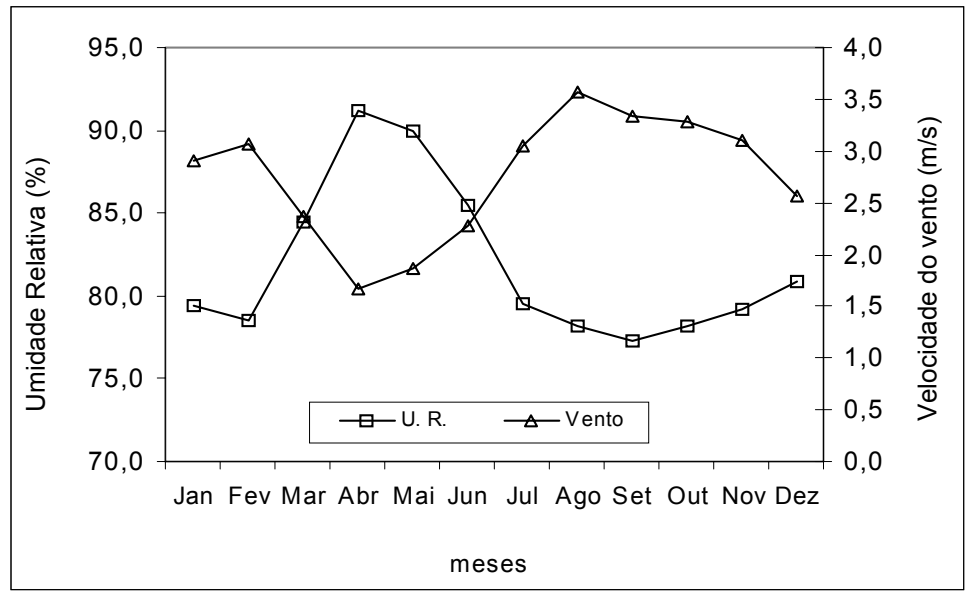

Figura 4 - Variação mensal da umidade relativa do ar e da velocidade do vento, no ano de 1997, em Paraipaba, CE.

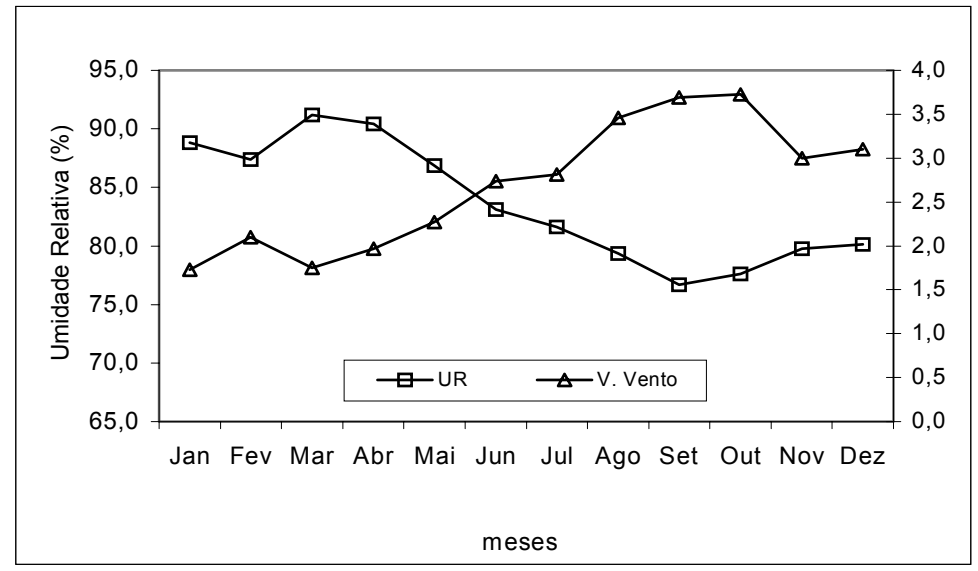

Figura 5 - Variação mensal da umidade relativa do ar e da velocidade do vento, no ano de 1998, em Paraipaba, CE.

Observa-se que o lisímetro, na escala diária (Figura 6a), produziu resultados com precisão $(r=0,74)$ e exatidão $(d=0,84)$ razoáveis, o que lhe conferiu, de acordo com o índice $c$ proposto por Camargo e Sentelhas (1997), um desempenho mediano. Com relação aos erros (Tabela 2), observa-se que o EMA foi de $0,481 \mathrm{mmd}^{-1}$, enquanto que o EM atingiu 1,725 $\mathrm{mmd}^{-1}$. Já Es foi de apenas $0,045 \mathrm{mmd}^{-1}$, ao passo que Ea foi de $0,504 \mathrm{mmd}^{-1}$, o que indica que os erros cometidos pelo equipamento na estimativa de ETo são, predominantemente, aleatórios. 
Tabela 2. Coeficiente de correlação (r), índice de concordância (d) e de desempenho (c) e erros médio absoluto (EMA), máximo (EM), sistemático (Es) e aleatório (Ea), entre a ETo medida no lisímetro e estimada pelo método de PenmanMonteith, nas escalas diária, qüinqüidial e decendial, em Paraipaba, CE.

\begin{tabular}{lccccccc}
\hline Escala de tempo & $\mathrm{r}$ & $\mathrm{d}$ & $\mathrm{c}$ & $\begin{array}{c}\text { EMA } \\
\left(\mathrm{mmd}^{-1}\right)\end{array}$ & $\begin{array}{c}\mathrm{EM} \\
\left(\mathrm{mmd}^{-1}\right)\end{array}$ & $\begin{array}{c}\text { Es } \\
\left(\mathrm{mmd}^{-1}\right)\end{array}$ & $\begin{array}{c}\mathrm{Ea} \\
\left(\mathrm{mmd}^{-1}\right)\end{array}$ \\
\hline Diária & 0,74 & 0,84 & 0,62 & 0,481 & 1,725 & 0,045 & 0,504 \\
Qüinqüidial & 0,63 & 0,74 & 0,47 & 0,421 & 1,127 & 0,053 & 0,216 \\
Decendial & 0,49 & 0,76 & 0,37 & 0,427 & 1,008 & 0,058 & 0,198 \\
\hline
\end{tabular}

Quando se comparam dados medidos de ETo em lisímetro de pesagem e dados calculados de ETo, pela equação de Penman-Monteith-FAO, espera-se que os resultados estejam bem correlacionados, o que não ocorreu neste caso. Segundo Allen et al. (1991), isso, possivelmente, se deva ao fato do dispositivo lisimétrico não estar operando satisfatoriamente.

Diversos são os trabalhos que mostram uma boa correlação entre dados de lisímetro e dados estimados pela equação de Penamn-Monteith-FAO. A exemplo podemos citar Allen (1986), Allen et al. (1989), Jensen et al. (1990), Allen et al. (1994a), Maggiotto (1996), Ribeiro (1996), Camargo e Sentelhas (1997), Sentelhas (1998), Pereira (1998), Hussein (1999), entre outros, sendo, no entanto, normal a ocorrência de alguma dispersão, em razão dos problemas relacionados à montagem e operação do lisímetro.

Uma das causa dessa dispersão pode estar relacionada à utilização da grama gengibre como cultura de referência, escolhida para implantação por se tratar de uma cultura bem adaptada às condições locais. Essa vegetação difere das gramas normalmente utilizadas na calibração de equações combinadas, citadas como gramas adaptadas para períodos frios.

Outras fontes de erro da medida lisimétrica podem se dar em razão da temperatura de operação da célula de carga (Silva et al., 1999), do efeito de pressão do vento sobre a superfície do lisímetro (Bergamaschi et al., 1997) e da alteração nas 
condições do solo (macroporosidade) em relação à área externa (Grebet \& Cuenca, 1991).

De acordo com Howell et al. (1991), outros fatores podem afetar a evapotranspiração do lisímetro. Como exemplo, pode-se citar a transferência de calor pelas paredes do lisímetro, o fluxo preferencial de água nas paredes da caixa interna, o tráfego de pessoas nas proximidades, os tratos culturais e a altura da cultura, sendo um outro problema, a calibração do zero na escala de medida da célula de carga.

Analisando-se os dados diários de ETo (Anexo 2), observa-se, na escala diária, que a EToPM média foi de 4,6mmd ${ }^{-1}$, enquanto que a ETolys foi de $4,4 \mathrm{mmd}^{-1}$, o que representa uma subestimativa de cerca de $4,34 \%$, muito semelhante ao desvio médio obtido pela análise de regressão (Figura 6a).

$\mathrm{Na}$ Figura 6b, nota-se o desempenho do lisímetro em relação às estimativas de ETo pelo método de Penman-Monteith-FAO, na escala qüinqüidial. Observa-se que valores dos coeficientes $\mathrm{r}$ e $\mathrm{d}$ foram reduzidos, a 0,63 e 0,74 , respectivamente, resultando em um valor de $\mathrm{c}=0,47$, o que representa um desempenho sofrível, fato que chama a atenção em razão de haver normalmente uma melhoria nos índices estatísticos quando se aumenta a escala de tempo (Allen et al., 1989).

Os dados médios foram calculados conforme a recomendação em Allen et al. (1998), em que os dados de Tmáx, Tmín, URmáx e URmín, são somados e divididos pelo número de dias do período. Foi observado que quando se usa procedimento de cálculo de pressão de vapor $\left(\mathrm{e}_{\mathrm{a}}=\mathrm{URméd}^{*} \mathrm{e}_{\mathrm{s}} / 100\right)$, em que $\mathrm{e}_{\mathrm{s}}$ é calculada com base na equação de Tétens, com temperatura média, (no caso média de 5 dias), o desempenho melhora significativamente. $\mathrm{O}$ índice de correlação observado nessa última situação é de $\mathrm{r}=0,997$. Provavelmente, com relação às condições locais, realmente ocorram problemas na aplicação da equação conforme preconiza a o boletim FAO 56 para dados médios de 5 dias. 

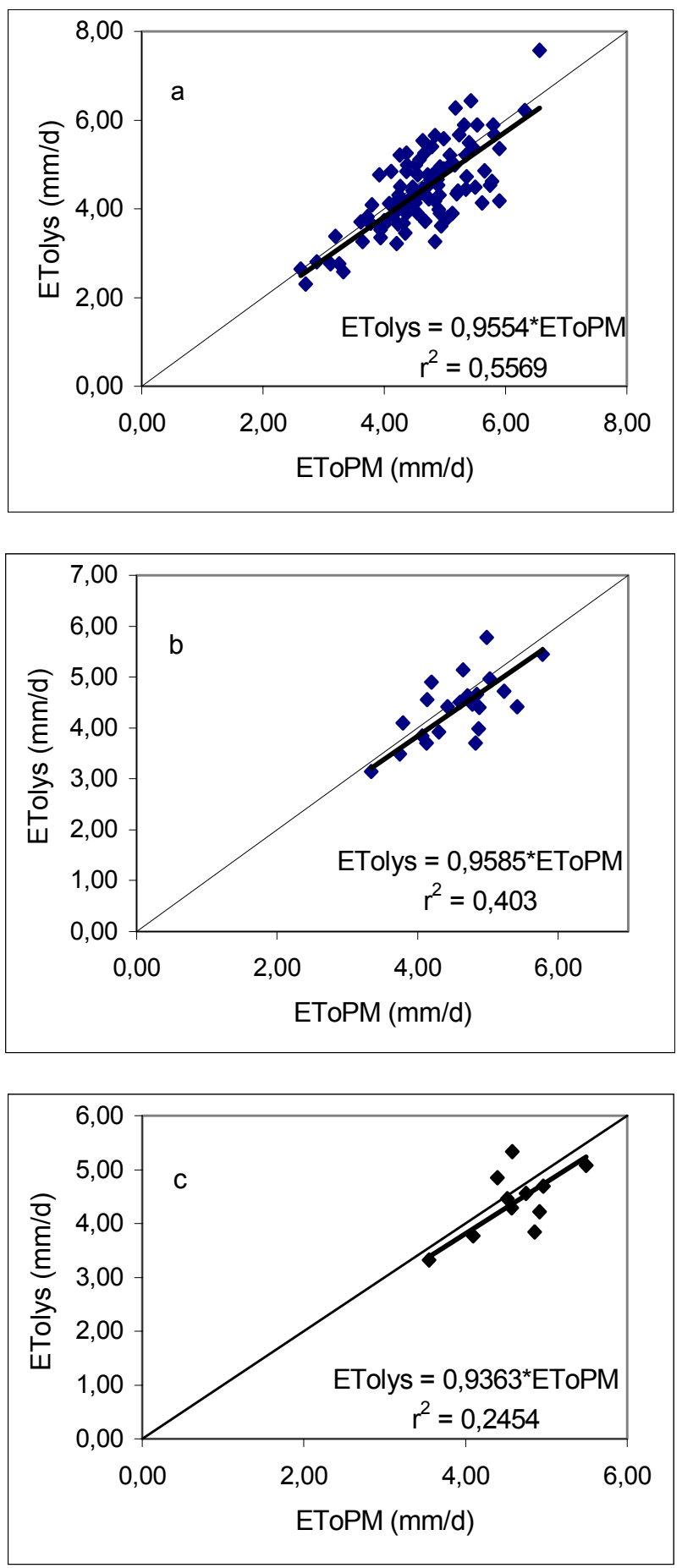

Figura 6 - Relação entre a evapotranspiração de referência estimada pelo método de Penman-Monteith (PM) e a evapotranspiração medida no lisímetro (lys) de pesagem, nas escalas diária (a), qüinqüidial (b) e decendial (c), em Paraipaba, CE, durante a estação chuvosa dos anos de 1997 e 1998. 
Os erros observados no caso de dados na escala qüinqüidial foram: EMA = $0,421 \mathrm{~mm} / \mathrm{d}, \mathrm{EM}=1,127 \mathrm{mmd}^{-1}, \mathrm{Es}=0,053 \mathrm{mmd}^{-1} \mathrm{e} \mathrm{Ea}=0,216 \mathrm{mmd}^{-1}$. Apesar da redução na precisão e na exatidão das estimativas, houve também uma redução nos erros, exceção para Es, com a mudança na escala tempo de diária para qüinqüidial, principalmente com relação ao Ea.

Analisando-se os dados de cada período (Anexo 2), observa-se uma diferença média entre EToPM e ETolys de $0,17 \mathrm{mmd}^{-1}$, representado uma subestimativa 3,81\%. Nesse caso (média de 5 dias), houve uma predominância de subestimativas do lisímetro.

$\mathrm{Na}$ Figura 6c, é apresentada a relação entre os valores de EToPM e de ETolys na escala decendial. Neste caso, houve nova redução de desempenho, com r $=0,49$ e $d=$ 0,76 , obtendo-se um valor de $\mathrm{c}=0,37$, que representa um mau desempenho.

Com relação aos erros, houve uma redução de $\operatorname{EM}\left(1,008 \mathrm{mmd}^{-1}\right)$ e $\mathrm{Ea}$ $\left(0,198 \mathrm{mmd}^{-1}\right)$ à medida que ocorreu aumento na escala de tempo. Os erros EMA $\left(0,427 \mathrm{mmd}^{-1}\right)$ e Es $\left(0,058 \mathrm{mmd}^{-1}\right)$ aumentaram em relação aos dados diários. No caso de dados médios de 10 dias, a diferença entre EToPM e ETolys foi, em média, de $0,21 \mathrm{mmd}^{-1}(4,47 \%)$, com predominância de subestimativas proporcionadas pelo lisímetro.

Os resultados revelam, por um lado, o problema relacionado à representatividade dos dados medidos em lisímetro, que podem estar ligados a uma série de variáveis, mas, por outro lado, a necessidade de verificação da validade dos procedimentos de cálculo de ETo, de acordo com o método de Penman-Monteith. Entretanto, considerando-se que o método de Penman-Monteith-FAO é uma referência internacional e que ele representa uma cultura hipotética a qual permite se obter resultados confiáveis do potencial de evapotranspiração de um local, como vem sendo observado por vários autores, conclui-se que a sua utilização seja válida como parâmetro de comparação envolvendo dispositivos lisimétricos. 
4.3 Avaliação de outros métodos de estimativa de ETo

Uma outra avaliação foi realizada, com o propósito de identificar uma ou mais equações alternativas para a estimativa de evapotranspiração de referência, na escala diária, qüinqüidial e decendial, para os casos em que há pouca disponibilidade de dados meteorológicos, fato muito comum em localidades próximas à região de estudo. Para essa avaliação, selecionou-se as seguintes equações: Thornthwaite (1948), Thornthwaite modificado por Camargo et al. (1999), Hargreaves \& Samani (1985), Tanque de Evaporação Classe A-FAO/56 (Allen et al., 1998) e Priestley-Taylor (1972). As três primeiras equações são baseadas na temperatura, a quarta em dados de evaporação do tanque classe A e a última em dados de saldo de radiação.

\subsubsection{Método de Thornthwaite}

$\mathrm{Na}$ Figura 7 são apresentadas as relações entre a evapotranspiração de referência estimada pelo método de Penman-Monteith (EToPM) e a estimada por Thornthwaite (EToTh).

Na escala diária (Figura 7a), os índices observados foram: $r=0,60, d=0,73$ e c $=0,44$, representando um desempenho sofrível muito próximo de mau, com uma leve tendência de superestimativas, em relação aos dados médios, da ordem de $0,02 \mathrm{mmd}^{-1}$ $(0,41 \%)$. Esse resultado era esperado, uma vez que a equação foi desenvolvida para condições de climas úmidos e por se basear apenas na temperatura média do ar. Resultados semelhantes foram obtidos por Amatya et al. (1992), que verificaram que dentre oito métodos utilizados para estimar a ETo em três localidades da Carolina do Norte (USA), o de Thornthwaite foi o que teve a correlação mais fraca quando comparado à ETo obtida pelo método de Penman-Monteith, porém com subestimativas dessa variável. Esses resultados diferem, dos encontrados por Camargo \& Sentelhas (1997) que obtiveram excelente desempenho do método de Thornthwaite, quando compararam a ETo estimada por esse método aos dados de lisímetro de drenagem nas escalas decendial e mensal. 
Silva (1989) revelou que, ao nível de 1\% de probabilidade, os métodos de Thornthwaite e Hargreaves \& Samani não diferem entre si, entretanto, variam com relação aos métodos combinados.

A Tabela 3 apresenta um resumo dos índices e erros de estimativas de ETo pelo método de Thornthwaite (1948) em relação ao método de Penman-Monteith, nas escalas diária, qüinqüidial e decendial.

Os erros observados em relação à análise de estimativa de ETo, na escala diária pelo método de Thornthwaite (1948) em relação ao de Penman-Monteith foram: EMA = $0,469 \mathrm{mmd}^{-1}, \mathrm{EM}=1,629 \mathrm{mmd}^{-1}, \mathrm{Es}=0,223 \mathrm{mmd}^{-1}$ e Ea $=0,242 \mathrm{mmd}^{-1}$.

A análise dos dados revela ter havido superestimativas e subestimativas, com um predomínio da primeira situação (Figura 7a). Doorenbos \& Pruittt (1977), comparando dados estimados pela equação de Thornthwaite, em Davis, CA, com dados medidos em lisímetro de $30 \mathrm{~m}^{2}$ de área, encontraram subestimativa do método.

Stanhill (1962) analisando dados climáticos de Israel, verificou que o método de Thornthwaite, subestima consideravelmente a ETo, dada a condição de aridez local, associada ao fato da equação não considerar o efeito da advecção.

$\mathrm{Na}$ Tabela 3 e na Figura $7 \mathrm{~b}$ nota-se os valores dos índices e erros cometidos na aplicação do método de estimativa de Thornthwaite, na escala de 5 dias. Os índices foram: $\mathrm{r}=0,32, \mathrm{~d}=0,74 \mathrm{e} \mathrm{c}=0,23$. Houve um aumento na precisão (EToTh $=$ 1,0042*EToPM), porém, uma redução na exatidão, com desempenho considerado péssimo. Contudo, em relação aos dados diários houve um leve aumento do desempenho, levando-se em consideração que nessa análise a reta foi forçada à passagem pela origem o que, normalmente, reduz o coeficiente de correlação.

Com relação aos erros, pode-se notar que todos eles foram bem menores em relação às estimativas na base diária, diferenciando da tendência observada com relação aos índices estatísticos. 

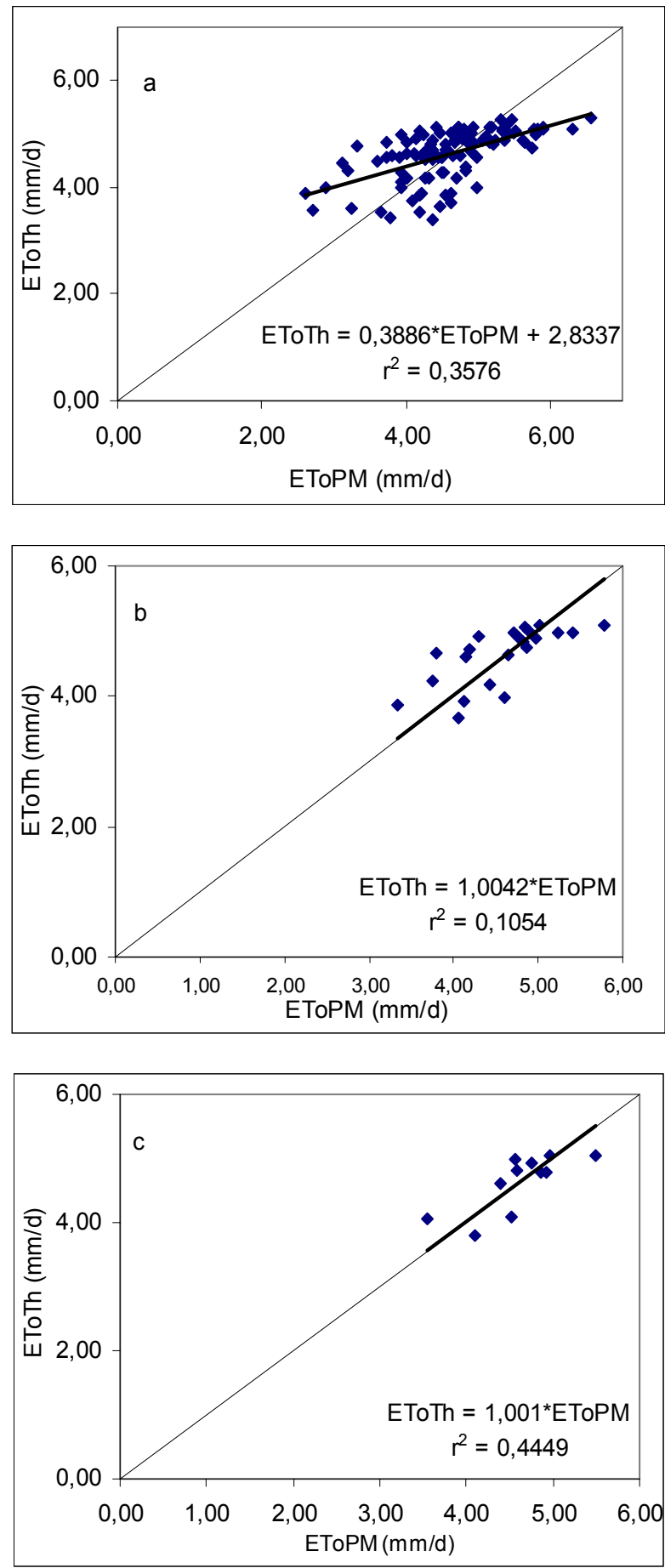

Figura 7 - Relação entre a evapotranspiração de referência estimada pelo método de Penman-Monteith (PM) e pelo método de Thornthwaite (Th), nas escalas diária (a), qüinqüidial (b) e decendial (c), em Paraipaba, CE, durante a estação chuvosa dos anos de 1997 e 1998. 
Tabela 3. Coeficiente de correlação (r), índice de concordância (d) e de desempenho (c) e erros médio absoluto (EMA), máximo (EM), sistemático (Es) e aleatório (Ea), entre a ETo estimada pelos métodos de Thornthwaite e de PenmanMonteith, nas escalas diária, qüinqüidial e decendial, em Paraipaba, CE.

\begin{tabular}{lccccccc}
\hline Escala de tempo & $\mathrm{r}$ & $\mathrm{d}$ & $\mathrm{c}$ & $\begin{array}{c}\text { EMA } \\
\left(\mathrm{mmd}^{-1}\right)\end{array}$ & $\begin{array}{c}\mathrm{EM} \\
\left(\mathrm{mmd}^{-1}\right)\end{array}$ & $\begin{array}{c}\text { Es } \\
\left(\mathrm{mmd}^{-1}\right)\end{array}$ & $\begin{array}{c}\text { Ea } \\
\left(\mathrm{mmd}^{-1}\right)\end{array}$ \\
\hline Diária & 0,60 & 0,73 & 0,44 & 0,469 & 1,629 & 0,223 & 0,242 \\
Qüinqüidial & 0,32 & 0,71 & 0,23 & 0,337 & 0,989 & 0,072 & 0,097 \\
Decendial & 0,67 & 0,86 & 0,58 & 0,276 & 0,925 & 0,025 & 0,074 \\
\hline
\end{tabular}

A diferença entre dados médios de estimativas dos métodos é de $0,05 \mathrm{mmd}^{-1}$ $(1,13 \%)$ representando uma superestimativa em relação à EToPM. Tendência já observada, no caso da análise na base diária.

$\mathrm{Na}$ Figura 7c é apresentada a relação entre as estimativas de ETo por Thornthwaite e Penman-Monteith na escala decendial. Nota-se uma menor dispersão em relação aos casos anteriores (escala diária e qüinqüidial), com $\mathrm{r}=0,67, \mathrm{~d}=0,86$ e c $=$ 0,58. O desempenho observado, nesse caso é mediano. O desempenho melhorou à medida que o período de tempo analisado aumentou, como era esperado já que o método foi desenvolvido para estimativas na escala mensal. Entretanto, nota-se, ainda, tendência de superestimativa do método de Thornthwaite, em relação ao método de PenmanMonteith-FAO, da ordem de 5\%. Esse resultado não está de acordo com Camargo e Sentelhas (1997), que encontraram desempenho considerado bom, quando analisando estimativas ETo com a equação de Thornthwaite, nessa mesma escala de tempo.

De acordo com a Tabela 3, os erros decorrentes da estimativa com base em dados decendiais foram: $\mathrm{EMA}=0,276 \mathrm{mmd}^{-1}, \mathrm{EM}=0,925 \mathrm{mmd}^{-1}, \mathrm{Es}=0,025 \mathrm{mmd}^{-1} \mathrm{e}$ $\mathrm{Ea}=0,074 \mathrm{mmd}^{-1}$. Ocorreram reduções nos erros em relação aos períodos de tempo anteriores. O que sugere que este método se adapta melhor, quanto maior for a escala de tempo utilizada. 


\subsubsection{Método de Thornthwaite Modificado (Camargo et al., 1999)}

Camargo et al. (1999) propuseram uma equação de Thornthwaite modificada, substituindo a temperatura média pela temperatura efetiva (Tef), baseada na amplitude térmica, partindo da premissa de que quanto mais seca a atmosfera, maior o aquecimento do ar durante o dia e o seu resfriamento durante a noite.

Na Figura 8 são apresentadas as relações entre a ETo estimada pelo método proposto por Camargo et al. (1999) e a estimada pelo método padrão, de PenmanMonteith, nas escalas diária, qüinqüidial e decendial.

Na Figura 8a é apresentada a relação entre a ETo estimada pelos métodos Thornthwaite modificado por Camargo et al. (1999) e de Penman-Monteith, com base em dados diários. Observa-se subestimativas do método de Camargo et al. (1999) em relação às estimativas feitas pelo método Penman-Monteth-FAO. A variação observada entre os valores médios de estimativas é de $0,78 \mathrm{mmd}^{-1}$, correspondendo a uma subestimativa de $16,99 \%$.

Os índices e erros analisados em relação ao referido método se encontram na Tabela 4, onde observam-se valores de r e d, na escala diária, da ordem de 0,75 e 0,67, respectivamente, resultando em um valor de $\mathrm{c}=0,50$.

Tabela 4. Coeficiente de correlação (r), índice de concordância (d) e de desempenho (c) e erros médio absoluto (EMA), máximo (EM), sistemático (Es) e aleatório (Ea), entre a ETo estimada pelos métodos de Thornthwaite, com temperatura efetiva, e de Penman-Monteith, nas escalas diária, qüinqüidial e decendial, em Paraipaba, CE.

\begin{tabular}{lccccccc}
\hline Escala de tempo & $\mathrm{r}$ & $\mathrm{d}$ & $\mathrm{c}$ & $\begin{array}{c}\text { EMA } \\
\left(\mathrm{mmd}^{-1}\right)\end{array}$ & $\begin{array}{c}\mathrm{EM} \\
\left(\mathrm{mmd}^{-1}\right)\end{array}$ & $\begin{array}{c}\text { Es } \\
\left(\mathrm{mmd}^{-1}\right)\end{array}$ & $\begin{array}{c}\text { Ea } \\
\left(\mathrm{mmd}^{-1}\right)\end{array}$ \\
\hline Diária & 0,75 & 0,67 & 0,50 & 0,800 & 1,900 & 0,696 & 0,097 \\
Qüinqüidial & 0,82 & 0,62 & 0,51 & 0,767 & 1,285 & 0,640 & 0,030 \\
Decendial & 0,86 & 0,57 & 0,49 & 0,806 & 1,243 & 0,684 & 0,016 \\
\hline
\end{tabular}



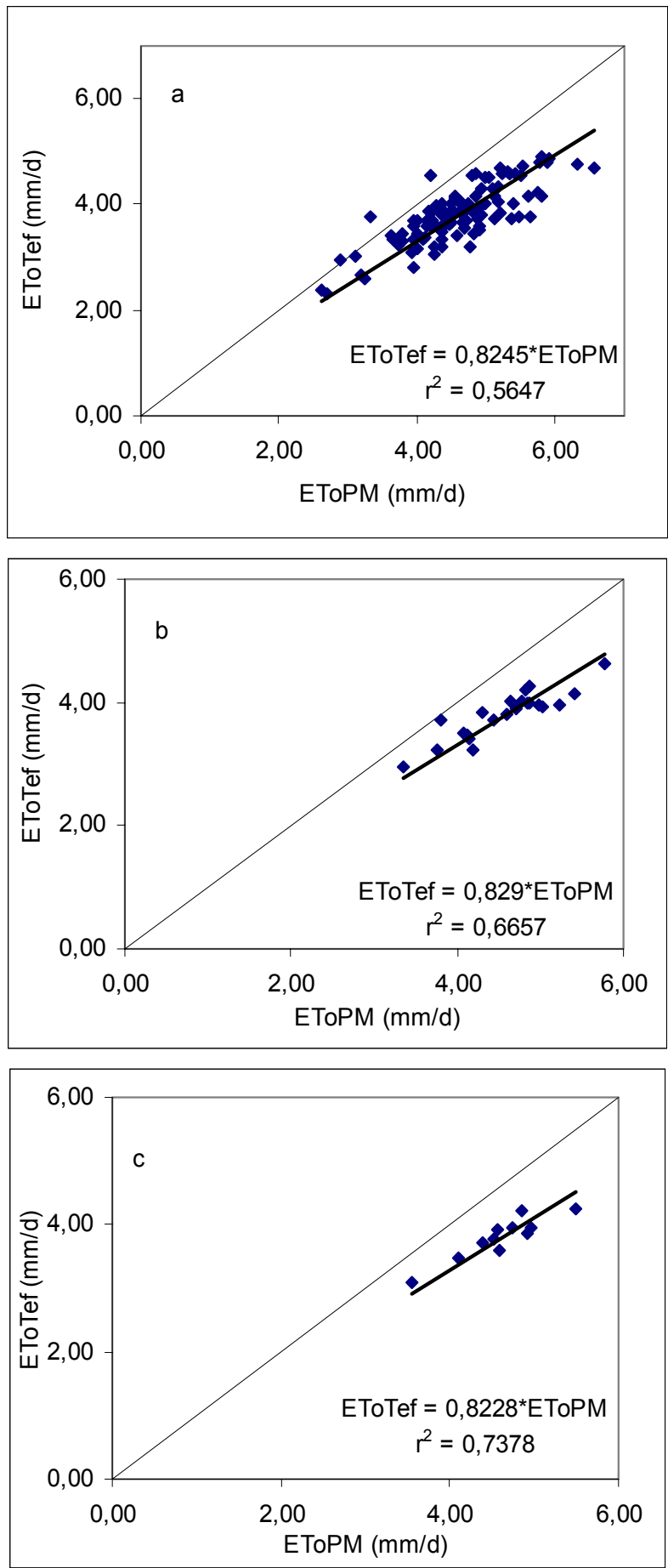

Figura 8 - Relação entre a evapotranspiração de referência estimada pelo método de Penman-Monteith (PM) e pelo método de Thornthwaite com temperatura efetiva (Tef), nas escalas diária (a), qüinqüidial (b) e decendial (c), em Paraipaba, CE, durante a estação chuvosa dos anos de 1997 e 1998. 
Em relação ao método original de Thornthwaite (1948), observa-se uma melhoria na precisão, porém, uma sensível redução na exatidão das estimativas pelo método Thornthwaite corrigido pela Tef, referente às estimativas nas escalas qüinqüidial e decendial.

Constatou-se um aumento dos erros em relação ao método original de Thornthwaite, exceção feita ao Ea, que foi menor. Os valores dos erros foram: EMA = $0,800 \mathrm{mmd}^{-1}, \mathrm{EM}=1,90 \mathrm{mmd}^{-1}, \mathrm{Es}=0,696 \mathrm{mmd}^{-1} \mathrm{e} \mathrm{Ea}=0,097 \mathrm{mmd}^{-1}$, na escala diária.

$\mathrm{Na}$ Figura $8 \mathrm{~b}$ e Tabela 4, podem ser observados os valores correspondentes aos índices e erros de estimativas, para a escala qüinqüidial. Os valores dos índices foram: $d$ $=0,62$ e $\mathrm{r}=0,82$, resultando em $\mathrm{c}=0,51$, representando desempenho mediano. Conforme observado, a equação proposta por Camargo et al. (1999), em que a temperatura média é substituída por Tef, que depende da temperatura máxima e mínima [Tef = 0,36.(3.Tmáx - Tmín)], nas condições de estudo, tem seu desempenho elevado no cálculo na base qüinqüidial, em relação a base diária, tendência também observada no método original de Thornthwaite.

A diferença média entre as estimativas de ETo pelos métodos de Thornthwaite modificado e de Penman-Monteith foi de $0,77 \mathrm{mmd}^{-1}(16,74 \%)$, bem superior aos valores encontrados com o modelo original.

Os erros com relação à aplicação do método de Thornthwaite modificado, na escala qüinqüidial, foram: EMA $=0,767 \mathrm{mmd}^{-1}, \mathrm{EM}=1,285 \mathrm{mmd}^{-1}, \mathrm{Es}=0,640 \mathrm{mmd}^{-1} \mathrm{e}$ $\mathrm{Ea}=0,030 \mathrm{mmd}^{-1}$. A mudança introduzida no método original de Thornthwaite, reduziu o valor dos erros. Esses erros podem decorrer do fato do método de Thornthwaite não apresentar um componente aerodinâmico, que considere o poder evaporante do ar, embora a diferença entre temperatura máxima e mínima represente uma opção de estimativa desse efeito.

Uma outra análise foi realizada com base na escala decendial, como apresentado na Figura 8c. Nota-se, novamente, subestimativa de ETo pelo método modificado por Camargo em relação ao padrão, em todo período analisado. Com relação aos índices, observou-se uma redução do desempenho, sendo $\mathrm{c}=0,49$, (com r $=0,86$ e d $=0,57)$. A precisão das estimativas (r) aumentou, porém, a exatidão (d) diminuiu. 
A diferença média entre estimativas de ETo pelo método proposto por Camargo et al. (1999) e pelo método padrão na escala decendial, foi de $0,81 \mathrm{~mm}(17,49 \%)$, com subestimativas em todo o período.

Os erros observados com relação aos dados na base decendial, foram EMA = $0,806 \mathrm{mmd}^{-1}, \mathrm{EM}=1,243 \mathrm{mmd}^{-1}, \mathrm{Es}=0,684 \mathrm{mmd}^{-1}$ e Ea $=0,016 \mathrm{mmd}^{-1}$. Observa-se, um aumento dos erros em relação ao método original de Thornthwaite, assim como verificado para as demais escalas de tempo, exceção feita ao Ea.

Notou-se uma predominância do método modificado (Tef), de subestimativas em relação a PM, resultado diferente do encontrado em relação ao método original, que mostrou tendência a superestimativa. Em relação ao modelo original, o esperado eram subestimativas, por se tratar de equação adaptada para o clima úmido. No caso da modificação introduzida por Camargo et al. (1999), a contribuição da amplitude térmica, deveria aumentar as estimativas pelo método. O resultado pode refletir o período em que as análises foram realizadas, por se tratar de época chuvosa, além da área ser litorânea.

\subsubsection{Método de Hargreaves \& Samani (1985)}

O método é também baseado em dados de temperatura máxima e mínima, o que representa uma alternativa para locais com pouca disponibilidade de dados climáticos, sendo recomendado pela FAO (Allen et al., 1998), para tais condições.

A Figura 9 apresenta a relação entre as estimativas de ETo pelos métodos de Penman-Monteith-FAO e de Hargreaves \& Samani (1985).

Análise semelhante às anteriores foi realizada com base em dados diários e médias de 5 e 10 dias. No caso de dados diários, observou-se que o método não se ajustou bem ao método padrão (Figura 9), cujos coeficientes encontrados foram: $\mathrm{r}=$ $0,68, \mathrm{~d}=0,67$, obtendo-se um valor de $\mathrm{c}=0,45$, representando desempenho sofrível (Tabela 5).

Os erros referentes ao método de Hargreaves \& Samani (1985), foram: EMA =

$0,551 \mathrm{mmd}^{-1}, \mathrm{EM}=1,762 \mathrm{mmd}^{-1}, \mathrm{Es}=0,389 \mathrm{mmd}^{-1}$ e Ea $=0,070 \mathrm{mmd}^{-1}$. De uma maneira geral, observam-se erros elevados na aplicação do método, exceção ao Ea, sendo o 
desempenho considerado sofrível, o que torna este método, na escala diária, inadequado para as condições climáticas deste estudo.

Tabela 5 . Coeficiente de correlação (r), índice de concordância (d) e de desempenho (c) e erros médio absoluto (EMA), máximo (EM), sistemático (Es) e aleatório (Ea), entre a ETo estimada pelos métodos de Hargreaves \& Samani e de Penman-Monteith, nas escalas diária, qüinqüidial e decendial, em Paraipaba, CE.

\begin{tabular}{lccccccc}
\hline Escala de tempo & $\mathrm{r}$ & $\mathrm{d}$ & $\mathrm{c}$ & $\begin{array}{c}\text { EMA } \\
\left(\mathrm{mmd}^{-1}\right)\end{array}$ & $\begin{array}{c}\mathrm{EM} \\
\left(\mathrm{mmd}^{-1}\right)\end{array}$ & $\begin{array}{c}\text { Es } \\
\left(\mathrm{mmd}^{-1}\right)\end{array}$ & $\begin{array}{c}\text { Ea } \\
\left(\mathrm{mmd}^{-1}\right)\end{array}$ \\
\hline Diária & 0,68 & 0,67 & 0,45 & 0,551 & 1,762 & 0,389 & 0,070 \\
Qüinqüidial & 0,73 & 0,66 & 0,48 & 0,438 & 1,453 & 0,267 & 0,037 \\
Decendial & 0,69 & 0,64 & 0,44 & 0,456 & 0,996 & 0,252 & 0,035 \\
\hline
\end{tabular}

A diferença média entre a ETo estimada, na escala diária, pelo método de Hargreaves \& Samani e Penman-Monteith foi da ordem de 0,40mmd ${ }^{-1}$ (8,69\%), com predominância das subestimativas.

Na Figura 9b e na Tabela 5, nota-se a variação da ETo estimada pelos métodos de Hargreaves \& Samani e de Penman-Monteith, na escala qüinqüidial. Observa-se, que houve leve melhoria, em relação à escala diária, na precisão $(\mathrm{r}=0,73)$ das estimativas, porém, com leve alteração da exatidão $(d=0,66)$, o que também resultou em desempenho sofrível $(\mathrm{c}=0,48)$.

Os erros decorrentes da aplicação deste método foram: $\mathrm{EMA}=0,438 \mathrm{mmd}^{-1}$, $\mathrm{EM}=1,453 \mathrm{mmd}^{-1}, \mathrm{Es}=0,267 \mathrm{mmd}^{-1}$ e Ea $=0,037 \mathrm{mmd}^{-1}$. O erro máximo (EM) foi elevado, porém, o EMA permaneceu próximo do valor anterior. O Ea foi relativamente pequeno, por outro lado, o Es, assim como na escala diária, foi bastante significativo, ora superestimando ETo ora subestimando essa variável.

A diferença média entre as estimativa de ETo pelo método de Hargreaves \& Samani e o método padrão na escala qüinqüidial foi da ordem de $0,37 \mathrm{mmd}^{-1}(8,14 \%)$, predominando as subestimativas. 

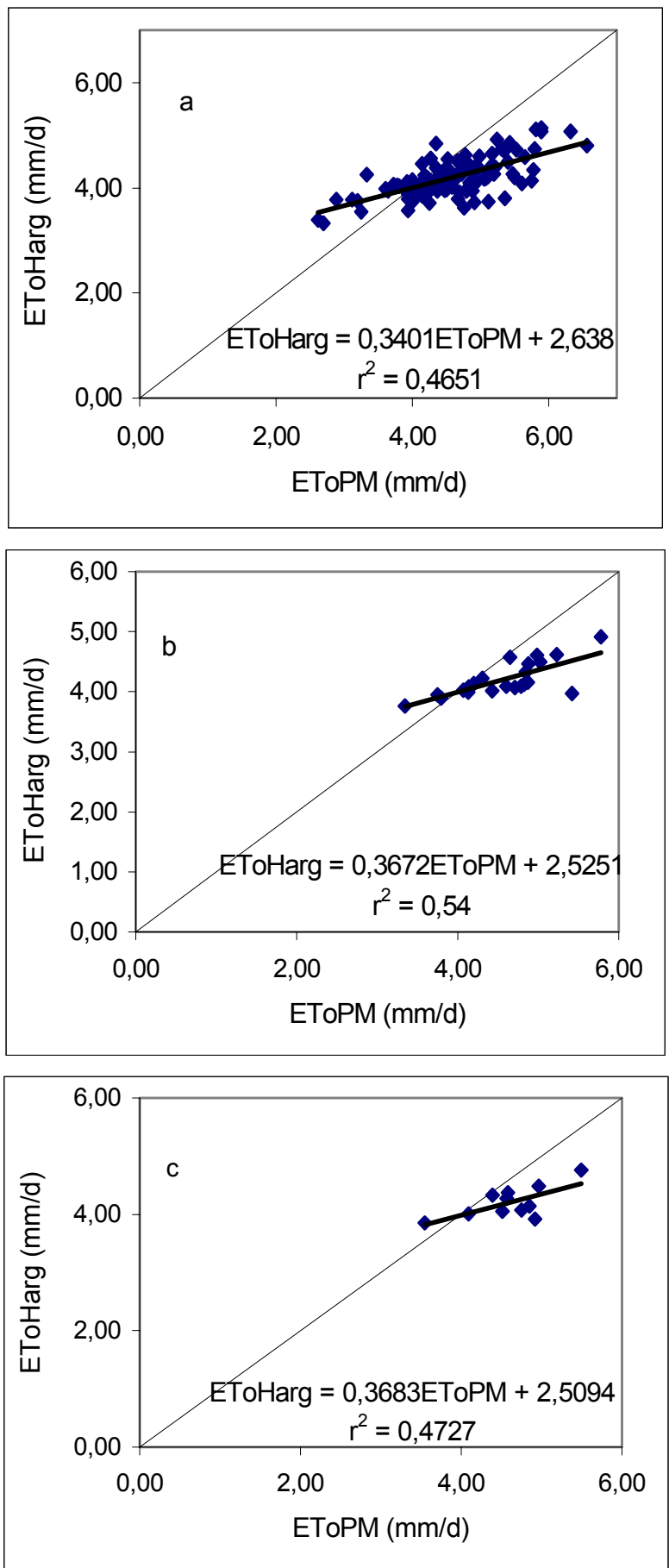

Figura 9 - Relação entre a evapotranspiração de referência estimada pelo método de Penman-Monteith (PM) e pelo método de Hargreaves \& Samani, nas escala diária (a), qüinqüidial (b) e decendial (c), em Paraipaba, CE, durante a estação chuvosa dos anos de 1997 e 1998. 
A Figura 9c, apresenta os valores de ETo estimados pelos métodos de Hargreaves \& Samani e de Penman-Monteith na escala decendial. Observa-se, novamente, que não houve ajuste satisfatório em relação a PM. Os coeficientes estatísticos encontrados nessa análise foram: $\mathrm{r}=0,69, \mathrm{~d}=0,64 \mathrm{e} \mathrm{c}=0,44$, o que representa desempenho, mais uma vez, sofrível.

A diferença média entre as estimativas de ETo pelo método de Hargreaves \& Samani e o método padrão foi da ordem de $0,40 \mathrm{~mm}(8,70 \%)$, predominando as subestimativas.

Os erros obtidos pela aplicação do método na escala decendial foram: $\mathrm{EM}=$ $0,996 \mathrm{mmd}^{-1}, \mathrm{EMA}=0,456 \mathrm{mmd}^{-1}$, Es $=0,252 \mathrm{mmd}^{-1} \mathrm{e} \mathrm{Ea}=0,035 \mathrm{mmd}^{-1}$. Com exceção do EMA, os demais foram inferiores aos valores observados na escala qüinqüidial.

Os resultados obtidos pelo método de Hargreaves \& Samani para a estimativa de ETo, mostram que ele não se adapta às condições de estudo, nas três escalas de tempo analisadas, certamente em decorrência do fato de ser baseado somente na temperatura do ar. Além disso, esse método foi desenvolvido para condições áridas. Resultados semelhantes foram obtidos por Sentelhas e Camargo (1996), para três locais do estado de São Paulo, por Medeiros (1996) e por Souza \& Yoder (1994), que encontraram superestimativas de ETo pelo método de Hargreaves \& Samani em relação aos valores estimados por Penman-Monteith, em Pentecoste, CE. Por outro lado, Medeiros (1998), analisando uma série de dados de Santa Maria, RS, encontrou um bom desempenho do método em questão na estimativa da ETo, na escala qüinqüidial. Os resultados foram condizentes com os observados por Oliveira et al. (1998), com base em dados de Paraipaba, CE, para o período de estação chuvosa.

\subsubsection{Método do tanque de evaporação Classe A - FAO}

O método do tanque de evaporação classe A - FAO é um dos mais utilizados no manejo da irrigação, sendo de fácil aplicação, simplicidade de instalação e manutenção, além do baixo custo, quando comparado com outros equipamentos. 
No caso específico deste estudo, os dados de evaporação foram tomados de uma estação convencional instada próxima a área do experimento.

Na Figura 10 são apresentados os dados relativos à comparação entre a ETo estimada pelos métodos de Penman-Monteith e do tanque classe A, nas escalas diária, qüinqüidial e decendial.

Nota-se na Figura 10a, para a escala diária, uma dispersão acentuada dos dados de ETo estimados pelos métodos do tanque e de Penman-Monteith, com baixos valores dos coeficientes de correlação $(r=0,65)$, de concordância $(d=0,68)$ e de desempenho (c $=0,44)$, sendo classificado como sofrível.

A diferença média proporcionada pelo método do tanque classe $\mathrm{A}$ foi da ordem de $0,51 \mathrm{mmd}^{-1}$, que corresponde à tendência preponderante de superestimativas, da ordem de $11,17 \%$.

Tabela 6. Coeficiente de correlação (r), índice de concordância (d) e de desempenho (c) e erros médio absoluto (EMA), máximo (EM), sistemático (Es) e aleatório (Ea), entre a ETo estimada pelos métodos do Tanque Classe A - FAO e de Penman-Monteith, nas escalas diária, qüinqüidial e decendial, em Paraipaba, CE.

\begin{tabular}{lccccccc}
\hline Escala de tempo & $\mathrm{r}$ & $\mathrm{d}$ & $\mathrm{c}$ & $\begin{array}{c}\text { EMA } \\
\left(\mathrm{mmd}^{-1}\right)\end{array}$ & $\begin{array}{c}\mathrm{EM} \\
\left(\mathrm{mmd}^{-1}\right)\end{array}$ & $\begin{array}{c}\text { Es } \\
\left(\mathrm{mmd}^{-1}\right)\end{array}$ & $\begin{array}{c}\text { Ea } \\
\left(\mathrm{mmd}^{-1}\right)\end{array}$ \\
\hline Diária & 0,65 & 0,68 & 0,44 & 0,977 & 3,750 & 0,298 & 1,095 \\
Qüinqüidial & 0,61 & 0,62 & 0,39 & 0,776 & 1,453 & 0,248 & 0,558 \\
Decendial & 0,83 & 0,74 & 0,60 & 0,762 & 1,252 & 0,522 & 0,616 \\
\hline
\end{tabular}

Os erros, que chegaram a um máximo na escala diária de $\mathrm{EM}=3,75 \mathrm{mmd}^{-1}$, são decorrentes de problemas inerentes à localização do tanque classe A, como sua superexposição à radiação solar e à ação dos ventos, variáveis que assumem valores elevados na região de estudo, em média, acima de $20 \mathrm{MJ} \cdot \mathrm{m}^{-2} \cdot \mathrm{d}^{-1}$, no caso da radiação solar global, e acima de $1,5 \mathrm{~m} \cdot \mathrm{s}^{-1}$, no caso da velocidade do vento (Figuras 2, 4 e 5), além do efeito da advecção de calor sensível. 

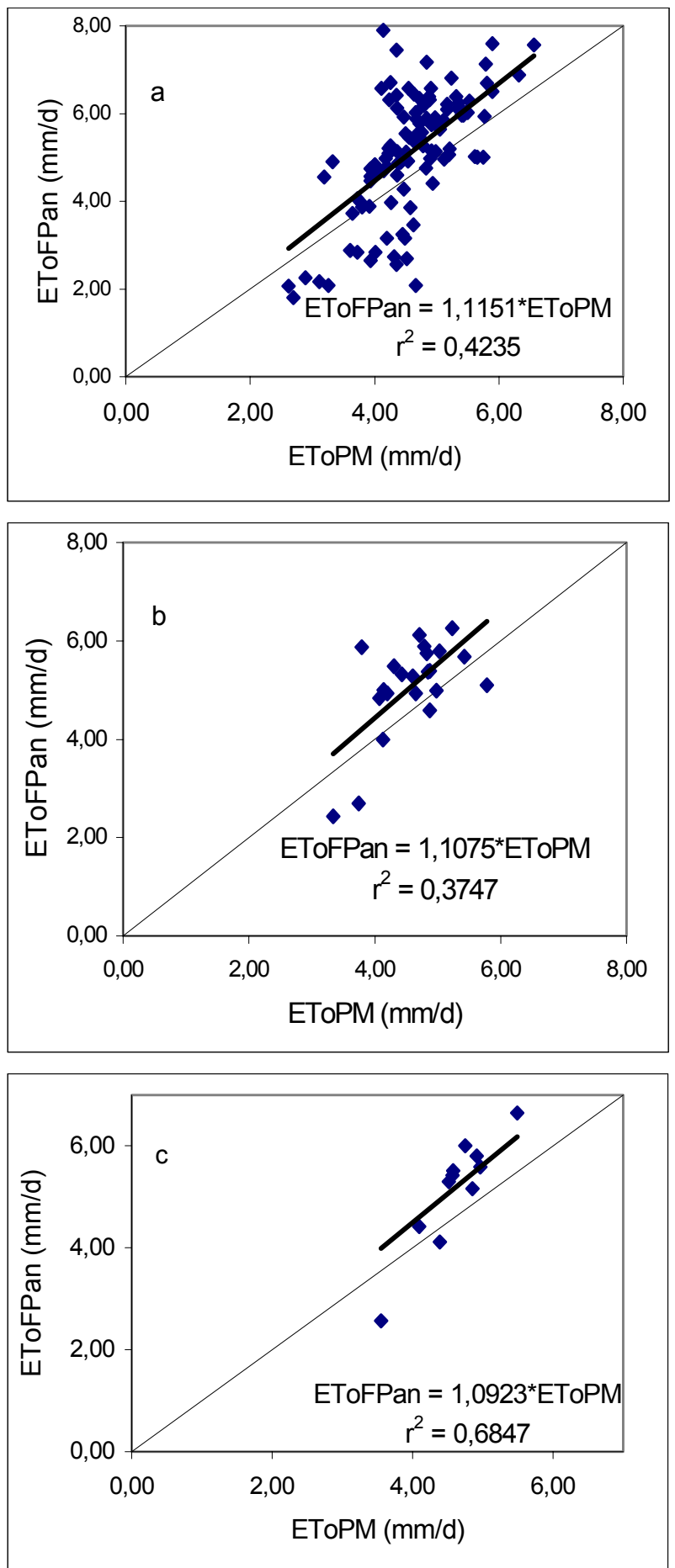

Figura 10 - Relação entre a evapotranspiração de referência estimada pelo método de Penman-Monteith (PM) e pelo método do tanque classe A - FAO, nas escala diária (a), qüinqüidial (b) e decendial (c), em Paraipaba, CE, durante a estação chuvosa dos anos de 1997 e 1998. 
Os demais erros, encontrados (Tabela 6) foram: EMA $=0,977 \mathrm{mmd}^{-1}$, Es $=$ 0,298 $\mathrm{mmd}^{-1}$ e Ea $=1,095 \mathrm{mmd}^{-1}$. O erro aleatório foi o mais elevado, em relação aos demais.

A Figura 10b apresenta os resultados obtidos na escala qüinqüidial. Novamente, nota-se uma predominância de superestimativas do método do tanque de evaporação classe A em relação ao método padrão da FAO. Os índices estatísticos encontrados voltaram a mostrar baixa precisão $(\mathrm{r}=0,61)$, baixa exatidão $(\mathrm{d}=0,62)$, o que resultou em mau desempenho do método $(c=0,39)$, indicando não ser esta a melhor opção para a estimativa da ETo na região em questão.

A diferença média entre os valores de ETo estimada pelo método do tanque classe A e pelo método padrão da FAO foi de $0,50 \mathrm{mmd}^{-1}$, correspondente a uma superestimativa de $10,87 \%$.

Os erros encontrados com relação à escala de tempo qüinqüidial foram: $\mathrm{EM}=$ 1,453 $\mathrm{mmd}^{-1}$, semelhante ao obtido quando utilizado o método de Hargreaves \& Samani (1985), EMA $=0,776 \mathrm{mmd}^{-1}, \mathrm{Es}=0,248 \mathrm{mmd}^{-1} \mathrm{e} \mathrm{Ea}=0,558 \mathrm{mmd}^{-1}$.

$\mathrm{Na}$ Figura 10c é apresentada a relação entre a ETo na escala decendial, estimada pelo tanque classe A e pelo método de Penman-Monteith. Observa-se que a tendência de superestimativas continua predominante, assim como nos casos anteriores. $\mathrm{Na}$ Tabela 6 , nota-se uma menor dispersão $(\mathrm{r}=0,83)$ e um aumento na exatidão $(\mathrm{d}=$ 0,74 ), proporcionando melhoria no desempenho do método, que passou a ser mediano (c $=0,60)$.

Com relação aos erros, foram obtidos valores de EM $=1,252 \mathrm{mmd}^{-1}$, EMA = 0,762 $\mathrm{mmd}^{-1}, \mathrm{Es}=0,522 \mathrm{mmd}^{-1}$ e Ea $=0,616 \mathrm{mmd}^{-1} . \mathrm{EM}$ e EMA diminuíram de valor enquanto que Es e Ea foram superiores aos da escala qüinqüidial.

A diferença entre estimativas médias de ETo pelos métodos FPan e PM, na escala decendial foi de $0,53 \mathrm{mmd}^{-1}$, correspondendo a uma superestimativa de $11,56 \%$.

Os resultados aqui obtidos estão de acordo com os de Medeiros (1996), que trabalhando com dados de Pentecoste, $\mathrm{CE}$, nas escalas diária e mensal, não encontraram bom ajuste entre os valores de ETo estimada pela equação de Penman-Monteith e do tanque classe A. Por outro lado, em Mossoró, RN, o autor observou melhor ajuste entre 
a ETo estimada por esse método, o que também foi constatado por Medeiros (1998), Lunardi et al. (1999), Almeida et al. (1999) e Al-Ghobari, (2000).

De acordo com Jensen et al. (1990), o método do tanque classe A, foi desenvolvido para um melhor ajuste com dados médios de 5 dias, sendo que sua aplicação para períodos de tempo diferentes pode reduzir a sua precisão. Isso não foi observado, como se pode ver na Figura 10 e na Tabela 6, pois independentemente da escala de tempo utilizada a tendência de superestimativas permaneceu, sendo, da ordem de $11,2 \%$.

\subsubsection{Método de Priestley e Taylor (1972)}

O método de Priestley e Taylor (1972), tem sido usado em diversos estudos de evapotranspiração de referência, devido sua simplicidade em relação aos métodos combinados, por não exigir dados de velocidade do vento e umidade relativa do ar.

Na Figura 11, observa-se a relação entre a ETo estimada pelo método padrão, Penman-Monteith-FAO e o método de Priestley-Taylor nas escalas diárias, qüinqüidial e decendial.

Em uma primeira análise, na escala diária (Figura 11a), nota-se que o método de Priestley e Taylor tende a superestimar levemente a ETo em relação ao método de Penman-Monteith.

Os valores dos coeficientes estatísticos observados na Tabela 7, mostram que apesar da superestimativa, houve uma razoável precisão $(\mathrm{r}=0,80)$, assim como exatidão $(\mathrm{d}=0,87)$, o que resultou em um índice de desempenho igual a 0,70 , considerado mediano, mas muito próximo de bom, o que também foi observado por Medeiros (1998). Camargo \& Sentelhas (1997) encontraram um desempenho considerado muito bom para este método.

Em uma primeira análise, na escala diária (Figura 11a), nota-se que o método de Priestley e Taylor tende a superestimar levemente a ETo em relação ao método de Penman-Monteith. 

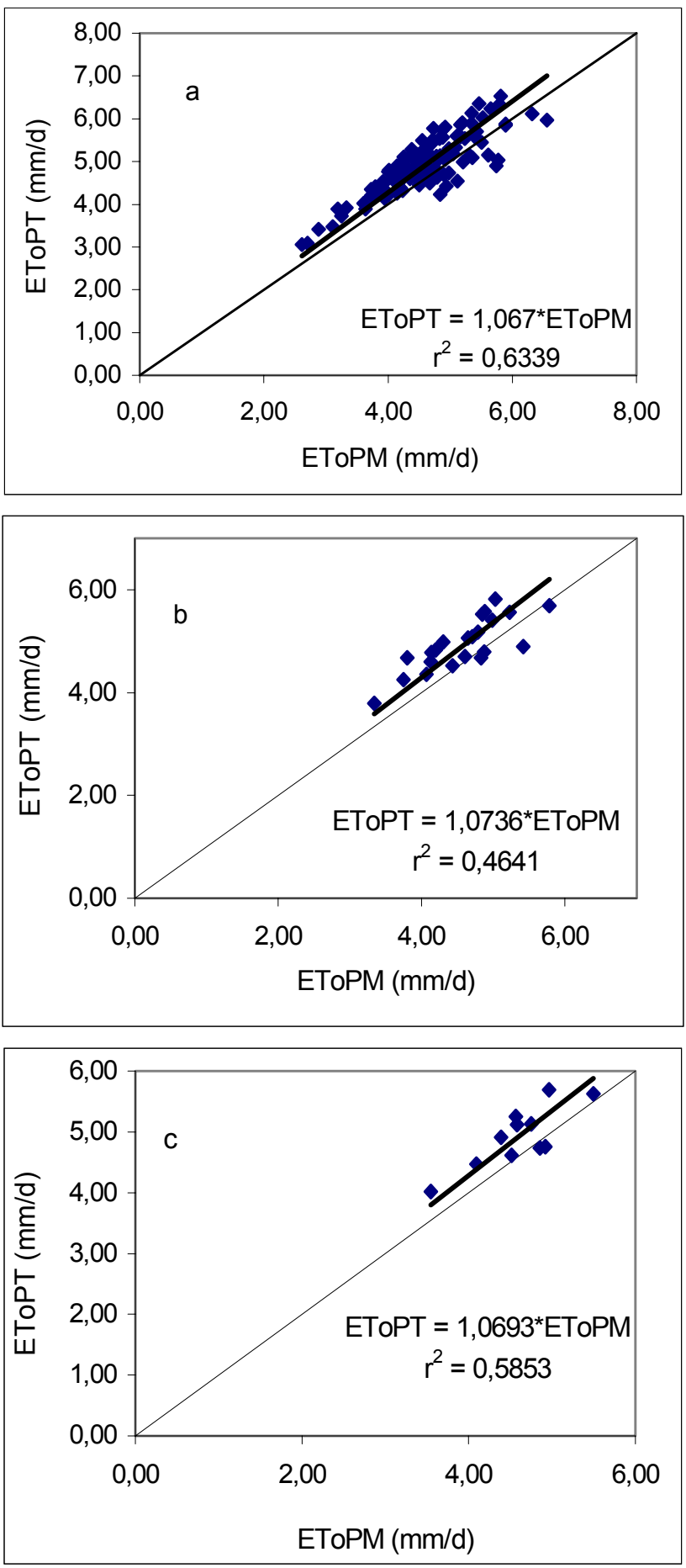

Figura 11 - Relação entre a evapotranspiração de referência estimada pelo método de Penman-Monteith (PM) e pelo método de Priestley-Taylor $(\alpha=1,26)$, nas escalas diária (a), qüinqüidial (b) e decendial (c), em Paraipaba, CE, durante a estação chuvosa dos anos de 1997 e 1998. 
Os valores dos coeficientes estatísticos observados na Tabela 7, mostram que apesar da superestimativa, houve uma razoável precisão $(\mathrm{r}=0,80)$, assim como exatidão $(\mathrm{d}=0,87)$, o que resultou em um índice de desempenho igual a 0,70 , considerado mediano, mas muito próximo de bom, o que também foi observado por Medeiros (1998). Camargo \& Sentelhas (1997) encontraram um desempenho considerado muito bom para este método.

Tabela 7. Coeficiente de correlação (r), índice de concordância (d) e de desempenho (c) e erros médio absoluto (EMA), máximo (EM), sistemático (Es) e aleatório (Ea), entre a ETo estimada pelos métodos de Priestley-Taylor $(\alpha=1,26)$ e de Penman-Monteith, nas escalas diária, qüinqüidial e decendial, em Paraipaba, CE.

\begin{tabular}{lccccccc}
\hline Escala de tempo & $\mathrm{r}$ & $\mathrm{d}$ & $\mathrm{c}$ & $\begin{array}{c}\text { EMA } \\
\left(\mathrm{mmd}^{-1}\right)\end{array}$ & $\begin{array}{c}\text { EM } \\
\left(\mathrm{mmd}^{-1}\right)\end{array}$ & $\begin{array}{c}\text { Es } \\
\left(\mathrm{mmd}^{-1}\right)\end{array}$ & $\begin{array}{c}\mathrm{Ea} \\
\left(\mathrm{mmd}^{-1}\right)\end{array}$ \\
\hline Diária & 0,80 & 0,87 & 0,70 & 0,455 & 1,033 & 0,137 & 0,129 \\
Qüinqüidial & 0,68 & 0,73 & 0,50 & 0,440 & 0,877 & 0,159 & 0,089 \\
Decendial & 0,77 & 0,80 & 0,62 & 0,384 & 0,733 & 0,120 & 0,076 \\
\hline
\end{tabular}

A diferença média entre as estimativas de ETo pelo método de Priestley-Taylor e de Penman-Monteith, foi de $0,34 \mathrm{mmd}^{-1}$ (7,38\%), caracterizando uma pequena superestimativa. Essa pequena diferença pode ser explicada pelo período de dados que correspondem aos meses chuvosos, em que a umidade é elevada, condição que se aproxima das obtidas com o parâmetro original de Priestley-Taylor. Em segundo lugar, porque a diferença entre os métodos comparados está no termo aerodinâmico, não considerado no método de PT. Na condição de umidade relativa elevada o termo aerodinâmico tende a ter uma menor contribuição, o que, provavelmente, estaria ocorrendo neste caso, justificando assim a tendência de superestimativa.

Os erros decorrentes da aplicação do método, foram relativamente reduzidos, em relação aos demais métodos, $\mathrm{EM}=1,033 \mathrm{mmd}^{-1}, \mathrm{EMA}=0,455 \mathrm{mmd}^{-1}, \mathrm{Es}=0,137$ $\mathrm{mmd}^{-1}$ e Ea $=0,129 \mathrm{mmd}^{-1}$. Segundo Peres et al. (1997), Priestley e Taylor (1972) 
estabeleceram empiricamente que evaporação/evapotranspiração potencial de uma superfície saturada, com mínima advecção, pode ser estimada pela equação (34) que foi usada na análise. Priestley \& Taylor (1972) encontraram valores de $\alpha$ variando de 1,08 (evaporação em solo nú) a 1,32 (evapotranspiração em solo vegetado), com valor médio de 1,26. Segundo Jensen et al. (1990), o modelo de Priestley-Taylor se aplica preferencialmente para climas úmidos.

No caso estudado o período chuvoso proporcionou uma menor contribuição da advecção. Allen (1986) encontrou boas estimativas com o método de Priestley-Taylor (PT) em climas onde a advecção é baixa. Entretanto, em climas áridos, onde a advecção é mais elevada, PT subestimou ETo e o autor sugeriu um $\alpha=1,34$, como adequado para região árida da Austrália.

Pereira \& Villa Nova (1992), mostraram que as variações do parâmetro de Priestley-Taylor, é descrita pelas flutuações de calor sensível (H). Os resultados mostram que a relação é linear e positiva, na base horária e diária. Os autores relatam que o valor original $(\alpha=1,26)$, para condições potenciais não representa uma situação de advecção. Os autores encontraram valores de $\alpha$ variando de 1,01 a 1,66.

Pereira et al. (1997a) encontraram para a grama em lisímetro de drenagem, na escala mensal, valores médios anuais de $\alpha$ inferiores a 1,26, para Campinas, Ribeirão Preto e Pindamonhagaba, SP.

$\mathrm{Na}$ Figura 11b, observa-se os resultados relativos à análise para a escala qüinqüidial. Nessa escala, novamente foi observada tendência de superestimativas em relação ao método padrão da FAO.

Os índices estatísticos (Tabela 7), foram: $\mathrm{r}=0,68, \mathrm{~d}=0,73$ e $\mathrm{c}=0,50$, com desempenho sofrível, porém, muito próximo de mediano. O desempenho foi reduzido em relação aos dados diários, ao contrário do que era esperado. Esses resultados diferem dos encontrados por Medeiros (1998).

A diferença entre valores médios de estimativa foi de $0,39 \mathrm{mmd}^{-1}$, correspondendo a superestimativa de 7,93\%.

Os erros proporcionados na escala de tempo de 5 dias foram de: $\mathrm{EM}=$ $0,887 \mathrm{mmd}^{-1}, \mathrm{EMA}=0,44 \mathrm{mmd}^{-1}, \mathrm{Es}=0,159 \mathrm{mmd}^{-1} \mathrm{e} \mathrm{Ea}=0,89 \mathrm{mmd}^{-1}$. 
A Figura 11c apresenta os resultados relativos à análise entre os métodos de Priestley-Taylor e de Penman-Monteith, na escala decendial. A tendência de superestimativa se manteve também nesta escala, o que é comprovado pelos índices estatísticos obtidos (Tabela 7), que foram: $\mathrm{r}=0,77 ; \mathrm{d}=0,80$ e $\mathrm{c}=0,62$, determinando desempenho mediano.

Os erros sofreram redução, na medida em que os períodos de tempo estudados passaram de diários para decendiais. $\mathrm{Na}$ base decendial observou-se valores de EMA $=$ $0,384 \mathrm{mmd}^{-1}, \mathrm{EM}=0,733 \mathrm{mmd}^{-1}, \mathrm{Es}=0,120 \mathrm{mmd}^{-1} \mathrm{e} \mathrm{Ea}=0,076 \mathrm{mmd}^{-1}$. Com relação às diferença médias entre as estimativas observou-se uma superestimativa de $0,33 \mathrm{mmd}^{-1}$ $(7,22 \%)$.

Por ser o método de Priestley-Taylor uma simplificação do método de Penman (1948), de certa forma esse melhor ajuste era esperado, porém, a tendência de superestimativa da ETo em relação ao método de Penman-Monteith, se deve ao fato deste último levar em consideração a resistência da cobertura $\left(\mathrm{r}_{\mathrm{c}}\right)$, que afeta o termo aerodinâmico, o que proporciona resultados menores quando comparado ao método original de Penman. Certamente, uma redução no parâmetro de Priestley-Taylor $(\alpha)$, resultaria em estimativas de ETo mais exatas, em relação a PMon.

Segundo Cunha \& Bergamaschi (1994), as características inerentes ao parâmetro $\alpha$ de Priestley-Taylor, impedem a universalidade desse método de estimativa para as diversas culturas e locais. Vários autores determinaram valores específicos para os locais estudados, Cunha \& Bergamaschi (1994), Pereira et al. (1997a), Pereira et al. (1997b) e Sentelhas et al. (2000). Sentelhas et al. (2000) encontraram grande dispersão de dados, quando comparadas as estimativas de ETo obtidas com o método de PriestleyTaylor $(\alpha=1,26)$ com dados medidos em lisímetro, indicando que o valor original não se aplica ao longo do ano. Os autores verificaram que a contribuição de calor sensível (por advecção) no período seco foi elevada, tendo sido influenciado pelo tamanho da área tampão, no caso de $35 \mathrm{~m}$ x 90m. Essa distância pode ser de alguns metros até algumas centenas de metros, dependendo das condições regionais de umidade. 
4.4 Análise dos ajustes propostos nas equações de Camargo et al. (1999) e de PriestleyTaylor (1972)

4.4.1 Método de Camargo et al. (1999) - Thornthwaite, com temperatura efetiva $(f=0,380)$

Foi realizado um ajuste no método proposto por Camargo et al. (1999), visando uma melhor precisão e exatidão em relação ao método de Penman-Montith-FAO. Simulações sucessivas foram realizadas, de modo a se obter o melhor ajuste entre a linha de tendência e a de valores iguais (1:1). Esse resultado foi alcançado com seguinte equação, para temperatura efetiva:

$$
\text { Tef }=\mathrm{f} *(3 * \text { Tmáx }- \text { Tmín })
$$

sendo $\mathrm{f}=0,380$.

A Figura 12 apresenta a relação entre as estimativas de ETo pelo método de Camargo et al. (1999) com a Tef corrigida (EToTefc) e pelo método de PenmanMonteih/FAO (EToPM), nas escalas diária, qüinqüidial e decendial, e na Tabela 8 são apresentados os índices estatísticos e os erros decorrentes dessa análise comparativa.

Nota-se que o ajuste realizado proporcionou sensível melhoria, na exatidão em relação a reta 1:1 (Figura 12). Entretanto, observou-se redução dos valores de r, d e c, nas escalas qüinqüidial e decendial.

Somente na escala decendial houve um ligeiro aumento de $c$. Na escala diária (Figura 12a e Tabela 8), os valores dos índices analisados foram $\mathrm{r}=0,28, \mathrm{~d}=0,84 \mathrm{e} \mathrm{c}=$ 0,24, resultando em desempenho péssimo. O ajuste modificou a exatidão (ajuste em relação à reta 1:1), porém, o desempenho foi reduzido de forma acentuada, dado ao aumento da dispersão $(\mathrm{r}=0,28)$.

Com relação aos erros, foram obtidos os seguintes valores: $\mathrm{EMA}=0,360$ $\mathrm{mmd}^{-1}, \mathrm{EM}=1,291 \mathrm{mmd}^{-1}, \mathrm{Es}=0,129 \mathrm{mmd}^{-1}$ e Ea $=0,077 \mathrm{mmd}^{-1}$. 
Tabela 8. Coeficiente de correlação (r), índice de concordância (d) e de desempenho (c) e erros médio absoluto (EMA), máximo (EM), sistemático (Es) e aleatório (Ea), entre a ETo estimada pelos métodos de Camargo et al. (1999) ajustado (f $=0,380)$ e de Penman-Monteith, nas escalas diária, qüinqüidial e decendial, em Paraipaba, CE.

\begin{tabular}{lccccccc}
\hline Escala de tempo & $\mathrm{r}$ & $\mathrm{d}$ & $\mathrm{c}$ & $\begin{array}{c}\text { EMA } \\
\left(\mathrm{mmd}^{-1}\right)\end{array}$ & $\begin{array}{c}\mathrm{EM} \\
\left(\mathrm{mmd}^{-1}\right)\end{array}$ & $\begin{array}{c}\text { Es } \\
\left(\mathrm{mmd}^{-1}\right)\end{array}$ & $\begin{array}{c}\mathrm{Ea} \\
\left(\mathrm{mmd}^{-1}\right)\end{array}$ \\
\hline Diária & 0,28 & 0,84 & 0,24 & 0,360 & 1,291 & 0,129 & 0,077 \\
Qüinqüidial & 0,22 & 0,73 & 0,16 & 0,245 & 0,757 & 0,077 & 0,031 \\
Decendial & 0,60 & 0,90 & 0,54 & 0,182 & 0,316 & 0,043 & 0,015 \\
\hline
\end{tabular}

O desempenho caiu ainda mais na escala qüinqüidial (Figura 12b e Tabela 8), com $r=0,22, d=0,73$ e $c=0,16$, que corresponde a um desempenho péssimo.

Os erros observados nessa escala qüinqüidial foram: $\mathrm{EMA}=0,245 \mathrm{mmd}^{-1}, \mathrm{EM}$ $=0757 \mathrm{mmd}^{-1}, \mathrm{Es}=0,077 \mathrm{mmd}^{-1} \mathrm{e} \mathrm{Ea}=0,031 \mathrm{mmd}^{-1}$. Nota-se um aumento da exatidão $($ EToTefc1 $=0,99498$. EToPM $)$, porém, com uma redução acentuada dos erros cometidos.

Na escala decendial (Figura 12c e Tabela 8), foi observado um melhor ajuste, em relação aos casos anteriores $\mathrm{r}=0,60, \mathrm{~d}=0,90$ e $\mathrm{c}=0,54$, o que é considerado um desempenho mediano, mostrando potencial ainda reduzido de uso deste método ajustado, nas condições climáticas semelhantes ao da região de Paraipaba, CE.

4.4.2 - Método de Camargo et al. (1999) - Thornthwaite, com temperatura efetiva $(f=0,379)$

A diferença em relação ao ajuste anterior é que não foi usado o critério para o cálculo de evapotranspiração padronizada (ETp) para $\mathrm{Tm} \geq 26,5^{\circ} \mathrm{C}$, ou seja, todos os valores de ETp foram calculadas a partir da equação (27). 

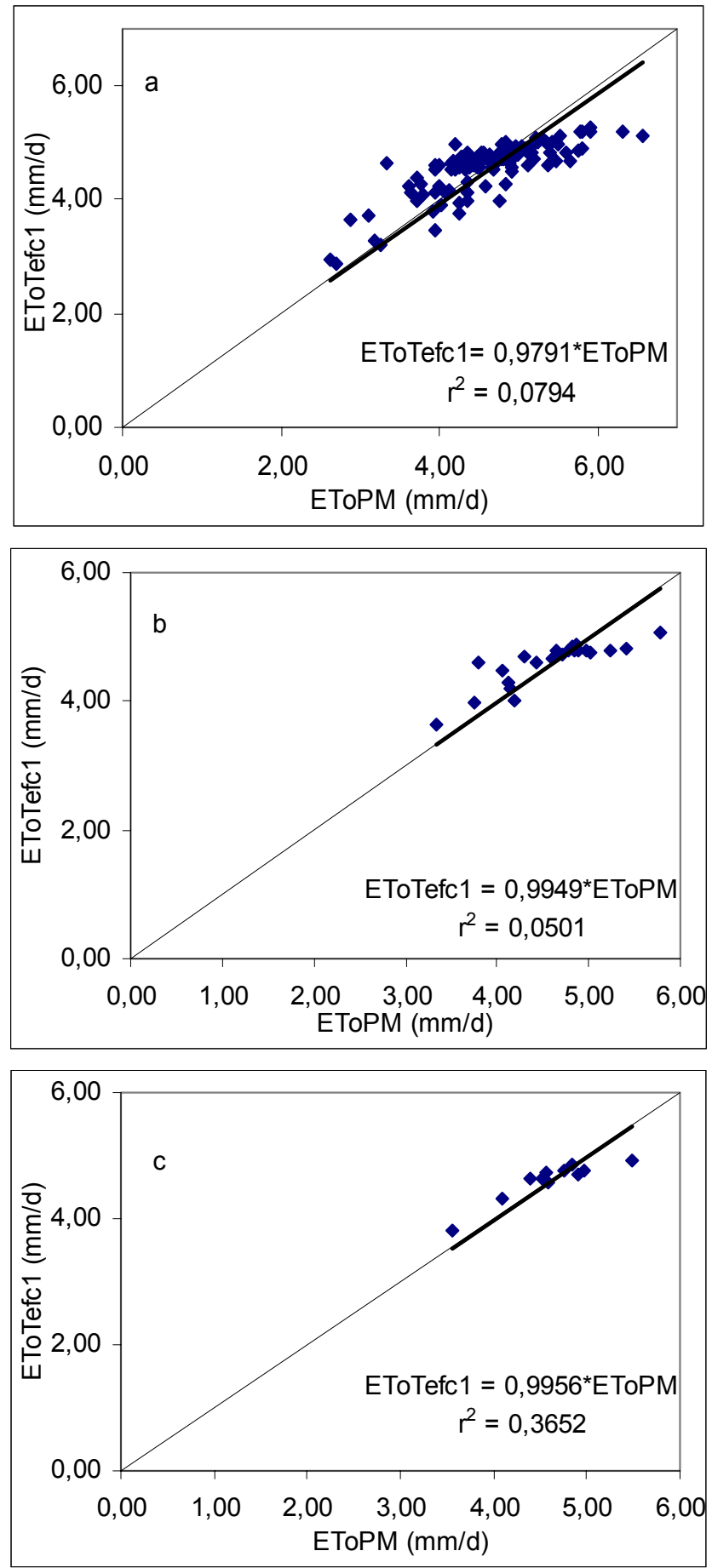

Figura 12 - Relação entre a evapotranspiração de referência estimada pelo método de Penman-Monteith (PM) e pelo método de Camargo et al. (1999) ajustado (f $=0,380$ ), nas escalas diária (a), qüinqüidial (b) e decendial (c), em Paraipaba, CE, durante a estação chuvosa dos anos de 1997 e 1998. 
Na Figura 13 são apresentados os valores decorrentes da aplicação do método proposto em relação a PM. A Tabela 9 apresenta os índices e os erros decorrentes do método ajustado em relação ao de Penman-Monteith.

Observa-se que o método ajustou-se melhor do que o anterior, com relação à precisão e exatidão, nos três períodos analisados.

Tabela 9. Coeficiente de correlação (r), índice de concordância (d) e de desempenho (c) e erros médio absoluto (EMA), máximo (EM), sistemático (Es) e aleatório (Ea), entre a ETo estimada pelos métodos de Camargo et al. (1999) ajustado (f $=0,379)$ e de Penman-Monteith, nas escalas diária, qüinqüidial e decendial, em Paraipaba, CE.

\begin{tabular}{lccccccc}
\hline Escala de tempo & $\mathrm{r}$ & $\mathrm{d}$ & $\mathrm{c}$ & $\begin{array}{c}\text { EMA } \\
\left(\mathrm{mmd}^{-1}\right)\end{array}$ & $\begin{array}{c}\mathrm{EM} \\
\left(\mathrm{mmd}^{-1}\right)\end{array}$ & $\begin{array}{c}\mathrm{Es} \\
\left(\mathrm{mmd}^{-1}\right)\end{array}$ & $\begin{array}{c}\mathrm{Ea} \\
\left(\mathrm{mmd}^{-1}\right)\end{array}$ \\
\hline Diária & 0,76 & 0,90 & 0,68 & 0,340 & 1,291 & 0,039 & 0,177 \\
Qüinqüidial & 0,80 & 0,81 & 0,65 & 0,223 & 0,757 & 0,033 & 0,047 \\
Decendial & 0,86 & 0,94 & 0,81 & 0,189 & 0,316 & 0,017 & 0,023 \\
\hline
\end{tabular}

Os índices obtidos foram: $\mathrm{r}=0,76, \mathrm{~d}=0,90$ resultando em $\mathrm{c}=0,68$, considerado como desempenho mediano, próximo de "bom", na escala diária.

A diferença média entre as estimativas de ETo foi de $0,07 \mathrm{mmd}^{-1}$ representado uma superestimativa de apenas $1,42 \%$.

Com relação aos dados qüinqüidiais, os índices observados foram: $r=0,80, d=$ 0,81 obtendo-se um desempenho mediano $(0,65)$, porém, com uma ligeira diferença em relação ao caso anterior. Com exceção do $\mathrm{EM}=0,757 \mathrm{mmd}^{-1}$, os demais foram reduzidos em relação aos dados diários. Essa observação está condizente com o aumento da exatidão.

Para os dados na escala decendial, observa-se um aumento da precisão e exatidão $(\mathrm{r}=0,86$ e d $=0,94)$, resultando em um desempenho muito bom $(\mathrm{c}=0,81)$. 

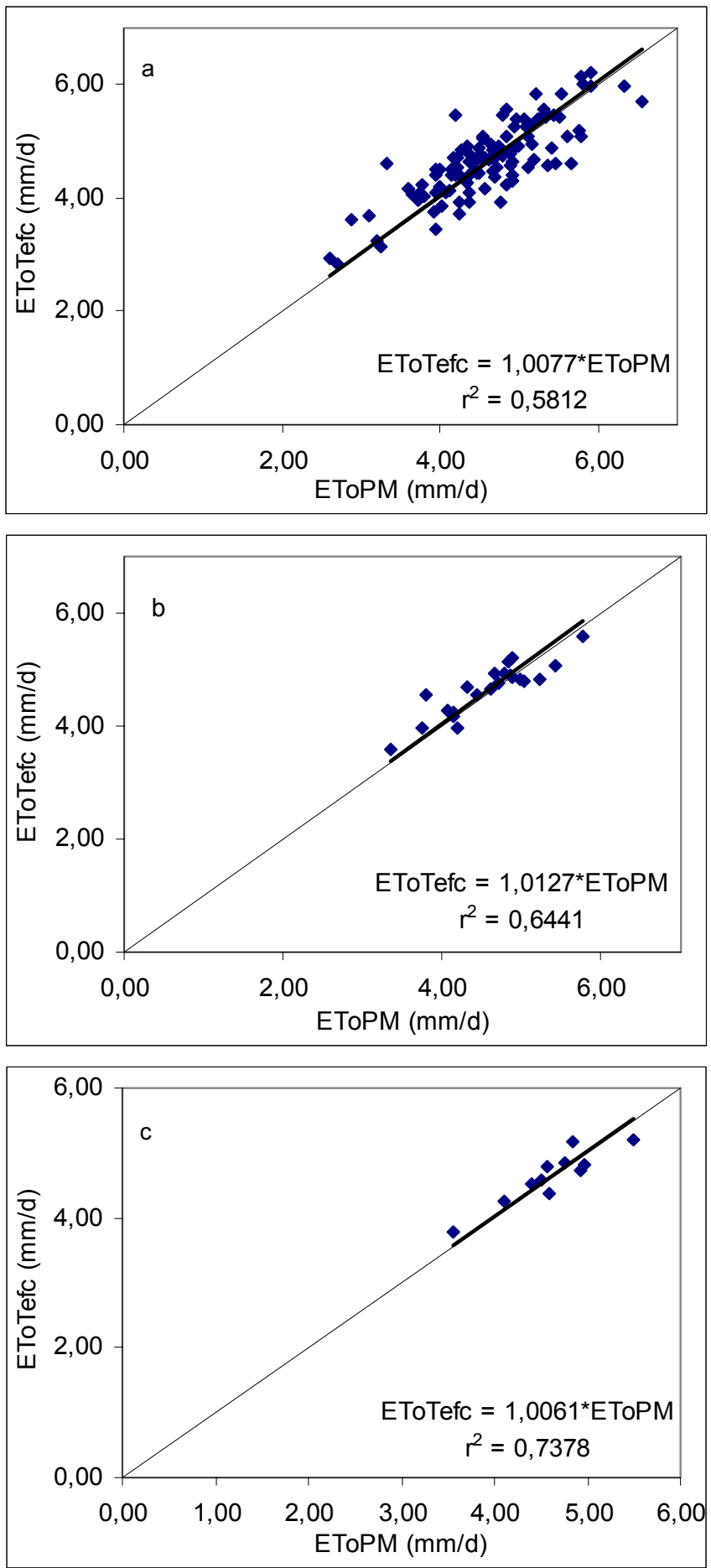

Figura 13 - Relação entre a evapotranspiração de referência estimada pelo método de Penman-Monteith (PM) e pelo método de Camargo et al. (1999) ajustado (f = 0,379), nas escalas diária (a), qüinqüidial (b) e decendial (c), em Paraipaba, CE, durante a estação chuvosa dos anos de 1997 e 1998. 
Com relação aos erros nota-se, de uma forma geral, que os valores são reduzidos à medida que a escala de tempo aumenta. $\mathrm{O}$ método mostra-se com grande potencial de utilização na região de estudo.

\subsubsection{Método de Priestley e Taylor Corrigido $(\alpha=1,19)$}

O método de Priestley-Taylor (PT), por sua performance em relação aos resultados de Penman-Monteith (PMon), foi corrigido a partir de regressão linear, com ajuste realizado em relação a linha 1:1. O parâmetro $\alpha$ foi ajustado de modo a se obter o melhor ajuste entre as estimativas de ETo, em relação ao método padrão, encontrando-se $\alpha=1,19$.

Na Tabela 10 são apresentados os índices e erros, correspondentes à aplicação da correção no método de Priestley-Taylor ajustado, com relação ao método de PenmanMonteith.

Na Figura 14 são apresentados os resultados das relações entre e ETo estimada pelo método de Priestley-Taylor ajustado e o método padrão da FAO. Observa-se que embora a dispersão dos valores analisados continue a mesma, com $\mathrm{r}$ variando de 0,68 a 0,80, a exatidão das estimativa melhorou sensivelmente, com d oscilando entre 0,79 e 0,91, havendo melhoria também no índice de desempenho, que foi de 0,73 na escala diária, considerado bom, 0,54 na escala quinqüidial, considerado mediano, e 0,68 na escala decendial, também considerado mediano.

Com o ajuste de $\alpha=1,19$, a diferença média entre a ETo estimada por Priestley-Taylor em relação a Penman-Monteith caiu para a faixa de 0,7 a 1,4\% (Figura 14).

Os erros encontrados (Tabela 10) sofreram redução em todas as escalas, havendo um leve aumento de Es, da escala diária para qüinqüidial.

Nota-se, de uma maneira geral, tendência, ainda, de leves superestimativas de ETo pelo do método de Priestley-Taylor (1972) ajustado $(\alpha=1,19)$, em todas as escalas analisadas. 
Tabela 10. Coeficiente de correlação (r), índice de concordância (d) e de desempenho (c) e erros médio absoluto (EMA), máximo (EM), sistemático (Es) e aleatório (Ea), entre a ETo estimada pelos métodos de Priestley-Taylor $(\alpha=1,19)$ e de Penman-Monteith, nas escalas diária, qüinqüidial e decendial, em Paraipaba, CE.

\begin{tabular}{lccccccc}
\hline Escala de tempo & $\mathrm{r}$ & $\mathrm{d}$ & $\mathrm{c}$ & $\begin{array}{c}\text { EMA } \\
\left(\mathrm{mmd}^{-1}\right)\end{array}$ & $\begin{array}{c}\mathrm{EM} \\
\left(\mathrm{mmd}^{-1}\right)\end{array}$ & $\begin{array}{c}\text { Es } \\
\left(\mathrm{mmd}^{-1}\right)\end{array}$ & $\begin{array}{c}\mathrm{Ea} \\
\left(\mathrm{mmd}^{-1}\right)\end{array}$ \\
\hline Diária & 0,80 & 0,91 & 0,73 & 0,317 & 1,120 & 0,037 & 0,116 \\
Qüinqüidial & 0,68 & 0,79 & 0,54 & 0,295 & 0,803 & 0,044 & 0,079 \\
Decendial & 0,77 & 0,90 & 0,69 & 0,267 & 0,429 & 0,017 & 0,067 \\
\hline
\end{tabular}

Quando ajustado o valor de $\alpha$, a contribuição do termo aerodinâmico correspondente caiu de $26 \%$ para $19 \%$, o que induz ao raciocínio de que nas condições estudadas, tal termo deve contribuir, em média, com essa percentagem na estimativa da evapotranspiração de referência. Com base nesse fato, verifica-se que o termo energético contribui com 74\%. A observação está de acordo com Chang (1968) e Amatya et al. (1992). A demanda atmosférica durante todo o período analisado foi reduzida, em razão da estação chuvosa, haja visto que em quase todo o período a umidade relativa média esteve por volta de 75 a $90 \%$, e a velocidade do vento abaixo de $2 \mathrm{~m} . \mathrm{s}^{-1}$. Levando-se em consideração que os cuidados foram tomados com relação à manutenção da umidade no solo, com irrigações freqüentes (em intervalos comuns de dois dias), como observou Camargo (1962), o fator determinante da taxa de evapotranspiração foi a disponibilidade de energia, seja ela com adveccão ou não.

4.5 Análise geral dos métodos de estimativa de ETo nas escalas de tempo estudadas

$\mathrm{Na}$ Tabela 11 é apresentado uma ordenação dos métodos de estimativa de evapotranspiração de referência em relação ao método de Penman-Monteith, de acordo com desempenho determinado pelo índice "c", nas três escalas de tempo estudadas. 

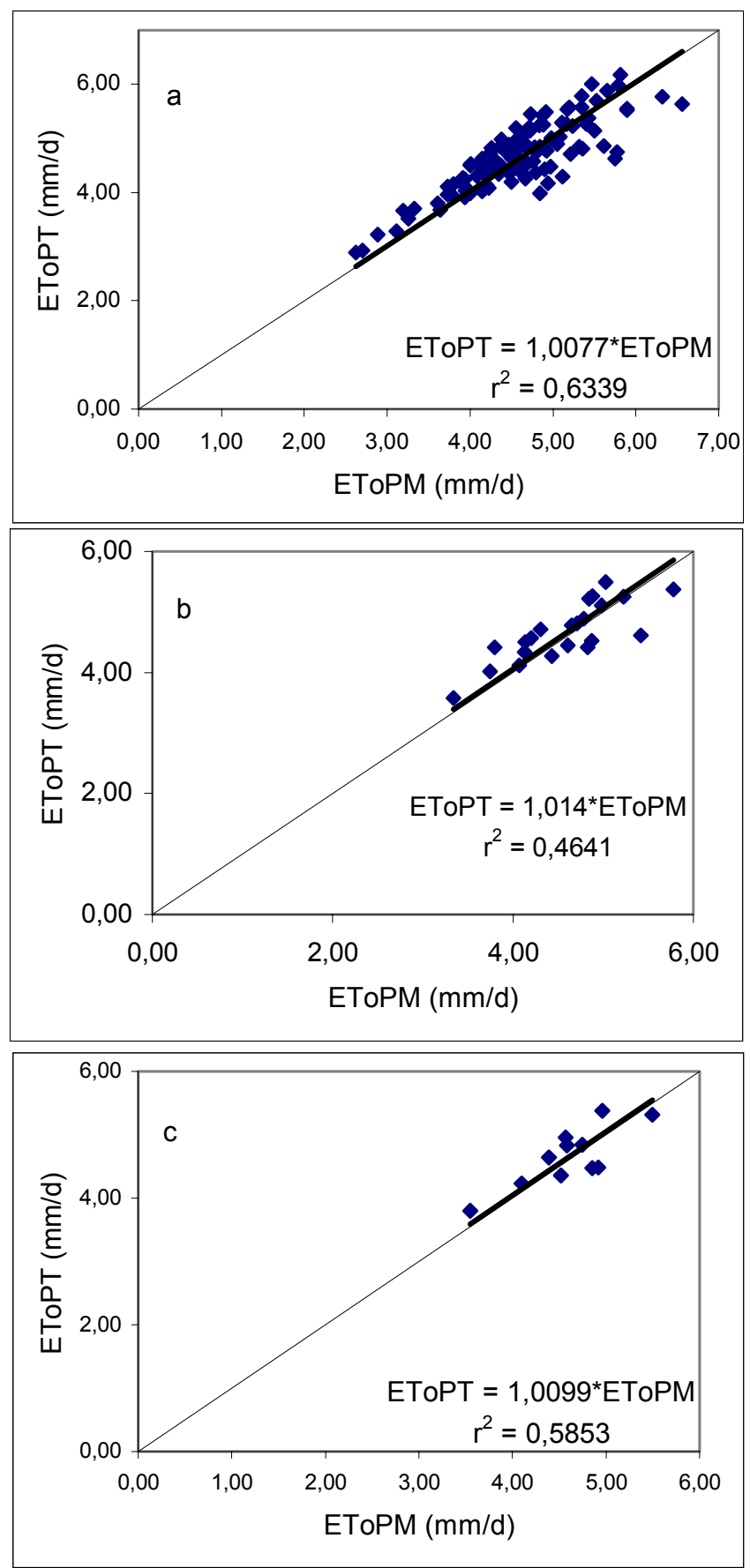

Figura 14 - Relação entre a evapotranspiração de referência estimada pelo método de Penman-Monteith (PM) e pelo método de Priestley-Taylor ajustado $(\alpha=$ 1,19), nas escalas diária (a), qüinqüidial (b) e decendial (c), em Paraipaba, CE, durante a estação chuvosa dos anos de 1997 e 1998. 
Nota-se que nas três escalas de tempo, predominam com melhor desempenho os métodos de Priestley-Taylor e Thornthwaite modificado por Camargo et al. (1999) ajustado com $\mathrm{f}=0,379$. O lisímetro mesmo na escala diária ficou em terceiro lugar, demonstrando um ajuste médio em relação ao método de Penman-Monteith, o que provavelmente está relacionado à cultura (grama) utilizada, manutenção e operação desse dispositivo para medida da evapotranspiração.

Com relação ao método de Hargreaves \& Samani, os resultados demonstraram melhor ajuste na escala qüinqüidial. Ficando em penúltimo lugar em relação a escala decendial. Desse modo, constata-se que o referido método não é uma boa opção para a estimativa da ETo nas condições do litoral Cearense.

O método do Tanque Classe $\mathrm{A}$ foi um dos piores nas escalas diária e qüinqüidial, passando a ter melhor desempenho na escala decendial, porém, permanecendo atrás dos métodos de Thornthwaite modificado e Priestley-Taylor.

O método de Thornthwaite original, em razão de ter sido desenvolvido para condições de clima úmido e para a escala mensal, teve seu melhor desempenho quando a ETo foi estimada a partir de dados decendiais. Porém, com a modificação proposta por Camargo et al. (1999), houve melhoria no desempenho das estimativas de ETo também na escala qüinqüidial. Essa melhoria foi ainda maior quando o fator $f$, proposto por Camargo et al. (1999), foi alterado para 0,379 e a ETp (evapotranspiração padrão) do método original de Thornthwaite foi calculada, independentemente da temperatura média, com a equação 27. Neste caso, o desempenho na escala diária ficou atrás apenas do método de Priestley-Taylor, enquanto que nas escalas qüinquidial e decendial, o desempenho foi o melhor entre os métodos analisados.

O método de Priestley-Taylor (1972) teve seu melhor desempenho nas escalas diária, ficando em segundo lugar. Nas escalas qüinqüidial e decendial, esse método apresentou inconsistências, ficando, respectivamente, em quarto e terceiro lugar. Quando ajustado o parâmetro $\alpha$ para 1,19, o método passou a estimar a ETo com melhor exatidão, ocupando no "ranking" de desempenho o primeiro lugar na escala diária e o segundo lugar nas escalas qüinqüidial e decendial. Provavelmente, esse novo valor de $\alpha$ 
não será o mesmo para o período seco, que vai julho a fevereiro, devendo assumir valor acima do valor original $(1,26)$.

Tabela 11. "Ranking" dos métodos de estimativa de evapotranspiração de referência (ETo), com base na ordenação decrescente do índice de desempenho "c", na base diária, qüinqüidial e decendial, em relação ao método de PenmanMonteith.

\begin{tabular}{clll}
\hline "Ranking" & Diária & Qüinqüidial & Decendial \\
\hline 1 & Priestley-Taylor $(1,19)$ & Thorthw. mod $(0,379)$ & Thorthw. mod $(0,379)$ \\
2 & Priestley-Taylor $(1,26)$ & Priestley-Taylor $(1,19)$ & Priestley-Taylor $(1,19)$ \\
3 & Thorthw. mod $(0,379)$ & Thorthwaite (Tef) & Priestley-Taylor $(1,26)$ \\
4 & Lisímetro & Priestley-Taylor $(1,26)$ & Tanque Classe A \\
5 & Thorthwaite (Tef) & Hargreaves - Samani & Thorthwaite $(1948)$ \\
6 & Hargreaves - Samani & Lisímetro & Thorthw mod $(0,380)$ \\
7 & Tanque Classe A & Tanque Classe A & Thorthwaite (Tef) \\
8 & Thorthwaite (1948) & Thorthwaite (1948) & Hargreaves - Samani \\
9 & Thorthw. mod (0,380) & Thorthw. mod $(0,380)$ & Lisímetro \\
\hline
\end{tabular}




\section{CONCLUSÕES}

Os resultados obtidos no presente estudo permitiram concluir que:

$1 \mathrm{O}$ desempenho dos métodos de estimativa de ETo, em relação às estimativas feita pelo método padrão de Penman-Monteith, variam com a escala de tempo adotada.

2 As medidas lisimétricas de ETo não apresentaram desempenho satisfatório nas três escalas adotadas, havendo piora com o aumento do intervalo de tempo considerado.

3 Dentre os métodos de estimativa de ETo analisados, os que apresentaram melhor desempenho nas três escalas de tempo, foram aqueles que sofreram ajuste local: Thornthwaite modificado por Camargo et al. (1999) ( $f=0,379)$, nas escalas qüinqüidial e decendial, Priestley-Taylor $(\alpha=1,19)$, na escala diária.

4. Os métodos que apresentaram pior desempenho foram os de Thornthwaite, Thornthwaite modificado por Camargo et al. (1999) ( $\mathrm{f}=0,380)$, Tanque Classe A e Hagreaves \& Samani, não sendo recomendado seu uso para a estimativa de ETo, nas condições semelhantes às deste estudo, por apresentarem baixa exatidão e precisão. 
ANEXOS 
Anexo A. Dados meteorológicos referentes aos meses de março a junho de 1997 e 1998, em Paraipaba, CE.

\begin{tabular}{|c|c|c|c|c|c|c|c|c|}
\hline Data & $\begin{array}{c}\mathrm{J} \\
\text { Dia juliano }\end{array}$ & $\begin{array}{l}\text { Tmáx } \\
{ }^{\circ} \mathrm{C}\end{array}$ & $\begin{array}{l}\text { Tmín } \\
{ }^{\circ} \mathrm{C}\end{array}$ & $\begin{array}{l}\text { Tméd } \\
{ }^{\circ} \mathrm{C}\end{array}$ & $\begin{array}{c}\text { URmáx } \\
\%\end{array}$ & $\begin{array}{c}\text { URmín } \\
\%\end{array}$ & $\begin{array}{l}\text { V. vent } \\
\mathrm{m} / \mathrm{s}\end{array}$ & $\begin{array}{c}\text { Rs } \\
\mathrm{MJ} / \mathrm{m}^{2} . \mathrm{dia}\end{array}$ \\
\hline $01 / 03 / 97$ & 60 & 31,40 & 22,27 & 26,66 & 99,00 & 60,24 & 2,1988 & 18,266 \\
\hline $02 / 03 / 97$ & 61 & 31,34 & 23,32 & 27,46 & 95,80 & 55,30 & 2,2455 & 25,688 \\
\hline $05 / 03 / 97$ & 64 & 31,90 & 24,83 & 27,97 & 98,40 & 59,32 & 3,0515 & 19,694 \\
\hline $06 / 03 / 97$ & 65 & 32,27 & 24,99 & 27,94 & 94,80 & 56,19 & 2,6561 & 22,191 \\
\hline $07 / 03 / 97$ & 66 & 32,10 & 23,73 & 27,51 & 99,70 & 56,28 & 2,7540 & 25,754 \\
\hline $08 / 03 / 97$ & 67 & 30,98 & 23,62 & 27,02 & 98,20 & 63,82 & 2,5582 & 18,346 \\
\hline $11 / 03 / 97$ & 70 & 33,28 & 25,14 & 28,60 & 92,30 & 49,81 & 4,0931 & 24,031 \\
\hline $13 / 03 / 97$ & 72 & 33,11 & 23,67 & 27,82 & 98,20 & 52,29 & 3,1781 & 23,658 \\
\hline $14 / 03 / 97$ & 73 & 33,34 & 23,66 & 28,06 & 99,80 & 52,67 & 3,2685 & 23,600 \\
\hline $15 / 03 / 97$ & 74 & 33,04 & 23,52 & 27,85 & 97,10 & 44,91 & 2,9357 & 25,443 \\
\hline $16 / 03 / 97$ & 75 & 32,22 & 22,97 & 27,18 & 100,00 & 55,07 & 2,4047 & 22,492 \\
\hline $18 / 03 / 97$ & 77 & 32,53 & 23,70 & 27,67 & 99,80 & 52,06 & 2,2896 & 23,104 \\
\hline $20 / 03 / 97$ & 79 & 33,09 & 24,95 & 28,55 & 94,10 & 55,17 & 2,9513 & 20,091 \\
\hline $23 / 03 / 97$ & 82 & 30,21 & 23,54 & 26,38 & 100,00 & 68,96 & 1,4957 & 20,386 \\
\hline $29 / 03 / 97$ & 88 & 30,56 & 22,41 & 25,94 & 100,00 & 62,67 & 2,0997 & 22,968 \\
\hline $30 / 03 / 97$ & 89 & 31,75 & 23,16 & 26,90 & 100,00 & 59,01 & 1,9080 & 24,014 \\
\hline $01 / 04 / 97$ & 91 & 30,12 & 23,10 & 26,30 & 100,00 & 66,19 & 1,5560 & 18,047 \\
\hline $05 / 04 / 97$ & 95 & 29,40 & 23,41 & 26,12 & 100,00 & 77,20 & 1,3941 & 14,987 \\
\hline $07 / 04 / 97$ & 97 & 30,87 & 24,57 & 27,08 & 100,00 & 64,59 & 2,6649 & 18,885 \\
\hline $08 / 04 / 97$ & 98 & 30,73 & 23,47 & 26,54 & 100,00 & 69,15 & 2,0818 & 20,589 \\
\hline $16 / 04 / 97$ & 106 & 31,19 & 22,28 & 26,36 & 100,00 & 62,03 & 2,2527 & 21,326 \\
\hline $17 / 04 / 97$ & 107 & 31,36 & 21,99 & 26,54 & 100,00 & 56,24 & 2,3781 & 22,258 \\
\hline $19 / 04 / 97$ & 109 & 31,04 & 21,66 & 25,89 & 100,00 & 59,75 & 2,0001 & 20,675 \\
\hline $20 / 04 / 97$ & 110 & 31,23 & 21,82 & 26,20 & 100,00 & 63,38 & 1,8238 & 19,621 \\
\hline $21 / 04 / 97$ & 111 & 32,44 & 23,28 & 27,07 & 100,00 & 55,59 & 1,8361 & 21,019 \\
\hline $27 / 04 / 97$ & 117 & 30,67 & 23,01 & 26,03 & 100,00 & 67,80 & 1,8530 & 19,435 \\
\hline $28 / 04 / 97$ & 118 & 30,99 & 22,80 & 26,41 & 100,00 & 71,40 & 1,7305 & 21,579 \\
\hline $29 / 04 / 97$ & 119 & 30,53 & 22,95 & 25,74 & 100,00 & 68,23 & 1,4947 & 17,945 \\
\hline $30 / 04 / 97$ & 120 & 30,51 & 22,77 & 26,01 & 100,00 & 69,37 & 1,4640 & 17,623 \\
\hline
\end{tabular}


Anexo A. Dados meteorológicos referentes aos meses de março a junho de 1997 e 1998, em Paraipaba, CE.

\begin{tabular}{|c|c|c|c|c|c|c|c|c|}
\hline Data & $\begin{array}{c}\mathrm{J} \\
\text { Dia juliano }\end{array}$ & $\begin{array}{c}\text { Tmáx } \\
{ }^{\circ} \mathrm{C}\end{array}$ & $\begin{array}{l}\text { Tmín } \\
{ }^{\circ} \mathrm{C}\end{array}$ & $\begin{array}{l}\text { Tméd } \\
{ }^{\circ} \mathrm{C}\end{array}$ & $\begin{array}{c}\text { URmáx } \\
\%\end{array}$ & $\begin{array}{c}\text { URmín } \\
\%\end{array}$ & $\begin{array}{c}\text { V. vent } \\
\mathrm{m} / \mathrm{s}\end{array}$ & $\begin{array}{c}\text { Rs } \\
\mathrm{MJ} / \mathrm{m}^{2} \cdot \mathrm{dia}\end{array}$ \\
\hline $01 / 05 / 97$ & 121 & 30,85 & 23,33 & 26,58 & 100,0 & 59,14 & 1,9032 & 21,181 \\
\hline $07 / 05 / 97$ & 127 & 28,70 & 22,88 & 25,49 & 100,0 & 77,30 & 1,6003 & 11,804 \\
\hline $08 / 05 / 97$ & 128 & 30,06 & 22,36 & 25,78 & 100,0 & 71,40 & 1,7608 & 19,900 \\
\hline $09 / 05 / 97$ & 129 & 31,36 & 21,97 & 26,05 & 100,0 & 59,09 & 1,7509 & 20,998 \\
\hline $11 / 05 / 97$ & 131 & 29,96 & 22,76 & 25,70 & 100,0 & 70,20 & 1,6488 & 13,801 \\
\hline $12 / 05 / 97$ & 132 & 31,16 & 22,35 & 26,31 & 100,0 & 60,09 & 1,6167 & 21,194 \\
\hline $14 / 05 / 97$ & 134 & 29,67 & 22,26 & 25,57 & 100,0 & 74,60 & 1,1118 & 13,552 \\
\hline $15 / 05 / 97$ & 135 & 30,59 & 22,49 & 25,59 & 100,0 & 66,39 & 1,6404 & 16,558 \\
\hline $21 / 05 / 97$ & 141 & 28,31 & 22,14 & 24,54 & 100,0 & 75,50 & 1,8164 & 12,383 \\
\hline $22 / 05 / 97$ & 142 & 28,76 & 21,78 & 25,11 & 100,0 & 73,10 & 2,2765 & 15,399 \\
\hline $26 / 05 / 97$ & 146 & 30,41 & 21,04 & 25,16 & 100,0 & 63,56 & 1,8547 & 20,506 \\
\hline $27 / 05 / 97$ & 147 & 30,63 & 21,91 & 25,64 & 100,0 & 66,01 & 2,3867 & 20,750 \\
\hline $29 / 05 / 97$ & 149 & 29,46 & 22,42 & 25,45 & 100,0 & 64,42 & 2,1667 & 18,620 \\
\hline $01 / 06 / 97$ & 152 & 30,31 & 21,95 & 25,82 & 100,0 & 67,80 & 1,9403 & 19,048 \\
\hline $05 / 06 / 97$ & 156 & 30,79 & 20,83 & 25,07 & 100,0 & 64,99 & 2,1248 & 20,511 \\
\hline $07 / 06 / 97$ & 158 & 30,45 & 19,85 & 24,88 & 100,0 & 63,66 & 2,1266 & 20,327 \\
\hline $08 / 06 / 97$ & 159 & 30,00 & 21,06 & 25,20 & 100,0 & 64,00 & 1,9304 & 20,018 \\
\hline $09 / 06 / 97$ & 160 & 29,88 & 20,13 & 24,65 & 100,0 & 65,85 & 1,8810 & 18,375 \\
\hline $11 / 06 / 97$ & 162 & 30,82 & 21,99 & 25,72 & 100,0 & 53,74 & 2,4220 & 19,596 \\
\hline $13 / 06 / 97$ & 164 & 29,80 & 20,54 & 24,81 & 100,0 & 64,33 & 2,0652 & 16,821 \\
\hline $15 / 06 / 97$ & 166 & 30,27 & 19,61 & 24,96 & 100,0 & 61,82 & 2,4335 & 21,119 \\
\hline $16 / 06 / 97$ & 167 & 31,09 & 20,33 & 25,31 & 100,0 & 56,72 & 2,2084 & 21,173 \\
\hline $17 / 06 / 97$ & 168 & 30,89 & 21,93 & 25,74 & 100,0 & 62,86 & 2,2067 & 17,651 \\
\hline $19 / 06 / 97$ & 170 & 30,61 & 20,32 & 25,20 & 100,0 & 53,63 & 2,5320 & 20,881 \\
\hline $20 / 06 / 97$ & 171 & 31,18 & 22,73 & 25,99 & 100,0 & 58,85 & 2,3151 & 18,493 \\
\hline $22 / 06 / 97$ & 173 & 30,48 & 23,22 & 26,11 & 100,0 & 54,76 & 2,7071 & 21,309 \\
\hline $24 / 06 / 97$ & 175 & 31,00 & 20,61 & 25,34 & 100,0 & 55,57 & 2,3414 & 21,382 \\
\hline $25 / 06 / 97$ & 176 & 30,66 & 21,91 & 25,62 & 100,0 & 54,80 & 2,4431 & 21,474 \\
\hline $26 / 06 / 97$ & 177 & 31,50 & 20,46 & 25,84 & 100,0 & 49,74 & 2,6508 & 21,551 \\
\hline $28 / 06 / 97$ & 179 & 30,17 & 22,33 & 25,81 & 99,8 & 63,13 & 2,4544 & 20,023 \\
\hline $29 / 06 / 97$ & 180 & 30,55 & 20,21 & 25,12 & 100,0 & 54,53 & 2,1125 & 20,934 \\
\hline $06 / 03 / 98$ & 65 & 32,17 & 25,72 & 28,38 & 100,00 & 63,41 & 2,4727 & 24,759 \\
\hline $07 / 03 / 98$ & 66 & 31,51 & 24,67 & 27,78 & 100,00 & 67,36 & 2,2380 & 22,701 \\
\hline $08 / 03 / 98$ & 67 & 33,06 & 23,46 & 27,63 & 100,00 & 58,29 & 2,2642 & 26,384 \\
\hline $12 / 03 / 98$ & 71 & 31,41 & 23,90 & 27,11 & 100,00 & 69,43 & 1,5722 & 18,993 \\
\hline $15 / 03 / 98$ & 74 & 31,87 & 25,11 & 27,92 & 100,00 & 65,04 & 1,7348 & 21,395 \\
\hline 29/03/98 & 88 & 30,80 & 24,30 & 26,94 & 100,00 & 67,46 & 1,8122 & 16,166 \\
\hline
\end{tabular}


Anexo A. Dados meteorológicos referentes aos meses de março a junho de 1997 e 1998, em Paraipaba, CE.

\begin{tabular}{|c|c|c|c|c|c|c|c|c|}
\hline Data & $\begin{array}{c}\mathrm{J} \\
\text { Dia juliano }\end{array}$ & $\begin{array}{c}\text { Tmáx } \\
{ }^{\circ} \mathrm{C}\end{array}$ & $\begin{array}{l}\text { Tmín } \\
{ }^{\circ} \mathrm{C}\end{array}$ & $\begin{array}{l}\text { Tméd } \\
{ }^{\circ} \mathrm{C}\end{array}$ & $\begin{array}{c}\text { URmáx } \\
\%\end{array}$ & $\begin{array}{c}\text { URmín } \\
\%\end{array}$ & $\begin{array}{c}\text { V. vent } \\
\mathrm{m} / \mathrm{s}\end{array}$ & $\begin{array}{c}\text { Rs } \\
\mathrm{MJ} / \mathrm{m}^{2} \cdot \mathrm{dia}\end{array}$ \\
\hline $03 / 04 / 98$ & 93 & 31,86 & 23,58 & 27,45 & 100,00 & 72,60 & 2,0538 & 22,708 \\
\hline $04 / 04 / 98$ & 94 & 32,08 & 25,09 & 27,89 & 100,00 & 62,05 & 2,3195 & 23,426 \\
\hline $05 / 04 / 98$ & 95 & 32,61 & 23,88 & 27,90 & 100,00 & 63,16 & 2,3319 & 24,475 \\
\hline $06 / 04 / 98$ & 96 & 32,74 & 24,11 & 27,76 & 100,00 & 57,87 & 2,1757 & 23,779 \\
\hline $10 / 04 / 98$ & 100 & 32,15 & 24,97 & 27,97 & 100,00 & 66,12 & 2,0602 & 21,324 \\
\hline $11 / 04 / 98$ & 101 & 31,97 & 24,37 & 28,01 & 100,00 & 67,60 & 2,1224 & 22,678 \\
\hline $15 / 04 / 98$ & 105 & 31,90 & 25,26 & 27,69 & 100,00 & 66,50 & 1,9475 & 19,795 \\
\hline $16 / 04 / 98$ & 106 & 31,93 & 24,60 & 27,70 & 100,00 & 65,05 & 1,8643 & 21,123 \\
\hline $21 / 04 / 98$ & 111 & 33,02 & 23,65 & 27,99 & 100,00 & 56,74 & 2,3283 & 24,671 \\
\hline $22 / 04 / 98$ & 112 & 32,67 & 24,55 & 28,30 & 100,00 & 58,75 & 2,4980 & 22,344 \\
\hline $24 / 04 / 98$ & 114 & 31,58 & 23,38 & 27,23 & 100,00 & 71,90 & 2,0160 & 22,009 \\
\hline $26 / 04 / 98$ & 116 & 31,45 & 23,35 & 26,65 & 100,00 & 74,30 & 1,3658 & 15,167 \\
\hline $29 / 04 / 98$ & 119 & 31,44 & 23,70 & 27,22 & 100,00 & 72,30 & 1,6623 & 18,852 \\
\hline $30 / 04 / 98$ & 120 & 31,68 & 24,79 & 27,69 & 100,00 & 68,21 & 2,2334 & 20,492 \\
\hline 03/05/98 & 123 & 31,64 & 24,71 & 27,37 & 100,00 & 71,00 & 1,9427 & 19,791 \\
\hline $05 / 05 / 98$ & 125 & 31,82 & 23,48 & 27,19 & 100,00 & 62,63 & 2,1804 & 21,251 \\
\hline $12 / 05 / 98$ & 132 & 32,23 & 23,91 & 27,18 & 100,00 & 58,25 & 2,1729 & 23,430 \\
\hline $14 / 05 / 98$ & 134 & 32,19 & 24,98 & 28,06 & 100,00 & 52,02 & 2,6541 & 18,851 \\
\hline $16 / 05 / 98$ & 136 & 32,13 & 24,67 & 27,76 & 98,10 & 58,44 & 2,4027 & 20,622 \\
\hline $17 / 05 / 98$ & 137 & 31,76 & 22,57 & 26,96 & 100,00 & 65,32 & 1,7932 & 21,840 \\
\hline $19 / 05 / 98$ & 139 & 31,63 & 24,72 & 27,43 & 100,00 & 68,19 & 2,6466 & 16,868 \\
\hline $21 / 05 / 98$ & 141 & 31,59 & 23,85 & 27,22 & 100,00 & 64,07 & 2,3165 & 23,202 \\
\hline $24 / 05 / 98$ & 144 & 32,36 & 23,64 & 27,81 & 97,40 & 58,89 & 2,6574 & 22,318 \\
\hline $26 / 05 / 98$ & 146 & 32,68 & 24,00 & 27,74 & 100,00 & 54,14 & 3,3088 & 22,984 \\
\hline $30 / 05 / 98$ & 150 & 32,81 & 24,23 & 27,56 & 100,00 & 61,55 & 2,1498 & 17,630 \\
\hline $31 / 05 / 98$ & 151 & 32,13 & 23,53 & 27,32 & 100,00 & 56,91 & 2,2184 & 21,718 \\
\hline $02 / 06 / 98$ & 153 & 32,19 & 23,64 & 27,53 & 98,10 & 48,23 & 3,3770 & 22,414 \\
\hline $04 / 06 / 98$ & 155 & 31,88 & 21,08 & 26,48 & 100,00 & 39,35 & 2,2621 & 19,013 \\
\hline $06 / 06 / 98$ & 157 & 31,56 & 24,08 & 27,17 & 96,20 & 53,27 & 2,4886 & 19,126 \\
\hline $07 / 06 / 98$ & 158 & 31,52 & 22,65 & 26,63 & 98,20 & 52,87 & 2,8418 & 20,446 \\
\hline 09/06/98 & 160 & 32,67 & 22,44 & 27,35 & 100,00 & 51,01 & 2,8150 & 21,681 \\
\hline $11 / 06 / 98$ & 162 & 32,43 & 23,23 & 27,68 & 98,40 & 56,86 & 2,6605 & 22,064 \\
\hline $15 / 06 / 98$ & 166 & 32,25 & 23,27 & 26,90 & 100,00 & 49,62 & 3,0018 & 18,979 \\
\hline $17 / 06 / 98$ & 168 & 31,29 & 22,10 & 26,02 & 100,00 & 60,62 & 2,0558 & 20,297 \\
\hline $18 / 06 / 98$ & 169 & 31,02 & 22,83 & 26,54 & 100,00 & 59,73 & 2,3500 & 18,010 \\
\hline $21 / 06 / 98$ & 172 & 31,23 & 22,23 & 26,41 & 100,00 & 62,49 & 2,4363 & 21,070 \\
\hline $22 / 06 / 98$ & 173 & 31,22 & 23,75 & 27,02 & 99,50 & 57,20 & 2,8242 & 21,874 \\
\hline $23 / 06 / 98$ & 174 & 32,01 & 22,76 & 26,84 & 97,00 & 40,19 & 3,1239 & 22,425 \\
\hline $25 / 06 / 98$ & 176 & 30,87 & 23,16 & 26,35 & 100,00 & 63,48 & 2,4442 & 17,631 \\
\hline $27 / 06 / 98$ & 178 & 31,65 & 24,00 & 27,09 & 96,90 & 54,64 & 3,6773 & 22,026 \\
\hline $28 / 06 / 98$ & 179 & 33,46 & 23,81 & 27,05 & 100,00 & 40,85 & 2,8192 & 22,385 \\
\hline $30 / 06 / 98$ & 181 & 31,76 & 24,44 & 27,33 & 95,60 & 50,56 & 3,2692 & 19,450 \\
\hline
\end{tabular}


Anexo B. Evapotranspiração de referência $(\mathrm{mm} / \mathrm{d})$ determinada pelos métodos de Penman-Monteith e lisímetro, com base em dados diários.

\begin{tabular}{|c|c|c|c|c|c|}
\hline Data & P-Monteith & Lisímetro & Data & P-Monteith & Lisímetro \\
\hline $01 / 03 / 97$ & 4,3498 & 3,4467 & 07/06/97 & 4,1779 & 4,0363 \\
\hline $02 / 03 / 97$ & 5,6510 & 4,8526 & 08/06/97 & 4,0812 & 4,1148 \\
\hline 05/03/97 & 4,9194 & 3,9002 & 09/06/97 & 3,7740 & 3,6735 \\
\hline 06/03/97 & 5,4006 & 5,4875 & $11 / 06 / 97$ & 4,4970 & 4,2630 \\
\hline $07 / 03 / 97$ & 5,7913 & 5,8957 & $13 / 06 / 97$ & 3,6422 & 3,2653 \\
\hline 08/03/97 & 4,3496 & 3,9270 & $15 / 06 / 97$ & 4,3636 & 3,9002 \\
\hline $11 / 03 / 97$ & 6,5614 & 7,5737 & $16 / 06 / 97$ & 4,5407 & 4,2630 \\
\hline $13 / 03 / 97$ & 5,8956 & 5,3515 & $17 / 06 / 97$ & 3,9407 & 3,5828 \\
\hline $14 / 03 / 97$ & 5,8973 & 4,1723 & $19 / 06 / 97$ & 4,6320 & 5,5329 \\
\hline $15 / 03 / 97$ & 6,3182 & 6,2132 & 20/06/97 & 4,2296 & 4,0363 \\
\hline $16 / 03 / 97$ & 5,2385 & 5,6689 & $22 / 06 / 97$ & 4,7603 & 4,6467 \\
\hline $18 / 03 / 97$ & 5,4281 & 6,4399 & $24 / 06 / 97$ & 4,6317 & 4,4444 \\
\hline $20 / 03 / 97$ & 5,3168 & 5,8957 & $25 / 06 / 97$ & 4,6897 & 4,4898 \\
\hline $23 / 03 / 97$ & 4,2548 & 5,2082 & $26 / 06 / 97$ & 4,9747 & 4,8980 \\
\hline 29/03/97 & 4,8317 & 5,6531 & 28/06/97 & 4,2544 & 4,2177 \\
\hline $30 / 03 / 97$ & 5,1701 & 6,2794 & 29/06/97 & 4,4735 & 4,4898 \\
\hline 01/04/97 & 3,9157 & 4,7619 & 06/03/98 & 5,4704 & 5,3696 \\
\hline $05 / 04 / 97$ & 3,1925 & 3,3769 & 07/03/98 & 4,9144 & 4,9433 \\
\hline $07 / 04 / 97$ & 4,3642 & 4,8472 & 08/03/98 & 5,8132 & 5,6689 \\
\hline 08/04/97 & 4,3631 & 5,2608 & $12 / 03 / 98$ & 4,1456 & 4,0866 \\
\hline $16 / 04 / 97$ & 4,6600 & 5,2608 & $15 / 03 / 98$ & 4,7179 & 4,7619 \\
\hline $17 / 04 / 97$ & 4,9810 & 5,5782 & $29 / 03 / 98$ & 3,7249 & 3,8181 \\
\hline $19 / 04 / 97$ & 4,5196 & 4,9887 & 03/04/98 & 4,7342 & 4,2177 \\
\hline $20 / 04 / 97$ & 4,2681 & 4,4984 & $04 / 04 / 98$ & 5,1958 & 4,3447 \\
\hline $21 / 04 / 97$ & 4,7807 & 5,3968 & 05/04/98 & 5,3467 & 4,4444 \\
\hline $27 / 04 / 97$ & 4,1144 & 4,8404 & 06/04/98 & 5,3484 & 5,2154 \\
\hline $28 / 04 / 97$ & 4,3784 & 4,9887 & $10 / 04 / 98$ & 4,7191 & 4,2630 \\
\hline $29 / 04 / 97$ & 3,7995 & 4,0816 & $11 / 04 / 98$ & 4,8780 & 4,6712 \\
\hline $30 / 04 / 97$ & 3,7275 & 3,7361 & $15 / 04 / 98$ & 4,4192 & 4,0363 \\
\hline $01 / 05 / 97$ & 4,5785 & 5,1125 & $16 / 04 / 98$ & 4,6286 & 4,4444 \\
\hline $07 / 05 / 97$ & 2,6182 & 2,6390 & $21 / 04 / 98$ & 5,5286 & 5,8957 \\
\hline 08/05/97 & 4,0110 & 3,6577 & $22 / 04 / 98$ & 5,1637 & 4,9887 \\
\hline $09 / 05 / 97$ & 4,4872 & 4,1270 & $24 / 04 / 98$ & 4,5552 & 3,9002 \\
\hline $11 / 05 / 97$ & 3,1118 & 2,7628 & $26 / 04 / 98$ & 3,3288 & 2,5850 \\
\hline $12 / 05 / 97$ & 4,4507 & 4,2630 & 29/04/98 & 4,0038 & 3,7397 \\
\hline $14 / 05 / 97$ & 2,8862 & 2,8118 & $30 / 04 / 98$ & 4,4700 & 4,4077 \\
\hline $15 / 05 / 97$ & 3,6103 & 3,7029 & 03/05/98 & 4,2389 & 4,3048 \\
\hline $21 / 05 / 97$ & 2,7001 & 2,3057 & 05/05/98 & 4,6644 & 4,4444 \\
\hline $22 / 05 / 97$ & 3,2534 & 2,7592 & $12 / 05 / 98$ & 5,1099 & 5,0340 \\
\hline $26 / 05 / 97$ & 4,1951 & 4,1270 & $14 / 05 / 98$ & 4,7925 & 4,7619 \\
\hline $27 / 05 / 97$ & 4,3175 & 3,6735 & $16 / 05 / 98$ & 4,7998 & 4,6259 \\
\hline $29 / 05 / 97$ & 3,9370 & 3,5252 & $17 / 05 / 98$ & 4,5494 & 4,7619 \\
\hline 01/06/97 & 3,9373 & 3,6281 & $19 / 05 / 98$ & 3,9412 & 3,3524 \\
\hline 05/06/97 & 4,2249 & 3,6612 & $21 / 05 / 98$ & 4,8837 & 4,5351 \\
\hline
\end{tabular}


Anexo B. Evapotranspiração de referência $(\mathrm{mm} / \mathrm{d})$ determinada pelos métodos de Penman-Monteith e lisímetro, com base em dados diários.

\begin{tabular}{lccccc}
\hline Data & P-Monteith & Lisímetro & Data & P-Monteith & Lisímetro \\
\hline $24 / 05 / 98$ & 5,0841 & 5,2154 & $15 / 06 / 98$ & 4,9405 & 3,6159 \\
$26 / 05 / 98$ & 5,5011 & 4,4898 & $17 / 06 / 98$ & 4,3566 & 4,1270 \\
$30 / 05 / 98$ & 4,2019 & 3,2200 & $18 / 06 / 98$ & 4,1425 & 3,8549 \\
$31 / 05 / 98$ & 4,8394 & 4,1723 & $21 / 06 / 98$ & 4,5085 & 4,1270 \\
$02 / 06 / 98$ & 5,6107 & 4,1270 & $22 / 06 / 98$ & 4,9068 & 4,3084 \\
$04 / 06 / 98$ & 4,8391 & 3,2653 & $23 / 06 / 98$ & 5,7487 & 4,5351 \\
$06 / 06 / 98$ & 4,6696 & 3,7188 & $25 / 06 / 98$ & 4,0035 & 3,6785 \\
$07 / 06 / 98$ & 4,9006 & 3,9909 & $27 / 06 / 98$ & 5,3599 & 4,7166 \\
$09 / 06 / 98$ & 5,2100 & 4,3991 & $28 / 06 / 98$ & 5,7733 & 4,6259 \\
$11 / 06 / 98$ & 5,0517 & 3,8095 & $30 / 06 / 98$ & 5,1195 & 3,9002 \\
\hline
\end{tabular}

Anexo C. Evapotranspiração de referência $(\mathrm{mm} / \mathrm{d})$ determinada pelos métodos de Thornthwaite, Thornthwaite modificado(Tef), Thornthwaite $(0,380)$, Thornthwaite $(0,379)$ e Priestley-Taylor $(1,26)$, com base em dados diários

\begin{tabular}{lccccc}
\hline Data & Thornthwaite & Thornt (Tef) & Thor $(0,380)$ & Thor $(0,379)$ & P-Tay $(1,26)$ \\
\hline $01 / 03 / 97$ & 4,6798 & 4,0307 & 4,8292 & 4,9288 & 4,5941 \\
$02 / 03 / 97$ & 4,8270 & 3,7668 & 4,6881 & 4,6062 & 6,2301 \\
$05 / 03 / 97$ & 5,1107 & 3,7995 & 4,7044 & 4,6462 & 5,0533 \\
$06 / 03 / 97$ & 5,1780 & 4,0017 & 4,8110 & 4,8934 & 5,5771 \\
$07 / 03 / 97$ & 4,9871 & 4,1666 & 4,8923 & 5,0950 & 6,3316 \\
$08 / 03 / 97$ & 4,8111 & 3,4821 & 4,3021 & 4,2580 & 4,6745 \\
$11 / 03 / 97$ & 5,3144 & 4,6855 & 5,1085 & 5,6997 & 5,9637 \\
$13 / 03 / 97$ & 5,1070 & 4,7867 & 5,1994 & 5,9885 & 5,8456 \\
$14 / 03 / 97$ & 5,1342 & 4,8587 & 5,2638 & 6,2066 & 5,8708 \\
$15 / 03 / 97$ & 5,0755 & 4,7779 & 5,1910 & 5,9669 & 6,1139 \\
$16 / 03 / 97$ & 4,8863 & 4,5671 & 4,9996 & 5,3972 & 5,5370 \\
$18 / 03 / 97$ & 5,0276 & 4,5873 & 5,0177 & 5,4520 & 5,6981 \\
$20 / 03 / 97$ & 5,2565 & 4,6329 & 5,0588 & 5,5743 & 5,1284 \\
$23 / 03 / 97$ & 4,6660 & 3,0523 & 3,7712 & 3,7325 & 5,1031 \\
$29 / 03 / 97$ & 4,3709 & 3,4537 & 4,2670 & 4,2233 & 5,5435 \\
$30 / 03 / 97$ & 4,8289 & 4,0360 & 4,8114 & 4,9354 & 5,8585 \\
$01 / 04 / 97$ & 4,5738 & 3,0756 & 3,7999 & 3,7609 & 4,5255 \\
$05 / 04 / 97$ & 4,3118 & 2,6542 & 3,2793 & 3,2456 & 3,8833 \\
$07 / 04 / 97$ & 4,8940 & 3,2126 & 3,9692 & 3,9285 & 4,7840 \\
$08 / 04 / 97$ & 4,7145 & 3,3392 & 4,1256 & 4,0833 & 5,1334 \\
$16 / 04 / 97$ & 4,5953 & 3,8473 & 4,7023 & 4,7046 & 5,1633 \\
$17 / 04 / 97$ & 4,5758 & 4,0180 & 4,7899 & 4,9133 & 5,3016 \\
$19 / 04 / 97$ & 4,2621 & 3,8805 & 4,7180 & 4,7452 & 4,9369 \\
$20 / 04 / 97$ & 4,5260 & 3,9674 & 4,7623 & 4,8514 & 4,7733 \\
$21 / 04 / 97$ & 4,9160 & 4,5651 & 4,9903 & 5,4488 & 5,1192 \\
$27 / 04 / 97$ & 4,6155 & 3,3774 & 4,1728 & 4,1300 & 4,7531 \\
$28 / 04 / 97$ & 4,6310 & 3,6062 & 4,5609 & 4,4097 & 5,2810 \\
$29 / 04 / 97$ & 4,5830 & 3,3075 & 4,0864 & 4,0445 & 4,4055 \\
$30 / 04 / 97$ & 4,5514 & 3,3295 & 4,3902 & 4,0714 & 4,3518
\end{tabular}


Anexo C. Evapotranspiração de referência $(\mathrm{mm} / \mathrm{d})$ determinada pelos métodos de Thornthwaite, Thornthwaite modificado(Tef), Thornthwaite $(0,380)$, Thornthwaite $(0,379)$ e Priestley-Taylor $(1,26)$, com base em dados diários

\begin{tabular}{|c|c|c|c|c|c|}
\hline Data & Thornthwaite & Thornt (Tef) & Thor $(0,380)$ & Thor $(0,379)$ & P-Tay $(1,26)$ \\
\hline $01 / 05 / 97$ & 4,6861 & 3,4167 & 4,2213 & 4,1781 & 5,0755 \\
\hline 07/05/97 & 3,9032 & 2,3936 & 2,9573 & 2,9270 & 3,0637 \\
\hline 08/05/97 & 4,1569 & 3,1497 & 3,8915 & 3,8516 & 4,7914 \\
\hline $09 / 05 / 97$ & 4,5507 & 4,0030 & 4,7690 & 4,8950 & 4,9361 \\
\hline $11 / 05 / 97$ & 4,4541 & 3,0228 & 3,7346 & 3,6963 & 3,4762 \\
\hline $12 / 05 / 97$ & 4,5756 & 3,7922 & 4,6579 & 4,6373 & 4,9979 \\
\hline $14 / 05 / 97$ & 4,0025 & 2,9565 & 3,6528 & 3,6153 & 3,4183 \\
\hline $15 / 05 / 97$ & 4,5072 & 3,4190 & 4,2242 & 4,1808 & 4,0241 \\
\hline $21 / 05 / 97$ & 3,5704 & 2,3248 & 2,8723 & 2,8429 & 3,0939 \\
\hline $22 / 05 / 97$ & 3,5949 & 2,5821 & 3,1902 & 3,1574 & 3,7288 \\
\hline 26/05/97 & 3,8526 & 3,5920 & 4,5403 & 4,3924 & 4,7028 \\
\hline $27 / 05 / 97$ & 4,1813 & 3,5497 & 4,5152 & 4,3407 & 4,8397 \\
\hline $29 / 05 / 97$ & 3,9787 & 2,8157 & 3,4788 & 3,4432 & 4,3527 \\
\hline $01 / 06 / 97$ & 4,0925 & 3,3535 & 4,1432 & 4,1007 & 4,4945 \\
\hline $05 / 06 / 97$ & 3,8985 & 3,8658 & 4,6884 & 4,7272 & 4,6898 \\
\hline 07/06/97 & 3,5223 & 3,8567 & 4,6832 & 4,7161 & 4,5829 \\
\hline 08/06/97 & 3,7348 & 3,3439 & 4,1314 & 4,0890 & 4,5647 \\
\hline 09/06/97 & 3,4431 & 3,4531 & 4,2663 & 4,2226 & 4,1959 \\
\hline $11 / 06 / 97$ & 4,2603 & 3,6430 & 4,5659 & 4,4548 & 4,4476 \\
\hline $13 / 06 / 97$ & 3,5320 & 3,3278 & 4,1115 & 4,0694 & 3,8891 \\
\hline $15 / 06 / 97$ & 3,4072 & 3,7922 & 4,6479 & 4,6372 & 4,6957 \\
\hline $16 / 06 / 97$ & 3,8374 & 4,1677 & 4,8362 & 5,0964 & 4,7123 \\
\hline $17 / 06 / 97$ & 4,2625 & 3,6971 & 4,5957 & 4,5209 & 4,1478 \\
\hline 19/06/97 & 3,6962 & 3,8569 & 4,6820 & 4,7163 & 4,5950 \\
\hline $20 / 06 / 97$ & 4,6176 & 3,7113 & 4,6035 & 4,5382 & 4,3213 \\
\hline $22 / 06 / 97$ & 4,5862 & 3,2079 & 3,9634 & 3,9227 & 4,8446 \\
\hline 24/06/97 & 3,8930 & 4,0459 & 4,7778 & 4,9475 & 4,7431 \\
\hline $25 / 06 / 97$ & 4,1841 & 3,5620 & 4,5186 & 4,3557 & 4,8036 \\
\hline $26 / 06 / 97$ & 3,9975 & 4,5273 & 4,9490 & 5,4036 & 4,7400 \\
\hline $28 / 06 / 97$ & 4,1627 & 3,2010 & 3,9548 & 3,9143 & 4,6246 \\
\hline $29 / 06 / 97$ & 3,6487 & 3,8427 & 4,6750 & 4,6990 & 4,6085 \\
\hline 06/03/98 & 5,2569 & 3,7818 & 4,6939 & 4,6245 & 6,3503 \\
\hline 07/03/98 & 5,0349 & 3,5903 & 4,5833 & 4,3903 & 5,8060 \\
\hline 08/03/98 & 5,0792 & 4,9187 & 5,2117 & 6,0147 & 6,5351 \\
\hline $12 / 03 / 98$ & 4,9083 & 3,6810 & 4,6332 & 4,5013 & 4,8919 \\
\hline $15 / 03 / 98$ & 5,1304 & 3,7131 & 4,6496 & 4,5405 & 5,5057 \\
\hline 29/03/98 & 4,8573 & 3,2311 & 3,9920 & 3,9511 & 4,1948 \\
\hline 03/04/98 & 4,8990 & 4,0123 & 4,7966 & 4,9063 & 5,7674 \\
\hline 04/04/98 & 5,1285 & 3,8292 & 4,7005 & 4,6825 & 5,9035 \\
\hline
\end{tabular}


Anexo C. Evapotranspiração de referência $(\mathrm{mm} / \mathrm{d})$ determinada pelos métodos de Thornthwaite, Thornthwaite modificado(Tef), Thornthwaite $(0,380)$, Thornthwaite $(0,379)$ e Priestley-Taylor $(1,26)$, com base em dados diários

\begin{tabular}{|c|c|c|c|c|c|}
\hline Data & Thornthwaite & Thornt (Tef) & Thor $(0,380)$ & Thor $(0,379)$ & P-Tay $(1,26)$ \\
\hline $05 / 04 / 98$ & 5,0390 & 4,5729 & 5,0007 & 5,4442 & 6,1257 \\
\hline 06/04/98 & 5,0848 & 4,5896 & 5,0157 & 5,4890 & 5,8988 \\
\hline $10 / 04 / 98$ & 5,1144 & 3,8933 & 4,7306 & 4,7608 & 5,4492 \\
\hline $11 / 04 / 98$ & 5,0116 & 3,9051 & 4,7361 & 4,7753 & 5,7502 \\
\hline $15 / 04 / 98$ & 5,1132 & 3,6718 & 4,6062 & 4,4900 & 5,0683 \\
\hline $16 / 04 / 98$ & 5,0306 & 3,8262 & 4,6910 & 4,6788 & 5,3340 \\
\hline $21 / 04 / 98$ & 5,0429 & 4,7136 & 5,1250 & 5,8539 & 6,0264 \\
\hline $22 / 04 / 98$ & 5,1123 & 4,3199 & 4,9298 & 5,2825 & 5,5758 \\
\hline 24/04/98 & 4,5552 & 3,8548 & 4,7013 & 4,7138 & 5,4945 \\
\hline 26/04/98 & 3,3288 & 3,7776 & 4,6586 & 4,6194 & 3,9225 \\
\hline 29/04/98 & 4,0038 & 3,6967 & 4,6121 & 4,5204 & 4,7696 \\
\hline $30 / 04 / 98$ & 4,4700 & 3,6207 & 4,5683 & 4,4275 & 5,1689 \\
\hline 03/05/98 & 4,2389 & 3,6103 & 4,5607 & 4,4148 & 5,0029 \\
\hline 05/05/98 & 4,6644 & 3,9780 & 4,7586 & 4,8644 & 5,1851 \\
\hline $12 / 05 / 98$ & 5,1099 & 4,1481 & 4,8381 & 5,0724 & 5,5991 \\
\hline $14 / 05 / 98$ & 4,7925 & 3,8877 & 4,7076 & 4,7540 & 4,6259 \\
\hline $16 / 05 / 98$ & 4,7998 & 3,9140 & 4,7203 & 4,7862 & 5,0276 \\
\hline $17 / 05 / 98$ & 4,5494 & 4,1289 & 4,8265 & 5,0490 & 5,2447 \\
\hline $19 / 05 / 98$ & 3,9412 & 3,5916 & 4,5426 & 4,3920 & 4,2696 \\
\hline $21 / 05 / 98$ & 4,8837 & 3,7430 & 4,6272 & 4,5770 & 5,5660 \\
\hline 24/05/98 & 5,0841 & 4,2889 & 4,8976 & 5,2446 & 5,3311 \\
\hline 26/05/98 & 5,5011 & 4,5349 & 4,9573 & 5,4127 & 5,4417 \\
\hline $30 / 05 / 98$ & 4,2019 & 4,5502 & 4,9709 & 5,4560 & 4,3730 \\
\hline $31 / 05 / 98$ & 4,8394 & 4,1543 & 4,8330 & 5,0800 & 5,1314 \\
\hline 02/06/98 & 5,6107 & 4,1691 & 4,8394 & 5,0981 & 5,1499 \\
\hline 04/06/98 & 4,8391 & 4,5872 & 5,0040 & 5,5575 & 4,2236 \\
\hline 06/06/98 & 4,6696 & 3,6706 & 4,5823 & 4,4885 & 4,5011 \\
\hline 07/06/98 & 4,9006 & 3,9439 & 4,7283 & 4,8228 & 4,6938 \\
\hline 09/06/98 & 5,2100 & 4,6928 & 5,0992 & 5,8556 & 4,9943 \\
\hline $11 / 06 / 98$ & 5,0517 & 4,5304 & 4,9520 & 5,4104 & 5,1833 \\
\hline $15 / 06 / 98$ & 4,9405 & 4,2898 & 4,8923 & 5,2457 & 4,4167 \\
\hline $17 / 06 / 98$ & 4,3566 & 3,9121 & 4,7107 & 4,7839 & 4,6920 \\
\hline $18 / 06 / 98$ & 4,1425 & 3,5938 & 4,5371 & 4,3947 & 4,2621 \\
\hline 21/06/98 & 4,5085 & 3,8463 & 4,6764 & 4,7034 & 4,8965 \\
\hline $22 / 06 / 98$ & 4,9068 & 3,5301 & 4,4998 & 4,3168 & 5,0865 \\
\hline $23 / 06 / 98$ & 5,7487 & 4,2417 & 4,8703 & 5,1868 & 4,9008 \\
\hline $25 / 06 / 98$ & 4,0035 & 3,4403 & 4,2505 & 4,2069 & 4,2142 \\
\hline 27/06/98 & 5,3599 & 3,7404 & 4,6198 & 4,5739 & 5,0915 \\
\hline 28/06/98 & 5,7733 & 4,7943 & 5,1900 & 6,1630 & 5,0276 \\
\hline $30 / 06 / 98$ & 5,1195 & 3,7182 & 4,6079 & 4,5467 & 4,5432 \\
\hline
\end{tabular}


Anexo D. Evapotranspiração de referência $(\mathrm{mm} / \mathrm{d})$ determinada pelos métodos de Hargreaves \& Samani, Tanque Classe A e Priestley-Taylor $(1,19)$, com base em dados diários.

\begin{tabular}{|c|c|c|c|c|c|c|c|}
\hline Data & Hargreav & Tanque & $\mathrm{PT}(1,19)$ & Data & Hargreav & Tanque & PT $(1,19)$ \\
\hline $01 / 03 / 97$ & 4,8442 & 7,4424 & 4,3389 & $01 / 06 / 97$ & 3,8826 & 4,4703 & 4,2448 \\
\hline $02 / 03 / 97$ & 4,5898 & 5,0093 & 5,8840 & $05 / 06 / 97$ & 4,1838 & 5,2075 & 4,4292 \\
\hline 05/03/97 & 4,4049 & 5,7388 & 4,7726 & 07/06/97 & 4,2406 & 4,9686 & 4,3283 \\
\hline 06/03/97 & 4,4940 & 5,9630 & 5,2672 & 08/06/97 & 3,9246 & 4,7042 & 4,3111 \\
\hline 07/03/97 & 4,7426 & 7,1239 & 5,9798 & 09/06/97 & 4,0448 & 3,9865 & 3,9628 \\
\hline 08/03/97 & 4,3854 & 6,4114 & 4,4148 & $11 / 06 / 97$ & 3,9678 & 5,5473 & 4,2005 \\
\hline $11 / 03 / 97$ & 4,7994 & 7,5625 & 5,6324 & $13 / 06 / 97$ & 3,9436 & 3,7298 & 3,6730 \\
\hline $13 / 03 / 97$ & 5,0714 & 7,5900 & 5,5208 & $15 / 06 / 97$ & 4,2033 & 6,1176 & 4,4349 \\
\hline $14 / 03 / 97$ & 5,1438 & 6,5060 & 5,5447 & $16 / 06 / 97$ & 4,2968 & 4,9103 & 4,4505 \\
\hline $15 / 03 / 97$ & 5,0728 & 6,8774 & 5,7742 & $17 / 06 / 97$ & 3,9823 & 4,5650 & 3,9174 \\
\hline $16 / 03 / 97$ & 4,9217 & 6,8043 & 5,2294 & 19/06/97 & 4,1736 & 6,4410 & 4,3397 \\
\hline 18/03/97 & 4,8546 & 5,9645 & 5,3816 & 20/06/97 & 3,9115 & 5,0875 & 4,0812 \\
\hline $20 / 03 / 97$ & 4,7430 & 6,3926 & 4,8435 & $22 / 06 / 97$ & 3,6164 & 5,5676 & 4,5755 \\
\hline $23 / 03 / 97$ & 4,0823 & 6,7113 & 4,8195 & $24 / 06 / 97$ & 4,2254 & 5,3690 & 4,4796 \\
\hline 29/03/97 & 4,4356 & 4,7534 & 5,2355 & $25 / 06 / 97$ & 3,9209 & 5,5356 & 4,5367 \\
\hline $30 / 03 / 97$ & 4,6462 & 6,1012 & 5,5330 & $26 / 06 / 97$ & 4,3748 & 5,9038 & 4,4766 \\
\hline $01 / 04 / 97$ & 4,1082 & 3,8772 & 4,2741 & 28/06/97 & 3,7119 & 5,2616 & 4,3677 \\
\hline 05/04/97 & 3,7504 & 4,5594 & 3,6676 & 29/06/97 & 4,1806 & 4,2765 & 4,3524 \\
\hline 07/04/97 & 3,9455 & 5,1326 & 4,5182 & 06/03/98 & 4,2587 & 6,0212 & 5,9975 \\
\hline 08/04/97 & 4,1696 & 4,5946 & 4,8483 & 07/03/98 & 4,3037 & 5,1548 & 5,4835 \\
\hline $16 / 04 / 97$ & 4,5039 & 2,0816 & 4,8765 & 08/03/98 & 5,1151 & 6,6916 & 6,1721 \\
\hline $17 / 04 / 97$ & 4,6020 & 5,1371 & 5,0071 & $12 / 03 / 98$ & 4,4545 & 4,6966 & 4,6202 \\
\hline $19 / 04 / 97$ & 4,5497 & 2,6979 & 4,6626 & $15 / 03 / 98$ & 4,2941 & 6,3349 & 5,1998 \\
\hline $20 / 04 / 97$ & 4,5643 & 3,9683 & 4,5082 & 29/03/98 & 4,0565 & 4,0626 & 3,9618 \\
\hline $21 / 04 / 97$ & 4,6279 & 5,2606 & 4,8348 & 03/04/98 & 4,5573 & 5,4367 & 5,4470 \\
\hline $27 / 04 / 97$ & 4,0777 & 6,5745 & 4,4891 & $04 / 04 / 98$ & 4,2591 & 5,0548 & 5,5755 \\
\hline 28/04/97 & 4,2112 & 4,8732 & 4,9877 & 05/04/98 & 4,7161 & 6,1109 & 5,7854 \\
\hline $29 / 04 / 97$ & 4,0273 & 3,8629 & 4,1608 & 06/04/98 & 4,6985 & 6,2391 & 5,5711 \\
\hline $30 / 04 / 97$ & 4,0504 & 2,8304 & 4,1101 & $10 / 04 / 98$ & 4,2640 & 5,7751 & 5,1465 \\
\hline $01 / 05 / 97$ & 4,0228 & 3,8609 & 4,7936 & $11 / 04 / 98$ & 4,3409 & 6,3898 & 5,4307 \\
\hline $07 / 05 / 97$ & 3,3860 & 2,0698 & 2,8935 & $15 / 04 / 98$ & 4,0583 & 4,8885 & 4,7867 \\
\hline $08 / 05 / 97$ & 3,9226 & 2,8358 & 4,5252 & $16 / 04 / 98$ & 4,2255 & 3,4599 & 5,0376 \\
\hline 09/05/97 & 4,3659 & 3,1589 & 4,6619 & 21/04/98 & 4,7294 & 6,2860 & 5,6916 \\
\hline $11 / 05 / 97$ & 3,7786 & 2,1600 & 3,2831 & 22/04/98 & 4,4183 & 6,2069 & 5,2660 \\
\hline $12 / 05 / 97$ & 4,2072 & 3,2508 & 4,7202 & 24/04/98 & 4,3110 & 5,4596 & 5,1893 \\
\hline $14 / 05 / 97$ & 3,7724 & 2,2586 & 3,2284 & 26/04/98 & 4,2562 & 4,8987 & 3,7046 \\
\hline $15 / 05 / 97$ & 3,9868 & 2,8824 & 3,8005 & 29/04/98 & 4,1454 & 4,8229 & 4,5047 \\
\hline $21 / 05 / 97$ & 3,3324 & 1,8009 & 2,9220 & $30 / 04 / 98$ & 3,9587 & 5,9234 & 4,8818 \\
\hline $22 / 05 / 97$ & 3,5409 & 2,0868 & 3,5217 & $03 / 05 / 98$ & 3,9356 & 6,3104 & 4,7249 \\
\hline $26 / 05 / 97$ & 4,1139 & 3,1511 & 4,4415 & 05/05/98 & 4,2470 & 6,0286 & 4,8970 \\
\hline $27 / 05 / 97$ & 4,0110 & 2,7334 & 4,5708 & $12 / 05 / 98$ & 4,2092 & 5,8426 & 5,2881 \\
\hline $29 / 05 / 97$ & 3,5646 & 2,6418 & 4,1108 & $14 / 05 / 98$ & 3,9439 & 6,1796 & 4,3689 \\
\hline
\end{tabular}


Anexo D. Evapotranspiração de referência $(\mathrm{mm} / \mathrm{d})$ determinada pelos métodos de Hargreaves \& Samani, Tanque Classe A e Priestley-Taylor $(1,19)$, com base em dados diários.

\begin{tabular}{cccccccc}
\hline Data & Hargreav & Tanque & PT $(1,19)$ & Data & Hargreav & Tanque & PT $(1,19)$ \\
\hline $16 / 05 / 98$ & 3,9775 & 6,2314 & 4,7483 & $09 / 06 / 98$ & 4,3899 & 6,2314 & 4,7169 \\
$17 / 05 / 98$ & 4,2871 & 6,5755 & 4,9533 & $11 / 06 / 98$ & 4,1806 & 6,5755 & 4,8953 \\
$19 / 05 / 98$ & 3,7844 & 4,7390 & 4,0324 & $15 / 06 / 98$ & 4,1124 & 4,7390 & 4,1714 \\
$21 / 05 / 98$ & 3,9489 & 6,3170 & 5,2567 & $17 / 06 / 98$ & 4,0591 & 6,3170 & 4,4313 \\
$24 / 05 / 98$ & 4,1919 & 5,7748 & 5,0349 & $18 / 06 / 98$ & 3,8503 & 5,7748 & 4,0253 \\
$26 / 05 / 98$ & 4,1974 & 6,0150 & 5,1393 & $21 / 06 / 98$ & 4,0159 & 6,0150 & 4,6244 \\
$30 / 05 / 98$ & 4,1604 & 4,7921 & 4,1301 & $22 / 06 / 98$ & 3,7205 & 4,7921 & 4,8039 \\
$31 / 05 / 98$ & 4,0967 & 5,8897 & 4,8463 & $23 / 06 / 98$ & 4,1310 & 5,8897 & 4,6286 \\
$02 / 06 / 98$ & 4,0800 & 5,0200 & 4,8638 & $25 / 06 / 98$ & 3,7415 & 5,0200 & 3,9801 \\
$04 / 06 / 98$ & 4,4293 & 7,1750 & 3,9890 & $27 / 06 / 98$ & 3,7963 & 7,1750 & 4,8086 \\
$06 / 06 / 98$ & 3,7881 & 5,8752 & 4,2510 & $28 / 06 / 98$ & 4,3411 & 5,8752 & 4,7483 \\
$07 / 06 / 98$ & 4,0539 & 4,9781 & 4,4330 & $30 / 06 / 98$ & 3,7410 & 4,9781 & 4,2908 \\
\hline
\end{tabular}

Anexo E. Evapotranspiração de referência. ( $\mathrm{mm} / \mathrm{d})$ determinada pelos métodos de Penman-Monteith, lisímetro, Hargreaves e Tanque Classe A, com base em dados qüinqüidiais.

\begin{tabular}{cccc}
\hline Penman-Monteith & Lisímetro & Hargreaves & Tanque Classe A \\
\hline 5,2284 & 4,7166 & 4,6229 & 6,2621 \\
5,7786 & 5,4475 & 4,9101 & 5,0960 \\
4,9824 & 5,7732 & 4,6116 & 4,9901 \\
4,1997 & 4,9052 & 4,1302 & 4,9276 \\
4,6504 & 5,1446 & 4,5702 & 4,9311 \\
4,1368 & 4,5518 & 4,0783 & 4,9971 \\
3,7481 & 3,4899 & 3,9438 & 2,7007 \\
3,3417 & 3,1413 & 3,7573 & 2,4379 \\
4,1293 & 3,7049 & 3,9892 & 3,9989 \\
4,0681 & 3,8434 & 4,0207 & 4,8307 \\
4,4268 & 4,4123 & 4,0092 & 5,3239 \\
4,6041 & 4,5079 & 4,0920 & 5,2750 \\
5,0255 & 4,9661 & 4,4984 & 5,7899 \\
4,8766 & 4,4081 & 4,4657 & 5,3887 \\
4,8444 & 4,6621 & 4,3331 & 5,3765 \\
4,3019 & 3,9243 & 4,2196 & 5,4811 \\
4,7094 & 4,6342 & 4,0666 & 6,1202 \\
4,7831 & 4,4709 & 4,0883 & 5,8841 \\
4,8276 & 3,7007 & 4,1211 & 5,7536 \\
4,8738 & 3,9885 & 4,1603 & 4,5821 \\
3,7944 & 4,1008 & 3,8955 & 5,8790 \\
5,4188 & 4,4142 & 3,9655 & 5,6745 \\
\hline
\end{tabular}


Anexo F. Evapotranspiração de referência $(\mathrm{mm} / \mathrm{d})$ determinada pelos métodos de Thornthwaite, Thornthwaite (Tef), Thornthwaite $(0,380)$ e Thornthwaite $(0,379)$, com base em dados qüinqüidiais.

\begin{tabular}{cccc}
\hline Thornthwaite & Thornthwaite (Tef) & Thornthwaite $(0,380)$ & Thornthwaite $(0,379)$ \\
\hline 4,9629 & 3,9509 & 4,7860 & 4,8313 \\
5,0938 & 4,6431 & 5,0697 & 5,5877 \\
4,8863 & 3,9499 & 4,7737 & 4,8300 \\
4,7067 & 3,2410 & 4,0043 & 3,9632 \\
4,6211 & 4,0295 & 4,7946 & 4,9274 \\
4,6137 & 3,4062 & 4,2084 & 4,1653 \\
4,2471 & 3,2333 & 3,9947 & 3,9538 \\
3,8681 & 2,9456 & 3,6392 & 3,6019 \\
3,9296 & 3,4714 & 4,2889 & 4,2449 \\
3,6660 & 3,5086 & 4,4876 & 4,2905 \\
4,1797 & 3,7183 & 4,6075 & 4,5469 \\
3,9735 & 3,7972 & 4,6505 & 4,6433 \\
5,0845 & 3,9159 & 4,7640 & 4,7885 \\
5,0041 & 3,9821 & 4,7812 & 4,8694 \\
5,0629 & 4,0033 & 4,7842 & 4,8954 \\
4,9099 & 3,8483 & 4,6965 & 4,7058 \\
4,9811 & 3,9047 & 4,7185 & 4,7748 \\
4,8921 & 4,0263 & 4,7747 & 4,9235 \\
4,8393 & 4,1915 & 4,8499 & 5,1255 \\
4,7440 & 4,2627 & 4,8806 & 5,2126 \\
4,6628 & 3,7224 & 4,6097 & 4,5519 \\
4,9629 & 4,1338 & 4,8205 & 5,0550 \\
\hline
\end{tabular}

Anexo G. Evapotranspiração de referência $(\mathrm{mm} / \mathrm{d})$ determinada pelos métodos de Priestley-Taylor $(1,26)$ e Priestley-Taylor $(1,19)$, com base em dados qüinqüidiais.

\begin{tabular}{cccc}
\hline $\begin{array}{l}\text { Priestley-Taylor } \\
(1,26)\end{array}$ & $\begin{array}{l}\text { Priestley-Taylor } \\
(1,19)\end{array}$ & $\begin{array}{l}\text { Priestley-Taylor } \\
(1,26)\end{array}$ & $\begin{array}{l}\text { Priestley-Taylor } \\
(1,19)\end{array}$ \\
\hline 5,5566 & 5,2479 & 4,9840 & 4,7071 \\
5,6920 & 5,3757 & 5,0896 & 4,8068 \\
5,4053 & 5,1050 & 5,1709 & 4,8836 \\
4,8353 & 4,5666 & 4,6752 & 4,4154 \\
5,0589 & 4,7778 & 4,7958 & 4,5293 \\
4,7725 & 4,5073 & 4,6714 & 4,4119 \\
4,2507 & 4,0146 & 4,8878 & 4,6163 \\
3,7929 & 3,5822 & & \\
4,5923 & 4,3372 & & \\
4,3584 & 4,1163 & & \\
4,5248 & 4,2734 & & \\
4,7041 & 4,4428 & & \\
5,8165 & 5,4934 & & \\
5,5756 & 5,2658 & & \\
5,5252 & 5,2183 & & \\
\hline
\end{tabular}


Anexo H. Evapotranspiração de referência $(\mathrm{mm} / \mathrm{d})$ determinada pelos métodos de Penman-Monteith, lisímetro, Hargreaves e Tanque Classe A, com base em dados decendiais.

\begin{tabular}{cccc}
\hline Penman-Monteith & Lisímetro & Hargreaves & Tanque Classe A \\
\hline 5,4944 & 5,0820 & 4,7628 & 6,6431 \\
4,5806 & 5,3392 & 4,3711 & 5,5108 \\
4,3919 & 4,8482 & 4,3261 & 4,1126 \\
3,5497 & 3,3156 & 3,8499 & 2,5695 \\
4,0954 & 3,7741 & 4,0059 & 4,4156 \\
4,5155 & 4,4601 & 4,0512 & 5,2994 \\
4,9628 & 4,6871 & 4,4832 & 5,5889 \\
4,5701 & 4,2932 & 4,2766 & 5,4286 \\
4,7493 & 4,5526 & 4,0792 & 6,0014 \\
4,8525 & 3,8446 & 4,1415 & 5,1669 \\
4,9177 & 4,2183 & 3,9219 & 5,8016 \\
\hline
\end{tabular}

Anexo I. Evapotranspiração de referência $(\mathrm{mm} / \mathrm{d})$ determinada pelos métodos de Thornthwaite, Thornthwaite (Tef), Thornthwaite $(0,380)$ e Thornthwaite $(0,379)$, com base em dados decendiais.

\begin{tabular}{cccc}
\hline Thornthwaite & Thornthwaite (Tef) & Thornthwaite $(0,380)$ & Thornthwaite $(0,379)$ \\
\hline 5,0294 & 4,2519 & 4,9319 & 5,1994 \\
4,7975 & 3,5822 & 4,5654 & 4,3805 \\
4,6174 & 3,7080 & 4,6215 & 4,5343 \\
4,0542 & 3,0869 & 3,8139 & 3,7748 \\
3,7961 & 3,4900 & 4,3118 & 4,2676 \\
4,0756 & 3,7576 & 4,6291 & 4,5949 \\
5,0444 & 3,9490 & 4,7728 & 4,8289 \\
4,9873 & 3,9252 & 4,7405 & 4,7999 \\
4,9369 & 3,9652 & 4,7469 & 4,8487 \\
4,7920 & 4,2270 & 4,8653 & 5,1689 \\
4,7792 & 3,8729 & 4,6905 & 4,7359 \\
\hline
\end{tabular}

Anexo J. Evapotranspiração de referência $(\mathrm{mm} / \mathrm{d})$ determinada pelos métodos de Priestley-Taylor $(1,26)$ e Priestley-Taylor $(1,19)$, com base em dados decendiais.

\begin{tabular}{cc}
\hline Priestley-Taylor $(1,26)$ & Priestley-Taylor $(1,19)$ \\
\hline 5,6242 & 5,3118 \\
5,1195 & 4,8351 \\
4,9155 & 4,6424 \\
4,0211 & 3,7977 \\
4,4752 & 4,2266 \\
4,6145 & 4,3582 \\
5,6959 & 5,3795 \\
5,2540 & 4,9621 \\
5,1302 & 4,8452 \\
4,7357 & 4,4726 \\
4,7524 & 4,4884 \\
\hline
\end{tabular}




\section{REFERÊNCIAS BIBLIOGRÁFICAS}

ABOUKHALED, A.; ALFARO, A.; SMITH, M. Lysimeters. Rome: FAO, 1982. 68p. (FAO. Irrigation and Drainage Paper, 39).

AL-GHOBARI, H. M. Estimation of reference evapotranspiration for southern region of Saudi Arabia. Irrigation Sciencem, v.19, n.2, p 81-86, 2000.

ALLEN, R.G. A Penman for all seasons. Journal of Irrigation and Drainage Engineering, v.112, n.4, p.348-368, 1986.

ALLEN, R.G. REF-ET: Reference evapotranspiration calculator, version 2.1. Logan: Utah State University, 1990. 39p.

ALLEN, R. G. Assessing integrity of weather data for reference evapotranspiration estimation. Journal of Irrigation and Drainage Enginnering, v.122, n.2. p 97 106, 1996.

ALLEN, R.G.; PRUITT, W.O. Rational use of the FAO Blaney-Criddle formula. Journal of Irrigation and Drainage Engineering, v.112, n.2, p.139-155, May, 1986. 
ALlEN, R. G.; PRUITT, W. O.; JENSEN, M. E. Environmental requirements of lisimeters. In: INTERNATIONAL SYMPOSIUM ON LYSIMETRY, Honolulu, 1991. Lysimeters for evapotranspiration and environmental measurements: proceedings. New York: ASCE, 1991, p.170-181.

ALLEN, R.G.; SMITH, M.; PERRIER, A. An update for the definition of reference evapotranspiration. ICID BULLETIN, v.43, n.2, p.1-34, 1994a.

ALLEN, R.G.; SMITH, M.; PERRIER, A. An update for the calculation of reference evapotranspiration. ICID BULLETIN, v.43, n.2, p.35-91, $1994 b$.

ALLEN, R.G.; JENSEN, M.E.; WRIGHT, J.L. et al. Operational estimates of reference evapotranspiration. Agronomy. Journal, v.81, p.650-662, 1989.

ALLEN R. G.; PEREIRA, L. S.; RAES, D. et al. Crop evapotranspiration. Rome: FAO, 1998. 297p (FAO Irrigation and Drainage Paper, 56).

AlMEIDA, A H.; KLAR, A. E.; VILlA NOVA, N. A. Comparação de dados de evapotranspiração de referência estimados por diferentes métodos. Irriga, v 4, n. 2, p.104-119, 1999.

ALVES, A. I.; PERRIER, A.; PEREIRA, L. S. Aerodynamic and surface resistances of complete cover crops: how good is the "big leaf"? Transactions of the ASAE, v.41, n.2, p.345-351, 1997.

AMATYA, D. M.; SKAGGS, R. W.; GREGORY, J. D. Comparation of methods for estimating potential evapotranspiration. St. Joseph: ASAE, 1992. 27p. (ASAE. Paper, 92-2630). 
AZEVEDO, B. M. Evapotranspiração de referência obtida com a Razão de Bowen, Lisímetro de pesagem e equação de Penman-Monteith utilizando sistemas automáticos. Piracicaba, 1999. 81p. Tese (Doutorado) - Escola Superior de Agricultura "Luiz de Queiroz", Universidade de São Paulo.

BASElGA, J. J.; ALLEN, R. G. A Penman-Monteith for semi-arid climate in southwestern Spain. In: EVAPOTRANSPIRATION AND IRRIGATION SCHEDULING INTERNATIONAL CONFERENCE, Sant Antonio, 1996. Proceedings. Sant Antonio: ASAE, 1996. p. 999-1007.

BERGAMASCH, H.; ROSA, L.M.G.; SANTOS, A. O. et al. Automação de um lisímetro de pesagem através de estação meteorológica, a campo. In: CONGRESSO BRASILEIRO DE AGROMETEOROLOGIA, 10., Piracicaba, 1997. Resumos. Piracicaba: ESALQ; Sociedade Brasileira de Agrometeorologia, 1997. v.1, p.262264.

CAMARGO, A.P. Contribuição para a determinação da evapotranspiração potencial no Estado de São Paulo. Bragantia, v.21, n.12, p.163-213, 1962.

CAMARGO, A. P.; CAMARGO M. B. P. Uma revisão da evapotranspiração potencial. Bragantia, v.59, n.2, p.125-137, 2000.

CAMARGO, A. P.; SENTElHAS, P. C. Avaliação do desempenho de diferentes métodos de estimativa da evapotranspiração potencial no Estado de São Paulo. Revista Brasileira de Agrometeorologia, v.5, n.1, p.89-97, 1997.

CAMARGO, A. P.; MARIN, F. R.; SENTElHAS, P. C. et al. Ajuste da equação de Thornthwaite para estimar a evapotranspiração potencial em climas áridos e superúmidos, com base na amplitude térmica diária. Revista Brasileira de Agrometeorologia, v.7 n.2, p.251-257, 1999. 
CHANG, J. Climate and agriculture: an ecological survey. Chicago: Aldine Publ., 1968. Cap. 13, p.129-143: Evapotranspiration.

CUNHA, G.R.; BERGAMASCHI, H. Coeficientes das equações de Makkink e Priestley-Taylor para a estimativa da evapotranspiração máxima da alfafa. Revista Brasileira de Agrometeorologia, v.2, n.1, p.33-36, 1994.

DOORENBOS, J.; PRUITT, W.O. Guidelines for predicting crop water requirements. 2.ed. Rome: FAO, 1977. 179p. (FAO. Irrigation and Drainage Paper, 24)

GREBET, P.; CUENCA, R. H., History of lysimeter design and effects of environmental disturbances. In: INTERNATIONAL SYMPOSIUM ON LYSIMETRY, Honolulu, 1991. Lysimeters for evapotranspiration and environmental measurements: proceedings. New York: ASCE, 1991, p.10-18.

HARGREAVES, G. H. Pontential evapotranspiration and irrigation requirements for northeast Brazil. Logan: Utah State University, 1974. p123.

HARGREAVES, G. H. Estimation of FAO evapotranspiration coeficients. Journal of Irrigation and Drainage Engineering, v.110, p.257 - 259, 1984.

HARGREAVES, G.H. Accuracy of estimated reference crop evapotranspiration. Journal of Irrigation and Drinage Enginerring, v.115, n.6, p.1000-1006, Dec. 1989.

HARGREAVES, G. H. Defining and using reference evapotranspiration. Journal of Irrigation and Drainage Engineering, v.120, p.1132-1139, 1994. 
HARGREAVES, G. H.; SAMANI, Z. A. Reference crop evapotranspiration from temperature. Applied Engineering Agricuture, v.1, n.2, p.96-99, 1985.

HOWELL, T. A.; McMORMICK, R. L.; PHENE, C. O. Design and installation of large weighing lysimeters. Transactions of the ASAE, v.28, n.2, p.106-117, 1985.

HOWELL, T. A.; SCHNEIDER, A. D.; JENSEN, M. E. History of lysimeter design and use of evapotranspiration measurements. In: INTERNATIONAL SYMPOSIUM ON LYSIMETRY, Honolulu, 1991. Lysimeters for evapotranspiration and environmental measurements: proceedings. New York: ASCE, 1991. p.1-9.

HUSSEIN, A. S. A. Grass ET estimates using Penman-type equations in Central Sudan. Journal of Irrigation and Drainage Engineering, v.125, n.6. p324-329. 1999.

JENSEN, M.W.; BURMAN, R.D.; ALLEN, R.G. et al. Evapotranspiration and irrigation water requirements New York: American Society of Civil Engineers, 1990. 329p. (ASCE. Manual and Reports on Engineering Practices, 70).

KIRKIHAM, R. R.; ROCKHOLD, M. L.; GEE, G. W. et al. Lysimeters: data acquisition and analysis. In: INTERNATIONAL SYMPOSIUM ON LYSIMETRY, Honolulu, 1991. Lysimeters for evapotranspiration and environmental measurements: proceedings. New York: ASCE, 1991. p.362-370.

LUNARDI, M. A.; LUNARDI, D. M. C.; CAVAGUTI, M. Comparação entre medidas evapotranspirométricas e metodologia da FAO, na determinação de evapotranspiração de referência. Irriga, v.4, n. 1, p.52-65, 1999.

MAGGIOTTO, S.R. Estimativa da evapotranspiração de referência pelo uso da termometria ao infravermelho. Piracicaba, 1996. 71p. Dissertação (Mestrado) Escola Superior de Agricultura “Luiz de Queiroz”, Universidade de São Paulo. 
MEDEIROS, A. T. Estimativa da evapotranspiração de referência através do programa REF-ET, para duas localidades do Nordeste. Fortaleza, 1996. 95p. Dissertação (Mestrado) - Departamento de Engenharia Agrícola, Universidade Federal do Ceará.

MEDEIROS, A. T.; FOLEGATTI, M. V. Relação entre evapotranspiração de referência para grama e alfafa. (compact disc) In: CONGRESSO BRASILEIRO DE ENGENHARIA AGRÍCOLA, 29., Fortaleza, 2000.Fortaleza: SBEA, 2000.

MEDEIROS, S. L. P. Avaliação de métodos de estimativa de evapotranspiração de referência para a região mesoclimática de Santa Maria, RS. Revista Brasileira de Agrometeorologia, v.6, n.1, p. 105-109, 1998.

MIRANDA, F. R.; YODER, R. E.; SOUZA, F. de. Instalação e calibração de um lisímetro de pesagem no Projeto de Irrigação Curu-Paraipaba, CE. Revista Brasileira de Engenharia Agrícola, v.3, n.1, p. 107-110, 1999.

MONTEITH, J.L Evaporation and environment. In: SYMPOSIUM OF THE SOCIETY FOR EXPERIMENTAL BIOLOGY, 6., Swansea, 1964. Cambridge: Cambridge University Press, 1965. p.205-234.

OLIVEIRA, C. W.; SOUZA, F.; YODER, R. E. et al. Estimating reference evapotranspiration in northeastern Brazil. Orlando: ASAE, 1998. 14p. (ASAE. Paper, 982184).

PENMAN, H.L. Natural evaporation from open water, bare soil and grass. Proceedings of the Royal Society of London, v.A193, p.120-146, 1948.

PEREIRA, A.R.; VILLA NOVA, N.A. Analysis of the Priestley-Taylor parameter. Agricultural and Forest Meteorology, v.61, p.1-9, 1992. 
PEREIRA, A.R.; VILLA NOVA, N.A.; SEDIYAMA, G.C. Evapo(transpi)ração Piracicaba: FEALQ, 1997a. 183p.

PEREIRA, A.R.; VILLA NOVA, N.A.; SENTELHAS, P. C. O parâmetro de PriestleyTaylor para a estimativa da evapotranspiração de referência na escala mensal. Revista Brasileira de Agrometeorologia, v.5, n.1, p.83-87, 1997 b.

PEREIRA, A.R.; VILLA NOVA, N.A.; PEREIRA, A.S. et al. A model for the class A pan coefficient. Agricultural and Forest Meteorology, v.76, p.75-82, 1995.

PEREIRA, F.A.C. Desempenho do modelo de Penman-Monteith e de dois evaporímetros na estimativa da evapotranspiração de referência (ETo) em relação a um lisímetro de pesagem. Piracicaba, 1998. 87p. Tese (Doutorado) - Escola Superior de Agricultura “Luiz de Queiroz”, Universidade de São Paulo.

PERES, J.G. Avaliação do modelo de Penman-Monteith, padrão FAO, para estimar a evapotranspiração de referência nas condições climáticas do Estado de São Paulo. Piracicaba, 1994. 116p. Dissertação (Mestrado) - Escola Superior de Agricultura “Luiz de Queiroz”, Universidade de São Paulo.

PERES, J. C.; PEREIRA, A. R.; FRIZZONE, J. A. et al. Calibração do modelo de Priestley-Taylor para estimar a evapotranspiração potencial da cana-de-açúcar Revista Brasileira de Agrometeorologia, v.5, n.1, p.77-82, 1997.

PRIESTLEY, C.H.B.; TAYLOR, R.J. On the assessment of surface heat flux and evaporation using large-scale parameters. Monthly Weather Review, v.100, p.8192, 1972.

RIBEIRO, R. S. F. ET estimation using Penman-Monteith equation compared to ET measured by lysimetry. Knoxville: University of Tennessee, 1996. 15p. 
SENTELHAS, P. C. Estimativa diária da evapotranspiração de referência com dados de estação meteorologia convencional e automática. Piracicaba, 1998. 97p. Tese (Doutorado) - Escola Superior de Agricultura “Luiz de Queiroz”, Universidade de São Paulo.

SENTELHAS, P. C.; MORAES, S.O.; PIEDADE, S. M. S. et al. Análise comparativa de dados meteorológicos obtidos por estações convencional e automática. Revista Brasileira de Agrometeorologia, v.5, n.2, p.215-221, 1997.

SENTELHAS, P. C.; PEREIRA, A. R.; FOLEGATTI, M. V. et al. Variação sazonal do parâmetro de Priestley-Taylor para estimativa diária da evapotranspiração de referência. Revista Brasileira de Agrometeorologia, v.8, n.1, p.49-53, 2000.

SILVA, A. A. G. Avaliação da eficiência de métodos de estimativa da evapotranspiração de referência para o município de Parnaíba-PI. Piracicaba, 1989. 81p. Dissertação (Mestrado) - Escola Superior de Agricultura "Luiz de Queiroz”, Universidade de São Paulo.

SILVA, F. C. Uso de dispositivos lisimétricos para medida da evapotranspiração de referência. Piracicaba, 1996. 68p. Dissertação (Mestrado) - Escola Superior de Agricultura "Luiz de Queiroz", Universidade de São Paulo.

SILVA, F. C.; FOLEGATTI, M. V.; MAGGiOTTO, S. R. Análise do funcionamento de um lisímetro de pesagem com célula de carga. Revista Brasileira de Agrometeorologia, v.7, n.1, p. 53-58, 1999.

SILVEIRA, S. S. Análise da componente principal como ferramenta para estimar os parâmetros meteorológicos de mais influência para o processo da evapotranspiração no Estado do Ceará. Fortaleza, 2000. 60p. Dissertação (Mestrado) - Departamento de Engenharia Agrícola, Universidade Federal do Ceará. 
SMITH, M. Report on the expert consultation on procedures for revision of FAO guidelines for prediction of crop water requirements: Rome: FAO, $1991.54 \mathrm{p}$.

SOUZA, F. de; YODER, R. ET estimation in the Northeast of Brazil: hargreaves or Penman-Monteith equation. St. Joseph: ASAE, 1994. 6p. (ASAE. Paper, 942545).

STANHILL, G. The use of piche evaporímeter in the calculation of evaporation. Quartrely Journal of the Royal Meteorological Society, v.88, p. 80-82, 1962.

THORNTHWAITE, C.W. Na approach toward a rational classification of climate. Geographycal Review, v.38, p.55-94, 1948.

VUOLO, J. H. Fundamentos da teoria de erros. São Paulo: Edgard Blücher, 1992. cap.6, p.68-84: Erros sistemáticos e estatísticos.

WILlMOTT, C. J. On the validation of models. Physical Geography, v.2, n.2, p. 184194, 1981.

WRIGHT, J. L. Using weighing lysimeters to develop evapotranspiration crop coefficients. In: INTERNATIONAL SYMPOSIUM ON LYSIMETRY, Honolulu, 1991. Lysimeters for evapotranspiration and environmental measurements: proceedings. New York: ASCE, 1991, p.191-199. 